Prepared for the U.S. Department of Energy

under Contract DE-AC05-76RL01830

\title{
Investigation of Hexavalent Chromium Flux to Groundwater at the 100-C-7:1 Excavation Site
}

\author{
MJ Truex \\ VR Vermeul \\ BG Fritz \\ RD Mackley \\ JA Horner \\ CD Johnson \\ DR Newcomer
}

November 2012

Pacific Northwest

NATIONAL LABORATORY

Proudly Operated by Battelle Since 1965 


\title{
DISCLAIMER
}

This report was prepared as an account of work sponsored by an agency of the United States Government. Neither the United States Government nor any agency thereof, nor Battelle Memorial Institute, nor any of their employees, makes any warranty, express or implied, or assumes any legal liability or responsibility for the accuracy, completeness, or usefulness of any information, apparatus, product, or process disclosed, or represents that its use would not inf ringe privately owned rights. Reference herein to any specific commercial product, process, or service by trade name, trademark, manufacturer, or otherwise does not necessarily constitute or imply its endorsement, recommendation, or favoring by the United States Government or any agency thereof, or Battelle Memorial Institute. The views and opinions of authors expressed herein do not necessarily state or reflect those of the United States Government or any agency thereof.

\author{
PACIFIC NORTHWEST NATIONAL LABORATORY \\ operated by \\ BATTELLE \\ for the \\ UNITED STATES DEPARTMENT OF ENERGY \\ under Contract DE-AC05-76RL01830
}

Printed in the United States of America
Available to DOE and DOE contractors from the
Office of Scientific and Technical Information
P.O. Box 62, Oak Ridge, TN 37831-0062;
ph: (865) 576-8401
fax: $(865) 576-5728$
email: reports@adonis.osti.gov

Available to the public from the National Technical Information Service

5301 Shawnee Rd., Alexandria, VA 22312

ph: (800) 553-NTIS (6847)

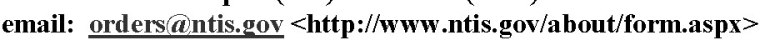

Online ordering: http://www.ntis.gov

This document was printed on recycled paper. 
PNNL-21845

RPT-DVZ-AFRI-005

\title{
Investigation of Hexavalent Chromium Flux to Groundwater at the 100-C-7:1 Excavation Site
}

\author{
MJ Truex \\ VR Vermeul \\ BG Fritz \\ RD Mackley \\ JA Horner \\ CD Johnson \\ DR Newcomer
}

November 2012

Prepared for

the U.S. Department of Energy

under Contract DE-AC05-76RL01830

Pacific Northwest National Laboratory

Richland, Washington 99352 


\section{Executive Summary}

Deep excavation of soil has been conducted at the 100-C-7 and 100-C-7:1 waste sites within the 100-BC Operable Unit at the U.S. Department of Energy's Hanford Site to remove hexavalent chromium $(\mathrm{Cr}(\mathrm{VI}))$ contamination, with excavations reaching to near the water table. Soil sampling showed that $\mathrm{Cr}(\mathrm{VI})$ contamination was still present at the bottom of the 100-C-7:1 excavation. In addition, $\mathrm{Cr}(\mathrm{VI})$ concentrations in a downgradient monitoring well have shown a transient spike of increased $\mathrm{Cr}(\mathrm{VI})$ concentration following initiation of excavation activities. Potentially, the increased $\mathrm{Cr}(\mathrm{VI})$ concentrations in the downgradient monitoring well are due to $\mathrm{Cr}(\mathrm{VI})$ from the excavation site. However, data were needed to evaluate this possibility and to quantify the overall impact of the 100-C-7:1 excavation site on groundwater. Data collected from a network of aquifer tubes installed across the floor of the 100-C-7:1 excavation and from temporary small-diameter wells installed at the bottom of the entrance ramp to the excavation were used to evaluate $\mathrm{Cr}(\mathrm{VI})$ releases into the aquifer and estimate local-scale hydraulic properties and groundwater flow velocity.

The Cr(VI) data collected from project-installed aquifer tubes show a short-lived and relatively small pulse of $\mathrm{Cr}(\mathrm{VI})$ was released to groundwater at the excavation site during the study period. This release occurred in response to the seasonal rise in the water table, and associated saturation of excavationbottom sediments, resulting from an increase in Columbia River stage. By the end of the study period, although the water table was still high, $\mathrm{Cr}(\mathrm{VI})$ concentrations had dissipated with no significant continuing source observed, providing direct evidence that sorption of $\mathrm{Cr}(\mathrm{VI})$ to vadose zone or aquifer sediments is minimal and that $\mathrm{Cr}(\mathrm{VI})$ present in the lower vadose zone is readily mobilized when the sediments become saturated.

Previously available hydraulic property information was sparse for the Hanford formation in the 100-BC Area. Taking advantage of the excavation depth, temporary small-diameter wells were installed using economical direct-push methods. Hydraulic property information was determined by analysis of constant rate injection hydraulic response data, tracer injection arrival curves, tracer elution response under natural gradient conditions, and electromagnetic borehole flow meter data. Direct-push penetration data also provided information about the local geological contact between the Hanford and Ringold Formations. Based on the hydraulic/tracer testing data and associated local-scale estimates of groundwater velocity in the vicinity of the 100-C-7:1 site, it is possible that $\mathrm{Cr}(\mathrm{VI})$ mobilized from the excavation and released to groundwater between November 2011 and February 2012 could have resulted in the $\mathrm{Cr}(\mathrm{VI})$ concentration peak observed in downgradient monitoring well 199-B4-14.

Access to the excavation floor near the water table enabled collection of a large amount of hydrologic and contaminant transport and distribution information within a short time frame. These data would be costly and more difficult to obtain with wells installed from the ground surface. Other opportunities where excavations provide relatively shallow access to the groundwater and enable use of direct-push drilling could be used to augment the hydraulic and contaminant data for the Hanford Site. Importantly, the ability to install multiple temporary wells enables use of constant rate injection (or discharge) testing with a stressed well and observation well(s), and to jointly conduct tracer tests that provide more comprehensive and quantitative hydraulic property information than can be obtained from the single-well slug testing that has been typically applied at the Hanford Site due to constraints of well installation cost. 


\section{Acknowledgements}

This document was prepared by the Deep Vadose Zone-Applied Field Research Initiative at Pacific Northwest National Laboratory. Funding for this work was provided by the U.S. Department of Energy, Richland Operations Office. The Pacific Northwest National Laboratory is operated by Battelle Memorial Institute for the U.S. Department of Energy under contract DE-AC05-76RL01830.

The support of the U.S. Department of Energy, Richland Operations Office (Greg Sinton and Tom Post) and the U.S. Environmental Protection Agency (Laura Buelow) is appreciated in facilitating project efforts to meet aggressive schedules for implementation of the study. Valuable logistical support and related excavation and groundwater data needed for conducting the project was provided by CH2M HILL Plateau Remediation Company and Washington Closure Hanford personnel. Energy Solutions, Inc. provided the direct-push drilling for the project. 


\section{Contents}

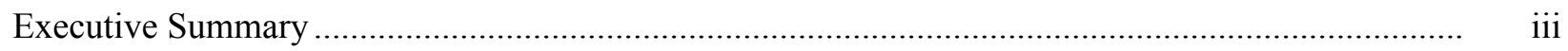

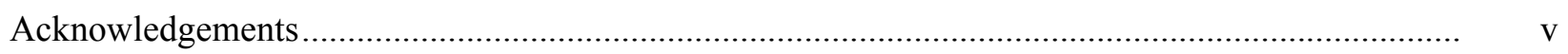

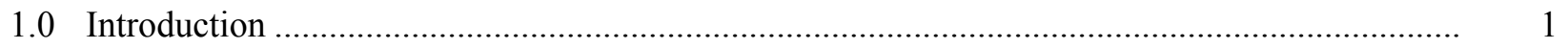

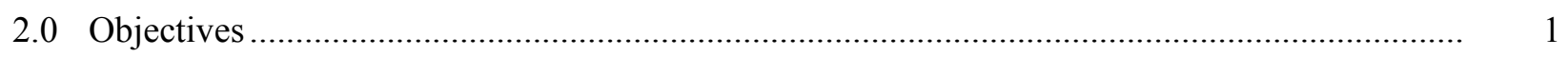

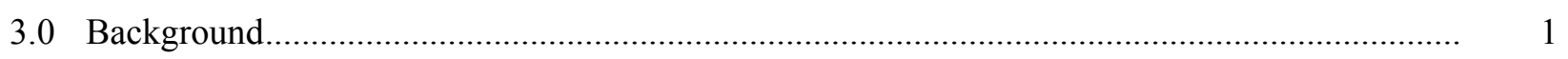

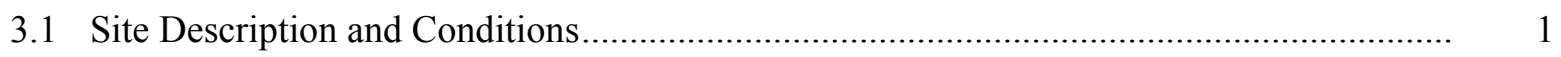

3.2 Soil Contaminant Conditions ................................................................................... 2

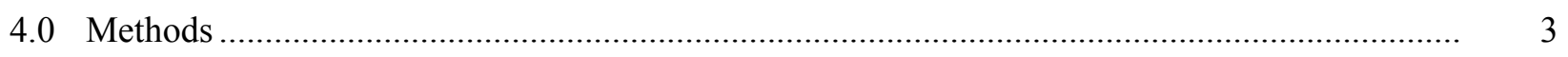

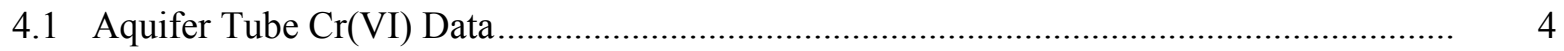

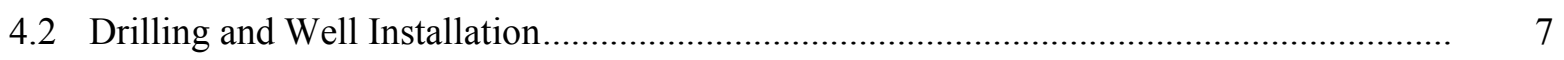

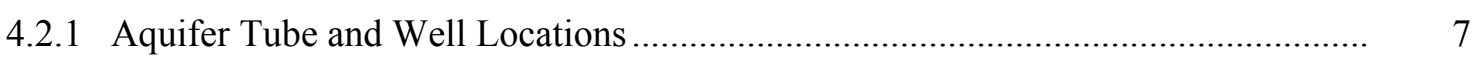

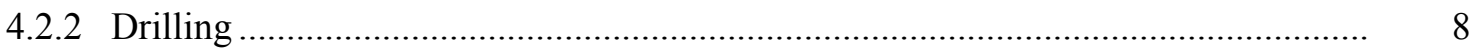

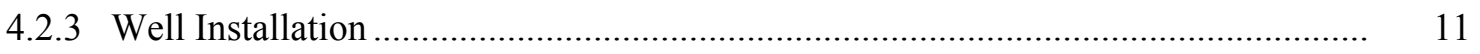

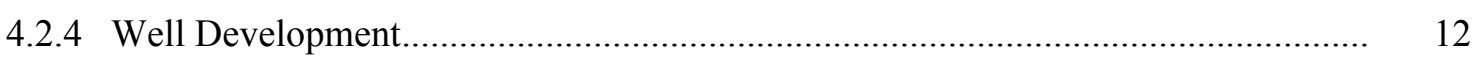

4.2.5 Well Modifications and Final Decommissioning .................................................. 12

4.3 Hydraulic Testing and Groundwater Flow Direction/Gradient....................................... 13

4.3.1 Constant-Rate Injection Tests .................................................................... 13

4.3.2 Groundwater Flow Direction and Gradient......................................................... 14

4.3.3 Electromagnetic Borehole Flow Meter ............................................................. 15

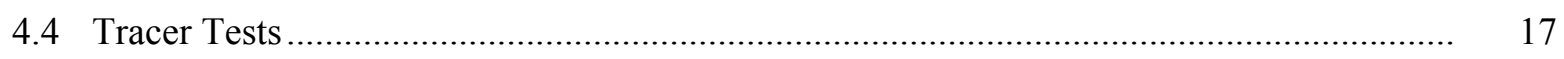

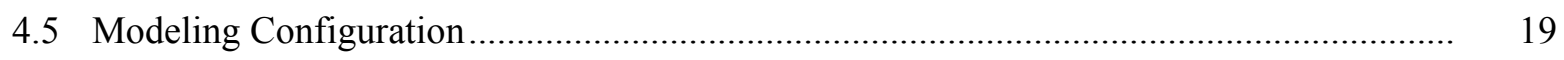

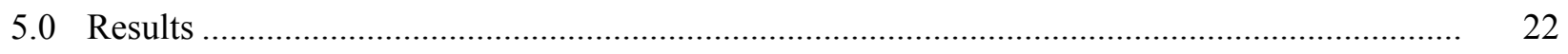

$5.1 \mathrm{Cr}(\mathrm{VI})$ Concentration, Mass, and Flux ....................................................................... 23

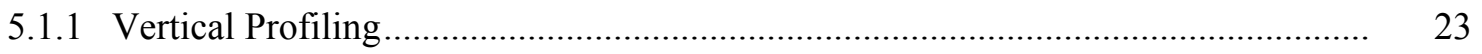

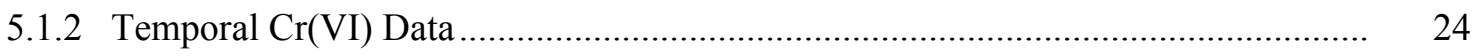

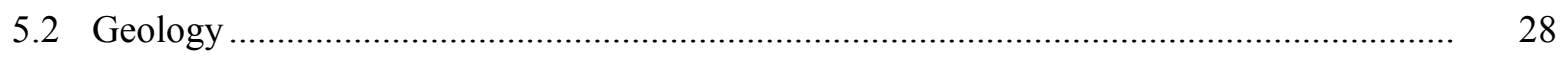

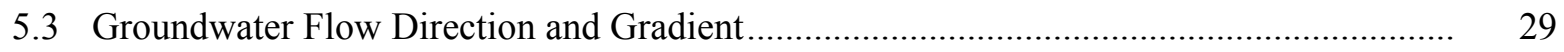

5.4 Local-Scale Hydrologic Characterization .................................................................... 31

5.4.1 Electromagnetic Borehole Flow Meter Results.................................................. 31

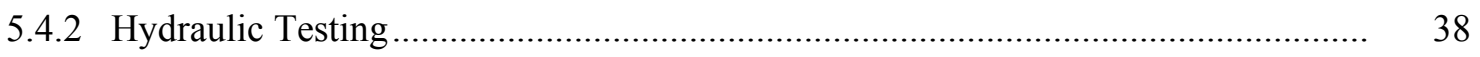

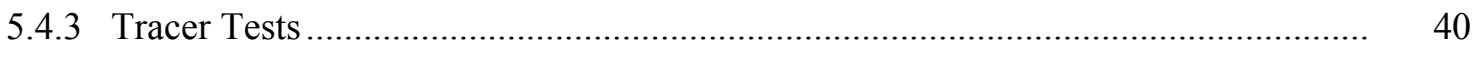

5.4.4 Modeling Interpretation of the Tracer Test ........................................................ 49

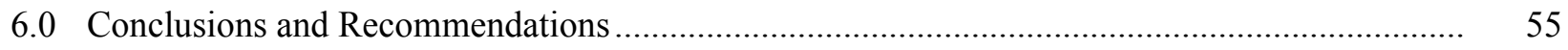

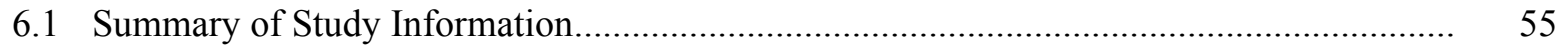




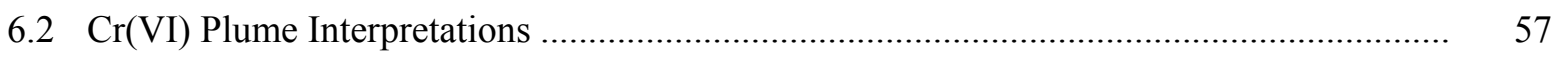

6.2.1 Downgradient Fluxes ................................................................................. 57

6.2.2 Correlation to Well 199-B4-14 Data ......................................................................... 58

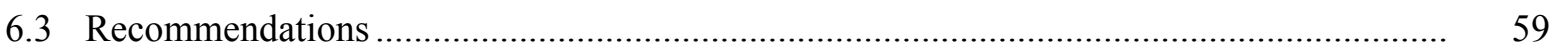

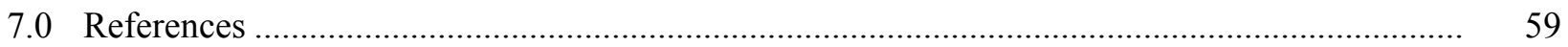

\section{Figures}

1 Aerial photo of the existing 100-C-7 and 100-C-7:1 excavations looking to the south............... 2

2 Soil sample data at the floor of the $100-\mathrm{C}-7: 1$ waste site .......................................................... 3

3 Locations of aquifer tubes for sample collection ............................................................... 5

4 Photo of the direct push technology drill rig that was used during drilling and installation of the 100-C-7:1 temporary small-diameter well network....................................................... 9

$5 \quad$ Plan view of the 100-C-7:1 well network and nearby aquifer tubes......................................... 9

6 Nominal cross section of the 100-C-7:1 test site showing the relative well locations and screen depths

7 Each well was developed by alternating the use of a dual flange surge block and

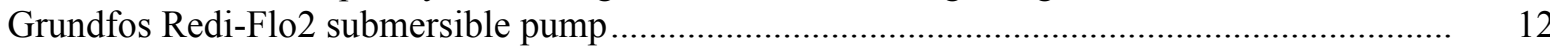

8 Location of water-level monitoring wells relative to the 100-C-7 and 100-C-7:1 sites ............. 15

9 Schematic drawing of the groundwater sample acquisition system............................................. 19

10 Plan view of the numerical model grid showing boundary condition cells, the injection

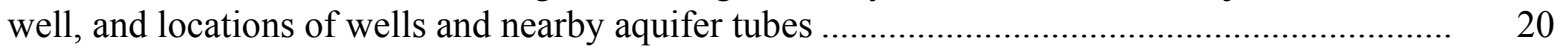

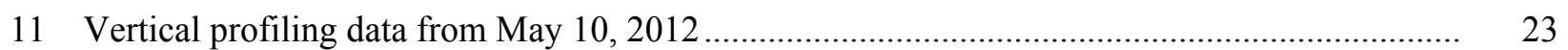

12 Comparison of May 8 and May 10, 2012, vertical profiling data for $\mathrm{Cr}(\mathrm{VI})$............................. 24

$13 \mathrm{Cr}(\mathrm{VI})$ concentrations measured at aquifer tubes during sampling from May through August 2012

14 Correlation of total chromium concentration results between laboratory and Hach $\mathrm{Cr}(\mathrm{VI})$ assays and between filtered and unfiltered laboratory assays

15 East-west transect showing the water table and the Hanford/Ringold Formation contact............ 28

16 Hydraulic head data for wells 199-B4-14, 199-B5-8, and 199-B8-6 along with the corresponding groundwater flow direction calculated from the head data using "three-point problem" techniques

17 Groundwater flow direction and hydraulic gradient calculated from the hydraulic head data for wells 199-B8-6, 199-B4-14, and 199-B5-8 using "three-point problem" techniques

18 Radial frequency histogram depicting the groundwater flow direction in $10^{\circ}$ bins as calculated from the hourly hydraulic head data for wells 199-B8-6, 199-B4-14, and 199-B5-8

19 Calculated hydraulic gradient and groundwater flow direction from hydraulic head data at wells 199-B8-6, 199-B4-14, and 199-B5-8 during the study period 
20 Estimated groundwater velocities in the Hanford formation beneath the 100-C-7 and 100-C-7:1 excavations based on calculated hydraulic gradients and hydraulic property estimates.

21 Ambient vertical wellbore flow profiles for well UG1 before and after well reconfiguration .....

22 Ambient vertical wellbore flow profiles for well CG1 before and after well reconfiguration .....

23 Ambient vertical wellbore flow profiles for well DG1 before and after well reconfiguration .....

24 Ambient vertical wellbore flow profiles for well DG2 before and after well reconfiguration .....

Ambient vertical wellbore flow profiles for well INJ before and after well reconfiguration ........

26 Normalized hydraulic conductivity profile for well UG1 prior to well reconfiguration ...

27 Normalized hydraulic conductivity profile for well CG1 prior to well reconfiguration...

28 Normalized hydraulic conductivity profile for well DG1 prior to well reconfiguration

29 Normalized hydraulic conductivity profile for well DG2 prior to well reconfiguration .......

30 Normalized hydraulic conductivity profile for well INJ prior to well reconfiguration

31 Observed pressure response in observation well CG1 for test in stress well INJ, with fitted Neuman type-curve.

32 Observed pressure response in observation well DG1 for test in stress well INJ, with fitted Neuman type-curve

33 Observed pressure response in observation well INJ for test in stress well CG1, with fitted Neuman type-curve

34 Tracer injection rate and measured bromide concentration during tracer test 1.

35 Tracer test 1 monitoring results during the injection phase for both discrete groundwater samples and the downhole probes.

36 Comparison of data for groundwater samples and the downhole probes for wells DG2 and INJ

37 Arrival curves for INJ and DG2 based on downhole probe data that has been filtered to remove artifacts resulting from groundwater sampling ...

38 Plot depicting an example of how the $50 \%$ arrival times were calculated; data in the vicinity of the $50 \%$ relative concentration were fit to a linear equation, which was then used to back-calculate the time for a relative concentration of $50 \%$

39 Downhole probe data for well DG1 during tracer test 1

40 Arrival and elution curves measured during tracer test 2

41 Tracer concentration in well CG2 during tracer test 3.

42 Data for tracer test 2 showing the arrival data at wells DG2, INJ, and CG1 and elution data for the injection well DG1 along with the corresponding smoothed data fits.

43 Arrival curves for wells DG2, INJ, and CG1 in tracer test 2 for simulations with varying porosity values

44 Arrival curves for wells DG2, INJ, and CG1 in tracer test 2 for simulations with varying longitudinal hydraulic conductivity values

45. Arrival curves for wells DG2, INJ, and CG1 in tracer test 2 for simulations with varying dispersivity values.

46 Elution curves for well DG1 in tracer test 2 for simulations with varying porosity values 
47 Elution curves for well DG1 in tracer test 2 for simulations with varying hydraulic conductivity values

48 Elution curves for well DG1 in tracer test 2 for simulations with varying dispersivity values

49 Comparison of tracer test 3 data to the corresponding simulation results

\section{Tables}

1 Sample collection requirements for aqueous water quality samples ...................................... 6

2 Analytical requirements for aqueous water quality samples .................................................

3 Elevation information for wells installed at the 100-C-7:1 site .............................................. 11

4 Sample collection requirements for aqueous tracer test samples ............................................ 18

$5 \quad$ Analytical requirements for aqueous tracer test samples................................................... 18

6 Descriptive parameters for the numerical model grid............................................................ 20

7 Information about the tracer tests and numerical model configuration .................................... 21

$8 \mathrm{Cr}(\mathrm{VI})$ concentrations based on aquifer tube sampling and field analyses performed

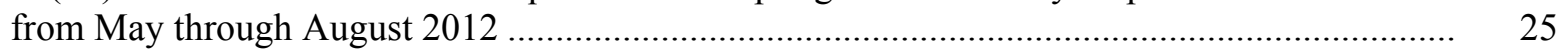

9 Average of AT-1 through AT-7 Cr(VI) concentrations at specific sampling depths .................. 27

10 Summary of pertinent EBF test information..................................................................... 32

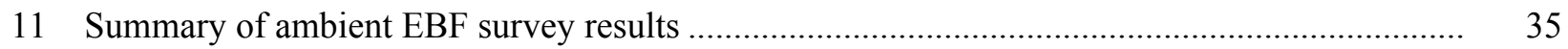

12 Summary of hydraulic conductivity estimates from constant-rate injection tests in

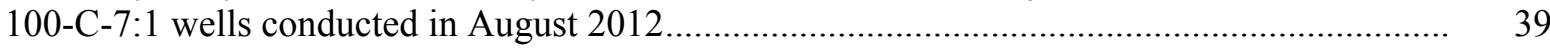

13 Simplified calculation of the drift velocity based on the elution time at well DG1 and the effective porosity and hydraulic conductivity based on arrival times during tracer test $1 \ldots \ldots \ldots \ldots . . . \quad 45$

14 Simplified calculation of the drift velocity based on the elution time at well DG1 and the effective porosity and hydraulic conductivity based on arrival times during tracer test $2 \ldots \ldots \ldots \ldots . \quad 48$

15 Simplified calculation of the drift velocity and hydraulic conductivity based on tracer elution measured during tracer test 3

16 Values of parameters tested in the simulation matrix .......................................................... 50

17 Hydrologic data used in the $\mathrm{Cr}(\mathrm{VI})$ flux calculation............................................................. 57

$18 \mathrm{Cr}(\mathrm{VI})$ concentrations at specific depth intervals for aquifer tubes AT-4, AT-5, AT-6, and AT-7 based on samples collected in May, June, and July/August 2012 ....

$19 \mathrm{Cr}(\mathrm{VI})$ mass information determined from flux plane calculations for aquifer tubes AT-4, AT-5, AT-6, and AT-7 based on data in Table 17 and Table 18 


\subsection{Introduction}

Deep excavation of soil has been conducted at the 100-C-7 and 100-C-7:1 waste sites within the 100-BC Operable Unit at the U.S. Department of Energy (DOE) Hanford Site to remove hexavalent chromium $(\mathrm{Cr}(\mathrm{VI}))$ contamination with excavations reaching to near the water table. Soil sampling showed that $\mathrm{Cr}(\mathrm{VI})$ contamination was still present at the bottom of the 100-C-7:1 excavation site. In addition, $\mathrm{Cr}(\mathrm{VI})$ concentrations in a downgradient monitoring well have shown a transient spike of increased $\mathrm{Cr}(\mathrm{VI})$ concentration following initiation of excavation. Potentially, the increased $\mathrm{Cr}(\mathrm{VI})$ concentrations in the downgradient monitoring well are due to $\mathrm{Cr}(\mathrm{VI})$ from the excavation site. However, data are needed to evaluate this possibility and to quantify the overall impact of the 100-C-7:1 excavation site on groundwater. Several types of data were collected to assess the release of $\mathrm{Cr}(\mathrm{VI})$ from the excavation site into the groundwater and impact on the groundwater quality. These data included 1) spatial and temporal $\mathrm{Cr}(\mathrm{VI})$ concentration data from the shallow groundwater beneath the 100-C-7:1 excavation; 2) hydraulic and tracer response data for characterization of local-scale groundwater flow and contaminant transport; and 3) hydraulic gradient data.

The study described herein was conducted opportunistically while the 100-C-7:1 excavation was accessible for characterization activities. Because the excavation was advanced to near the water table, methods applicable for shallow subsurface investigation became feasible for use in studying the $\operatorname{Cr}(\mathrm{VI})$ concentrations and hydraulic properties of the aquifer within the Hanford formation. The study was initiated in April 2012 and completed in September 2012.

\subsection{Objectives}

The study was conducted with the following objectives:

- Quantify the release of $\mathrm{Cr}(\mathrm{VI})$ from the excavation site to the groundwater in terms of contaminant mass discharge into the downgradient aquifer.

- Provide hydraulic property and groundwater flow and gradient estimates for the Hanford formation aquifer beneath the 100-C-7:1 excavation site.

\subsection{Background}

\subsection{Site Description and Conditions}

The 100-C-7 and 100-C-7:1 waste sites were excavated to remove soil contaminated with $\mathrm{Cr}(\mathrm{VI})$. These excavations removed soil down to the water table, a total excavation depth of about $26 \mathrm{~m} \mathrm{(85 \textrm {ft } )}$ below the original ground surface (Figure 1). No additional excavation is planned for 100-C-7 because verification sampling shows that soil cleanup levels for $\mathrm{Cr}(\mathrm{VI})$ have been achieved. Continued excavation in the upper portion of 100-C-7:1 is planned for the future. In addition, soil $\mathrm{Cr}(\mathrm{VI})$ contamination above soil cleanup levels was identified at the bottom of 100-C-7:1; however, deeper excavation could not continue because the bottom of the waste site had reached the water table. 


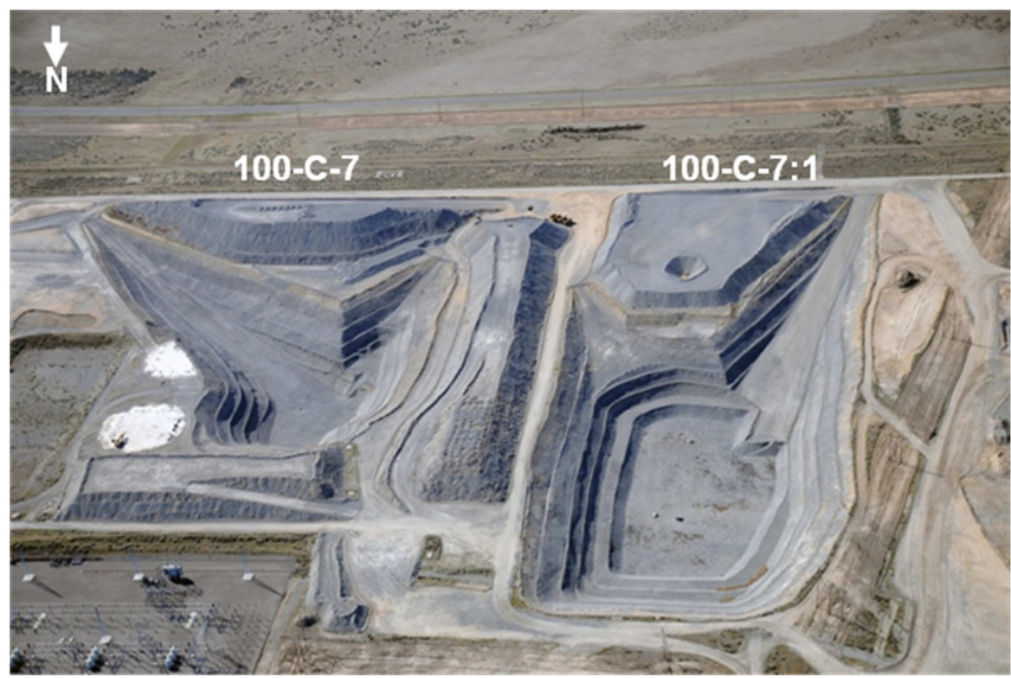

Figure 1. Aerial photo of the existing 100-C-7 and 100-C-7:1 excavations (April 2012) looking to the south

Standard excavation processes were applied at these sites, including the addition of water for dust control purposes.

The 100-C-7:1 excavation floor elevation of nominally $122 \mathrm{~m}$ above mean sea level (msl) was above the water table in April 2012. However, the water table elevation increased and began flooding the excavation in May. The excavation floor remained underwater from mid-May 2012 through the end of the study period.

\subsection{Soil Contaminant Conditions}

Soil contamination data were collected in March 2012 at the floor of the 100-C-7:1 waste site with sample locations J1NLD4, J1NLD5, J1NLD7, J1NLD9, J1NLF0, and J1NLF1 showing concentrations above $10 \mathrm{mg} / \mathrm{kg}$ up to a maximum at J1NLD7 of about $40 \mathrm{mg} / \mathrm{kg}$ (Figure 2). These samples were collected from approximately $7.5 \mathrm{~cm}$ below the excavation floor in the rewetted zone. Verification sampling for the 100-C-7 site shows that soil cleanup levels for $\mathrm{Cr}(\mathrm{VI})$ have been achieved. 


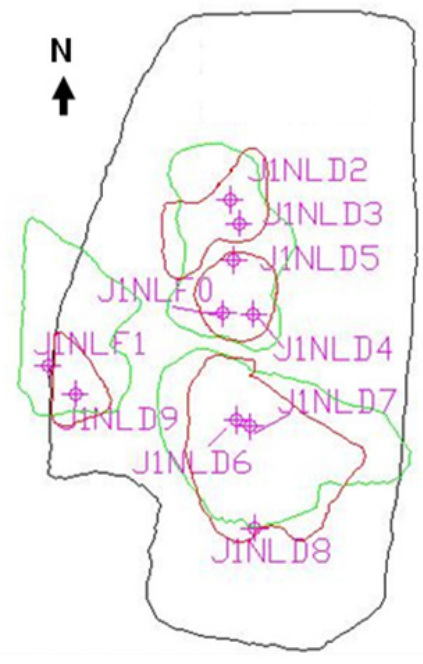

Figure 2. Soil sample data at the floor of the 100-C-7:1 waste site. The black line is the floor outline. The red lines show interpreted contamination zones from the March 2012 excavation floor sample results. The green lines show interpreted contamination zones from previous higherelevation sample results. Sample locations are shown for the March 2012 sampling of the excavation floor. Soil data and interpretations were provided by Washington Closure Hanford.

\subsection{Methods}

There were three elements to the investigation.

Element 1. Spatially and temporally distributed $\mathrm{Cr}(\mathrm{VI})$ data in the shallow groundwater (top 1-3 $\mathrm{m}$ of aquifer) were collected using aquifer tubes. In addition to spatial and temporal $\mathrm{Cr}(\mathrm{VI})$ data in the shallow aquifer, aquifer tubes were also used to collect a vertical profile of $\mathrm{Cr}(\mathrm{VI})$ concentrations to a depth of approximately $3 \mathrm{~m}$.

Element 2. Local-scale hydrologic data were collected by installing a temporary network of smalldiameter monitoring wells (by direct-push drilling methods) at the bottom of the entrance ramp (above high water level). The well network was installed to characterize the upper portion of the Hanford formation, which is present at the water table. Measurements collected during direct-push drilling, hydraulic testing, and tracer injection and natural gradient drift testing were analyzed to provide estimates for the following:

- Elevation of the contact between the Hanford and Ringold Formations

- Effective porosity

- Groundwater velocity and associated hydraulic gradient

- Hydraulic properties (hydraulic conductivity, specific yield).

Element 3. A water-level monitoring network in the vicinity of the excavation (wells 199-B8-6, 199-B4-14, and 199-B5-8) was used to monitor hydraulic heads throughout the life of the project. These 
data were used to calculate the hydraulic gradient and groundwater flow direction that were used in conjunction with the localized hydraulic property information, tracer data, and $\mathrm{Cr}(\mathrm{VI})$ concentration data to assess release of $\mathrm{Cr}(\mathrm{VI})$ from the excavation site to the groundwater and estimate impacts to the downgradient aquifer.

Following a series of planning and coordination meetings and subsequent DOE approval to start work, project activities initially focused on installing a network of aquifer tubes so that baseline $\mathrm{Cr}(\mathrm{VI})$ concentrations could be measured before the excavation was flooded with groundwater. Although a longer baseline period would have been preferable, aquifer tubes were installed in time to monitor elevated $\mathrm{Cr}(\mathrm{VI})$ concentrations that were mobilized as the water table came into contact with excavation bottom sediments. This aquifer tube network was routinely monitored over the duration of the project.

A temporary, small-diameter monitoring well network was installed (by direct-push drilling methods) for determination of local-scale hydraulic and transport property estimation. The well network, which was located directly adjacent to the excavation on an elevated access road, was originally designed to focus interrogation on a 3-m (10-ft) interval of Hanford formation, the top of which was the approximate elevation of the excavation floor. Results from initial hydraulic and tracer testing in this well network revealed that the Hanford formation was most transmissive near the water table, and that another zone of increased permeability near the bottom of the 3-m (10 ft) screened interval resulted in significant vertical wellbore flow in these wells under ambient conditions. Because the observed wellbore flows significantly impacted the concentration of tracers measured in the monitoring wells and limited the ability to quantitatively assess natural gradient tracer drift response data, the wells were reconfigured using bentonite fill material to decrease the test interval to the upper $1.5 \mathrm{~m}$ of each $3-\mathrm{m}$ well screen. This reconfigured well network, which effectively mitigated the ambient wellbore flow problem and focused hydrologic interrogation on the upper $1.5-\mathrm{m}$ test interval, was then used to perform both hydraulic and tracer injection and natural gradient drift tests. Results from these tests, along with hydraulic gradient information from a well network in the vicinity of the site, were used to characterize properties controlling local-scale groundwater flow and contaminant transport.

Field testing and monitoring activities conducted in support of the three project elements listed above are discussed in more detail in the following sections.

\subsection{Aquifer Tube $\mathrm{Cr}(\mathrm{VI})$ Data}

Groundwater samples were collected and analyzed to determine $\mathrm{Cr}(\mathrm{VI})$ concentration. Eight lateral sampling locations within the 100-C-7:1 excavation floor were selected for the installation of aquifer tubes used to collect groundwater samples (Figure 3).

Vertical profiling of $\mathrm{Cr}(\mathrm{VI})$ concentration was conducted with a preliminary profiling on May 8 , 2012, at location AT-1 and additional profiling on May 10, 2012, at locations AT-1, AT-3, and AT-6 to a

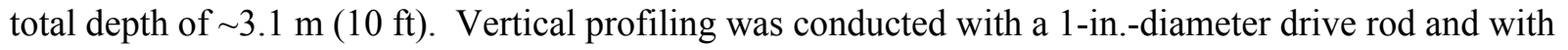
sampling every $\sim 0.5 \mathrm{~m}$ (1.5 ft). Surface water samples were also collected at these locations. The drive rod was advanced into a pre-dug 15-cm-deep hole. After the aquifer tube was below the bottom of the hole, the hole was filled with coated bentonite pellets to create a surface seal during additional advancement of the rod and sampling. Samples were analyzed for $\mathrm{Cr}(\mathrm{VI})$ using a field spectrophotometric method (described in the following paragraphs). 


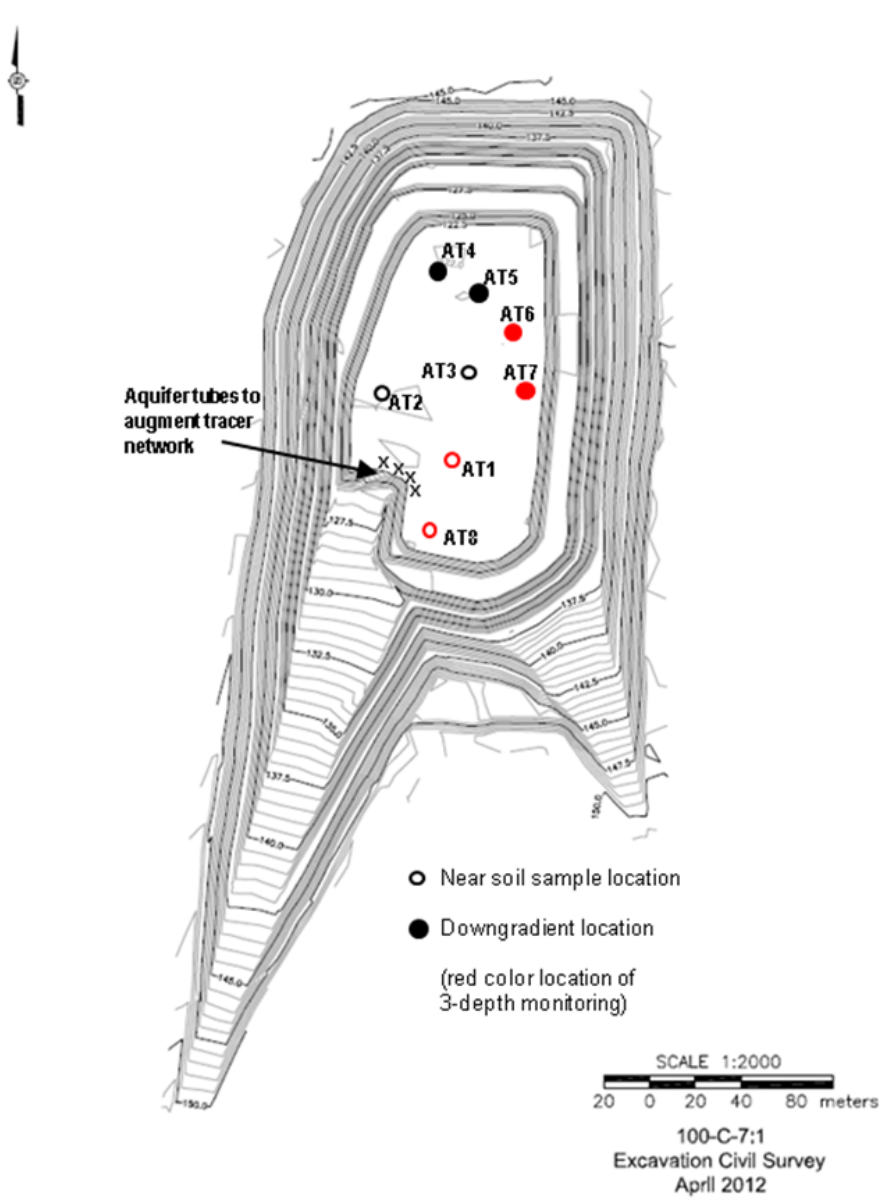

Figure 3. Locations of aquifer tubes for sample collection. Open circles indicate areas of elevated $\mathrm{Cr}(\mathrm{VI})$ concentration from soil samples. Filled circles are downgradient monitoring locations.

Each of the primary eight monitoring locations consisted of at least two sample depth intervals with a shallow well-point aquifer tube installed to a depth of about $1 \mathrm{~m}$ below the excavation floor and another aquifer tube installed to a depth of $3 \mathrm{~m}$. At locations AT-1, AT-6, AT-7, and AT-8, an additional aquifer tube was installed to a depth of $2 \mathrm{~m}$. Well-point aquifer tubes were used for the shallow sample depth interval because the installation method did not require back-pulling of a drive rod and provided for a better surface seal at these shallow depths. All abovementioned depths represent the depth from ground surface to the middle of the screen. The well-point aquifer tubes were constructed of 3.2-cm ID stainlesssteel pipe with a $30-\mathrm{cm}$-long wire wrapped screen. A cap with a bulkhead fitting was attached to the top of the well point to allow pass through of the sample tubing to the screened interval. Aquifer tubes were constructed of $1-\mathrm{cm}$ outside diameter polyethylene tube with a $30-\mathrm{cm}$ screen interval. The screen was constructed of 50- $\mu \mathrm{m}$ polyethylene mesh wrapped around perforations in the tubing. Aquifer tubes and well-point aquifer tubes were installed using methods previously developed for sampling along the Columbia River shoreline (Fritz et al. 2007). Surface completion at all aquifer tube locations consisted of emplacing a bentonite surface seal, as described for the vertical profiling above, to prevent surface water from moving vertically along the aquifer tube during sampling. In addition to the eight primary sampling locations, seven aquifer tubes were installed near the well field to provide supplemental monitoring for the natural gradient tracer testing. Four of these aquifer tubes (AT-9, -10, -11, -12) were installed with the screen midpoint at an elevation of $121.5 \mathrm{~m}$, which is the approximate midpoint of the original well 
network's 3-m (10-ft) screen intervals. Three additional tubes (AT-13, -14, and -15) were installed with the screen at the approximate midpoint of the reconfigured well network test interval (i.e., upper $1.5 \mathrm{~m}$ [5 ft] of the original screen interval). The location of these aquifer tubes (on the slope near the access road) required a deeper installation depth than the other shallow installations, but the elevation of the aquifer tubes was comparable to that of the shallow well points at the other eight sampling locations. The installation and completion of these seven aquifer tubes was comparable to that of the eight primary locations.

Groundwater samples were pumped from the aquifer tubes using a peristaltic pump. Purge times were scaled according to the tubing length and flow rate such that two to three tubing volumes were purged prior to sample collection. During sample collection, field parameters (specific conductance, $\mathrm{pH}$, dissolved oxygen, and oxidation reduction potential) were measured using a flow-through cell (model MP20, QED Environmental Systems, Ann Arbor, Michigan) and monitored for stability. The dissolved oxygen and oxidation reduction potential values were consistently above $7 \mathrm{mg} / \mathrm{L}$ and $150 \mathrm{mV}$, respectively, indicating suitable (oxic) conditions for collection of $\mathrm{Cr}(\mathrm{VI})$ samples. The probe was calibrated for specific conductance and $\mathrm{pH}$ prior to each sampling event. Field parameters were handrecorded on a field data sheet and transferred to an electronic data file at the completion of field activities. After recording the field parameters, a sample was collected in a clean, triple-rinsed glass beaker. The sample was then divided into three sub-samples; a filtered/acidified sample, an unfiltered acidified sample, and a filtered sample for field analysis of $\mathrm{Cr}(\mathrm{VI})$.

Aqueous sample collection and analytical requirements are shown in Table 1 and Table 2, respectively. Measurement of $\mathrm{Cr}(\mathrm{VI})$ occurred in the field less than 1 hour after sample collection. Concentrations of $\mathrm{Cr}(\mathrm{VI})$ were measured using spectrophotometric methods (model DR 2000, Hach Co., Loveland, Colorado). The filtered sample was transferred to a reagent bottle and allowed to sit for $5 \mathrm{~min}$. During this time, $\mathrm{Cr}(\mathrm{VI})$ present in the sample reacted with the reagent, turning the sample purple.

Table 1. Sample collection requirements for aqueous water quality samples

\begin{tabular}{|c|c|c|c|c|}
\hline Parameter & Media/Matrix & Sampling Frequency $^{(a)}$ & Volume/Container & Preservation \\
\hline $\begin{array}{l}\text { RCRA/Trace Metals: } \\
\mathrm{Cr}\end{array}$ & Water & $\begin{array}{l}\text { Collected for all samples; } \\
\text { subset selected for analysis }\end{array}$ & $\begin{array}{l}25-\mathrm{mL} \text { plastic vial } \\
\text { (acid washed) }\end{array}$ & $\begin{array}{l}\text { Filtered and } \\
\text { unfiltered, } \\
\mathrm{HNO}_{3} \text { to } \mathrm{pH}<2 \\
\text { Hold time: } 60 \text { days }\end{array}$ \\
\hline $\mathrm{Cr}(\mathrm{VI})$ & Water & $\begin{array}{l}10 \text { sampling events, varying } \\
\text { frequency }\end{array}$ & Field measurement & Filtered \\
\hline $\mathrm{pH}$ & Water & $\begin{array}{l}\text { Measure for all samples } \\
\text { collected }\end{array}$ & Field measurement & None \\
\hline Electrical conductivity & Water & $\begin{array}{l}\text { Measure for all samples } \\
\text { collected }\end{array}$ & Field measurement & None \\
\hline Dissolved oxygen & Water & $\begin{array}{l}\text { Measure for all samples } \\
\text { collected }\end{array}$ & Field measurement & None \\
\hline $\begin{array}{l}\text { Oxidation reduction } \\
\text { potential }\end{array}$ & Water & $\begin{array}{l}\text { Measure for all samples } \\
\text { collected }\end{array}$ & Field measurement & None \\
\hline
\end{tabular}

(a) Sampling frequency for temporal monitoring, not profiling.

$\mathrm{QC}=$ quality control; RCRA = Resource Conservation and Recovery Act. 
Table 2. Analytical requirements for aqueous water quality samples

\begin{tabular}{|c|c|c|c|c|}
\hline Parameter & Analysis Method & Detection Limit & $\begin{array}{c}\text { Typical } \\
\text { Precision/Accuracy }\end{array}$ & QC Requirements \\
\hline $\begin{array}{l}\text { RCRA/Trace Metals: } \\
\text { Cr }\end{array}$ & $\begin{array}{l}\text { ICP-MS, } \\
\text { PNNL-AGG-415 } \\
\text { (similar to EPA } \\
\text { Method 6020) (EPA } \\
\text { 2007) }\end{array}$ & $\begin{array}{l}1 \mu \mathrm{g} / \mathrm{L} \text { for trace } \\
\text { elements }\end{array}$ & $\pm 10 \%$ & $\begin{array}{l}\text { Daily calibration; } \\
\text { blanks and duplicates } \\
\text { and matrix spikes at } \\
10 \% \text { level }\end{array}$ \\
\hline $\mathrm{Cr}(\mathrm{VI})$ & $\begin{array}{l}\text { Hach DR-2000 w/ } \\
\text { Accuvac Ampules }\end{array}$ & $10 \mu \mathrm{g} / \mathrm{L}$ & $\pm 10 \mu \mathrm{g} / \mathrm{L}$ & $\begin{array}{l}\text { Blanks, duplicates at } \\
10 \% \text { level }\end{array}$ \\
\hline $\mathrm{pH}$ & pH electrode & Not applicable & $\pm 0.1 \mathrm{pH}$ unit & User calibrate \\
\hline Electrical conductivity & Electrode & $1 \mu \mathrm{S} / \mathrm{cm}$ & $\pm 10 \%$ & User calibrate \\
\hline Dissolved oxygen & Membrane electrode & $0.1 \mathrm{ppm}$ & $\pm 15 \%$ & For indication only \\
\hline $\begin{array}{l}\text { Oxidation reduction } \\
\text { potential }\end{array}$ & Electrode & Not applicable & $\pm 10 \%$ & For indication only \\
\hline
\end{tabular}

The intensity of the purple color was proportional to the $\mathrm{Cr}(\mathrm{VI})$ concentration, which was quantified by the spectrophotometer instrument. The measured concentrations were also hand-recorded on the field data sheet and transferred to an electronic data file at the completion of field activities. Archived samples were held for laboratory analysis of total chromium (Table 1). A sub-set of the archived samples were selected for total chromium analysis by inductively coupled plasma mass spectrometry (ICP-MS) (Table 2).

\subsection{Drilling and Well Installation}

This section summarizes activities related to the drilling, construction, and decommissioning of the 100-C-7:1 well network.

\subsubsection{Aquifer Tube and Well Locations}

Horizontal and vertical coordinates of the aquifer tubes and wells were either mapped for approximate location or surveyed for a more precise coordinate. The horizontal coordinates of the eight primary aquifer tube monitoring locations on the excavation floor (AT-1 through -8) were mapped using a hand-held global positioning system (GPS; model Montana 650t, Garmin Ltd., Olathe, Kansas). The GPS receiver reported a horizontal accuracy of about $\pm 5 \mathrm{~m}$ when these locations were mapped. The elevation of the ground surface for these eight points was based on elevation contours from the civil survey obtained from Washington Closure Hanford (Figure 3). ${ }^{1}$

The seven aquifer tubes located near the well field (AT-9 through -15) and the six wells were surveyed using an electronic total station (model Set330R, Sokkia Corp., Olathe, Kansas) with an overall horizontal and vertical accuracy of about $\pm 0.02 \mathrm{~m}$. The horizontal coordinates for these points are relative

\footnotetext{
${ }^{1}$ Martinez C. 2012. E-mail to Rob Mackley (Pacific Northwest National Laboratory) from Charlene Martinez (Washington Closure Hanford), "Locations of aquifer tubes for sample collection," May 7, 2012, Richland, Washington.
} 
x-y positions - no control was used to reference the horizontal coordinates into the "real world" (e.g., latitude/longitude). These relative horizontal coordinates were used to calculate radial distances and bearings between the injection and monitoring wells and aquifer tubes. The vertical coordinates of these locations were converted to real-world elevations based on water table elevation according to the following steps:

1. The known top of casing elevation for well 199-B8-6 from the Hanford Well Information System was combined with a depth-to-water measurement (using the same e-tape as described in Section 4.3.2) to calculate the water table elevation.

2. The depth-to-water was measured in well DG2 within 5 min of the measurement in well 199-B8-6. The water table in the two wells was assumed to be similar in elevation (within the error of the survey) due to their close proximity (about $300 \mathrm{~m}$ ).

3. The depth-to-water in well DG2 was added to the water table elevation to find the unknown elevation of the top of the well casing.

4. All vertical survey measurements with the total station were referenced to the top of casing elevation for well DG2 and converted to a real-world elevation (NAVD88).

\subsubsection{Drilling}

A network of six temporary, small-diameter wells was installed near the bottom of the entrance ramp to the 100-C-7:1 excavation site to support aquifer hydraulic/tracer testing. All of the borings were drilled and wells installed during a single drilling campaign using direct-push technology (DPT) drilling methods (Figure 4). Each boring was advanced to total depth using nominally sized 7.6-cm-(3-in.-) diameter carbon steel temporary casing fitted with a $10.8-\mathrm{cm}(41 / 4-i n$.) diameter drive point that was knocked out and left in place prior to well installation. The well network (Figure 5 and Figure 6) consists of one central well (INJ) through which initial tracer injection testing was conducted, three shallow nearfield monitoring wells (DG1, UG1, and CG1), one shallow far-field monitoring well (DG2), and one deep near-field monitoring well (CG2). All shallow wells were completed with 3-m (10-ft) screens, nominally placed between elevations of $119 \mathrm{~m}$ to $122 \mathrm{~m}$ above msl. The top of this interval is the approximate elevation of the excavation bottom. To monitor for vertical migration of injected tracer solution, one deep near-field monitoring well was completed with a $0.6-\mathrm{m}(2-\mathrm{ft})$ screen interval placed from $116.4 \mathrm{~m}$ to $117.0 \mathrm{~m}$ above $\mathrm{msl}$. 


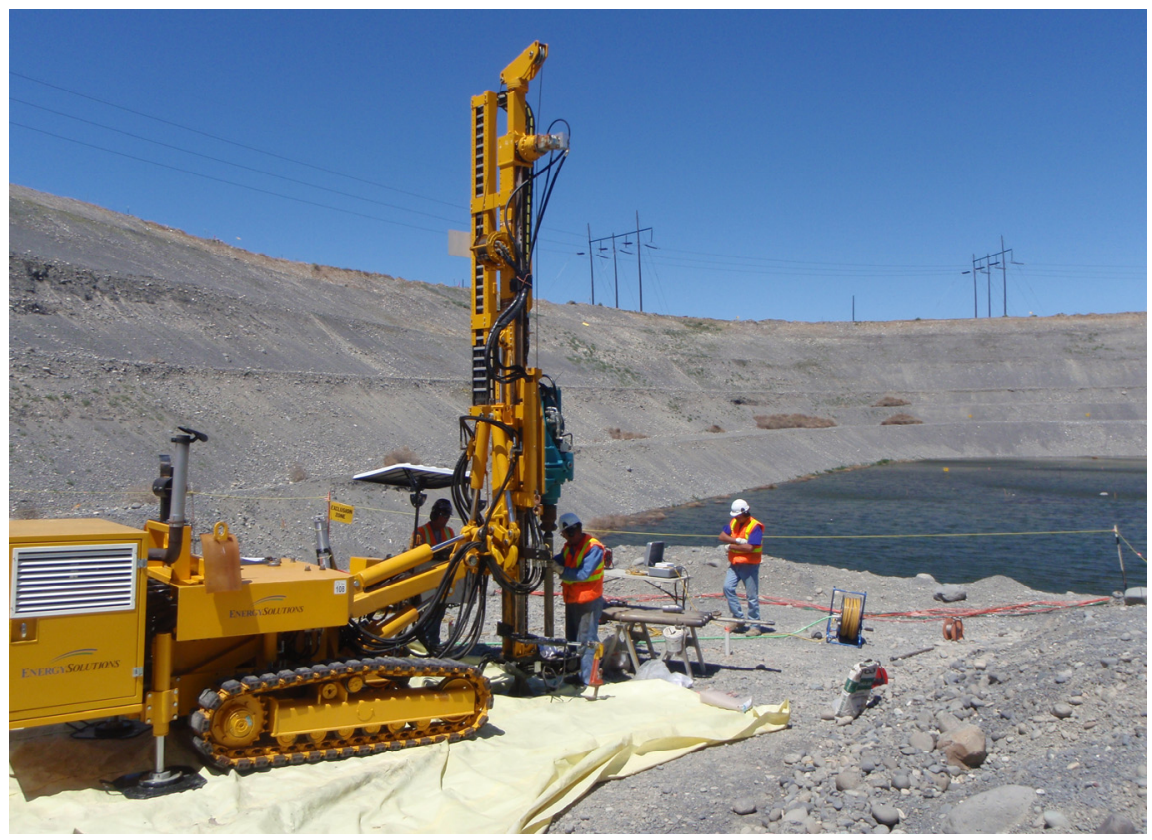

Figure 4. Photo of the direct push technology drill rig that was used during drilling and installation of the 100-C-7:1 temporary small-diameter well network

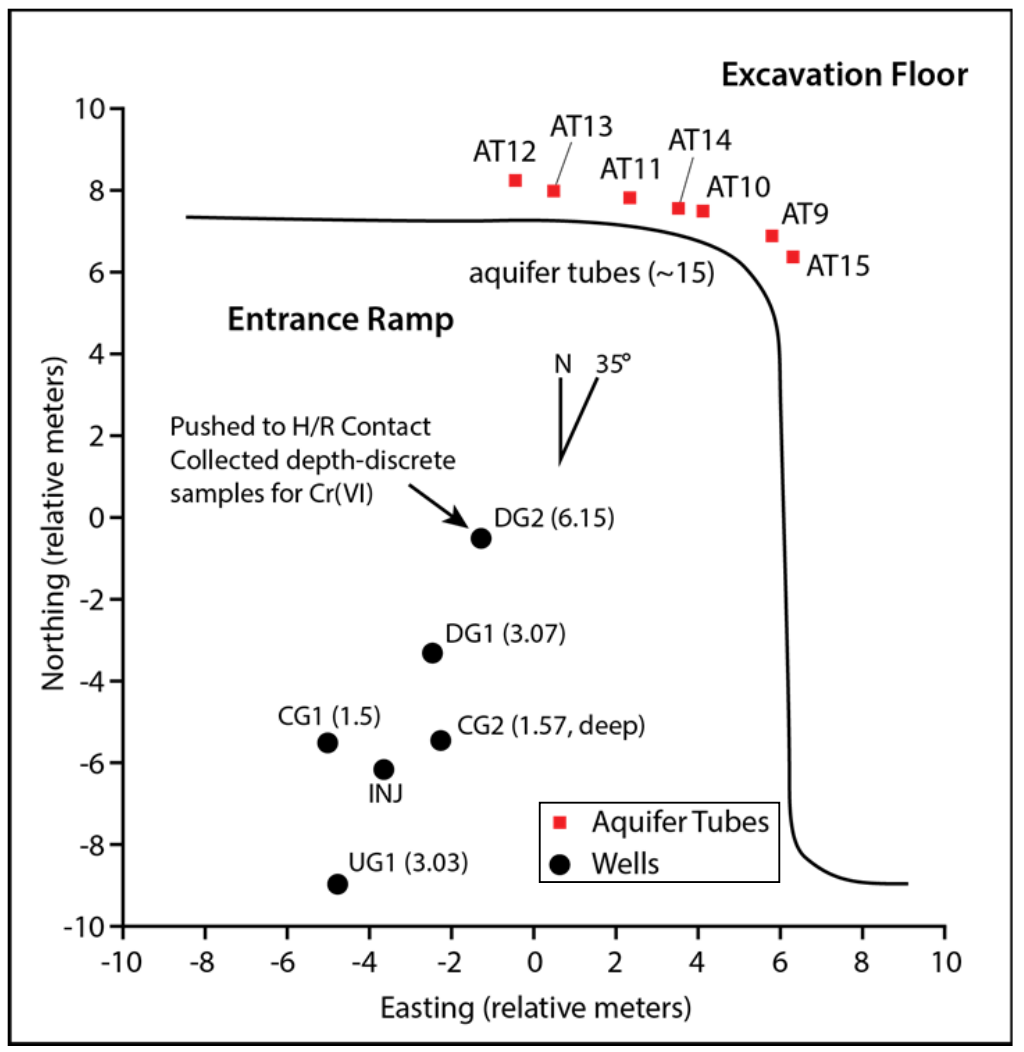

Figure 5. Plan view of the $100-\mathrm{C}-7: 1$ well network and nearby aquifer tubes. Numbers in parentheses indicate the radial distance from the INJ well in meters. The notation "H/R" refers to the contact between the Hanford and Ringold Formation geologic units. The line of wells UG1, INJ, DG1, and DG2 lie along an azimuth of $35^{\circ}$. 
Vertical profile sampling of $\mathrm{Cr}(\mathrm{VI})$ was conducted at discrete depth intervals while advancing the temporary drill casing for the installation well DG2. A total of four groundwater samples were collected at $2.6,3.5,12.0$, and $15.4 \mathrm{~m}(8.5,11.5,39.5$, and $50.5 \mathrm{ft}$, respectively) below the top of the water table, which itself was $3.8 \mathrm{~m}$ (12.5 ft) below ground surface. To characterize $\mathrm{Cr}(\mathrm{VI})$ concentrations closer to the groundwater surface, an additional sample was collected from well DG1 at approximately $0.6 \mathrm{~m}(2 \mathrm{ft})$ below the water table. None of the samples collected during drilling contained measurable $\mathrm{Cr}(\mathrm{VI})$ concentrations. All groundwater samples were collected and $\mathrm{Cr}(\mathrm{VI})$ concentrations were measured in the field using the methods described in Section 4.1.

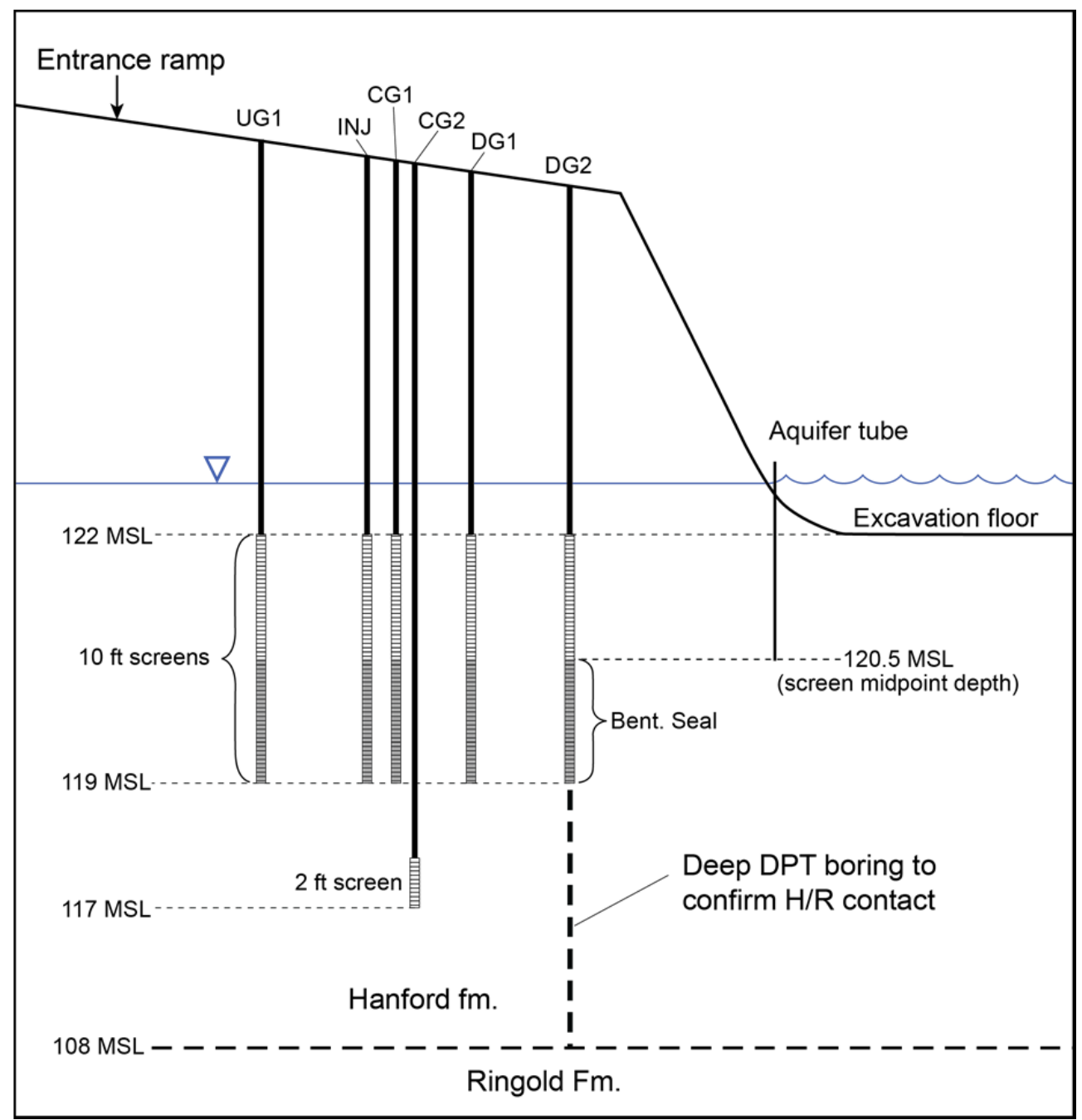

Figure 6. Nominal cross section of the 100-C-7:1 test site showing the relative well locations (with CG1 and CG2 projected onto the cross section) and screen depths. The figure is not to scale. Elevations are in meters; screen lengths are $3 \mathrm{~m}(10 \mathrm{ft})$ and $0.6 \mathrm{~m}(2 \mathrm{ft})$. The notation "H/R" refers to the contact between the Hanford and Ringold geologic formations (fm). Bentonite material was used to reconfigure the $3-\mathrm{m}(10-\mathrm{ft})$ well screens to $1.5-\mathrm{m}(5-\mathrm{ft})$ screens. 


\subsubsection{Well Installation}

Each well was constructed using 5-cm-(2-in.-) diameter polyvinyl chloride (PVC) casing (Schedule 40, ASTM D1785, F480 with flush-threaded joints and Viton "O" rings) and 20-slot (0.05-cm [0.020-in.]) PVC screens (ASTM D1785, F480, continuous wire wrap, with flush-threaded joints and Viton "O" rings); no glues or solvents were used. Filter pack material consisted of 10-20 mesh filter pack sand. These selections were based on the hydrogeology encountered during drilling, as well as information from nearby wells.

Filter pack installation and initial well development consisted of introducing silica sand into the annular space around the screen and settling the filter pack to eliminate void spaces. A dual-flange surge block was used to develop and settle the filter pack in the annular space between the screen and the borehole wall. Surging of the $3-\mathrm{m}(10-\mathrm{ft})$ screens was carried out in two stages, developing the screen in $1.5-\mathrm{m}(5-\mathrm{ft})$ intervals. The $0.6-\mathrm{m}(2-\mathrm{ft})$ screen installed at well CG2 was developed in one stage.

The five shallow wells (INJ, UG1, CG1, DG1, and DG2) were constructed with a hydrated bentonite crumble seal placed above each screen's filter pack interval to ground surface. However, the single deep well (CG2) required an alternate construction method to install an annular seal because the top of the filter pack material was located too far below the water table to use bentonite crumbles without the risk of bridging, and the annular space was too small to accommodate bentonite chips or pellets. For this reason, bentonite slurry was mixed at the surface and pumped down the annular space using a peristaltic pump. To prevent intrusion of bentonite slurry into the filter pack, approximately $0.15 \mathrm{~m}(0.5 \mathrm{ft})$ of 20-40 mesh silica sand was placed above the 10-20 mesh filter pack prior to pumping bentonite slurry. Bentonite slurry was pumped and allowed to settle to within $0.15 \mathrm{~m}(0.5 \mathrm{ft})$ of the ground surface, and then covered with a hydrated bentonite crumble seal at the surface. Because all six wells were temporary completions, surface casing and protective bollards were not installed. Each well was completed with $0.15 \mathrm{~m}$ to $0.46 \mathrm{~m}$ ( 0.5 to $1.5 \mathrm{ft}$ ) of stickup above ground surface and fitted with a J-plug type well cap. Additional details are provided in Table 3.

Table 3. Elevation information for wells installed at the 100-C-7:1 site

\begin{tabular}{ccccc}
\hline Well & $\begin{array}{c}\text { Approx. Ground } \\
\text { Surface Elevation } \\
(\mathrm{m} \mathrm{msl})\end{array}$ & $\begin{array}{c}\text { Approx. } \\
\text { Groundwater } \\
\text { Elevation } \\
(\mathrm{m} \mathrm{msl})\end{array}$ & $\begin{array}{c}\text { Elevation of the Top of } \\
\text { the Well Screen } \\
(\mathrm{m} \mathrm{msl})\end{array}$ & $\begin{array}{c}\text { Elevation of the } \\
\text { Bottom of the Well } \\
\text { Screen } \\
(\mathrm{m} \mathrm{msl})\end{array}$ \\
\hline UG1 & 126.99 & 122.57 & 121.92 & 118.97 \\
INJ & 126.72 & 122.59 & 121.98 & 118.93 \\
CG1 & 126.76 & 122.44 & 121.91 & 118.87 \\
CG2 & 126.67 & 122.63 & 117.02 & 116.41 \\
DG1 & 126.49 & 122.60 & 122.16 & 119.11 \\
DG2 & 126.19 & 122.60 & 122.01 & 118.96 \\
\hline m msl = meters mean sea level. & & & \\
\hline \multicolumn{5}{l}{}
\end{tabular}




\subsubsection{Well Development}

Final well development was performed by alternating the use of a dual flange surge block and a Grundfos Redi-Flo2 submersible pump (Figure 7) to develop the wells until groundwater clarity was determined sufficient and field parameters, including temperature and conductivity, had stabilized. Water level drawdown during development was monitored periodically using an electronic tape measure. During development, the pump was operated with the intake located at multiple stages within the screened intervals. The flow rates were measured at approximately 11.4-13.2 L/min (3.0-3.5 gallons per min [gpm]) with less than $3 \mathrm{~cm}(0.10 \mathrm{ft})$ of drawdown.

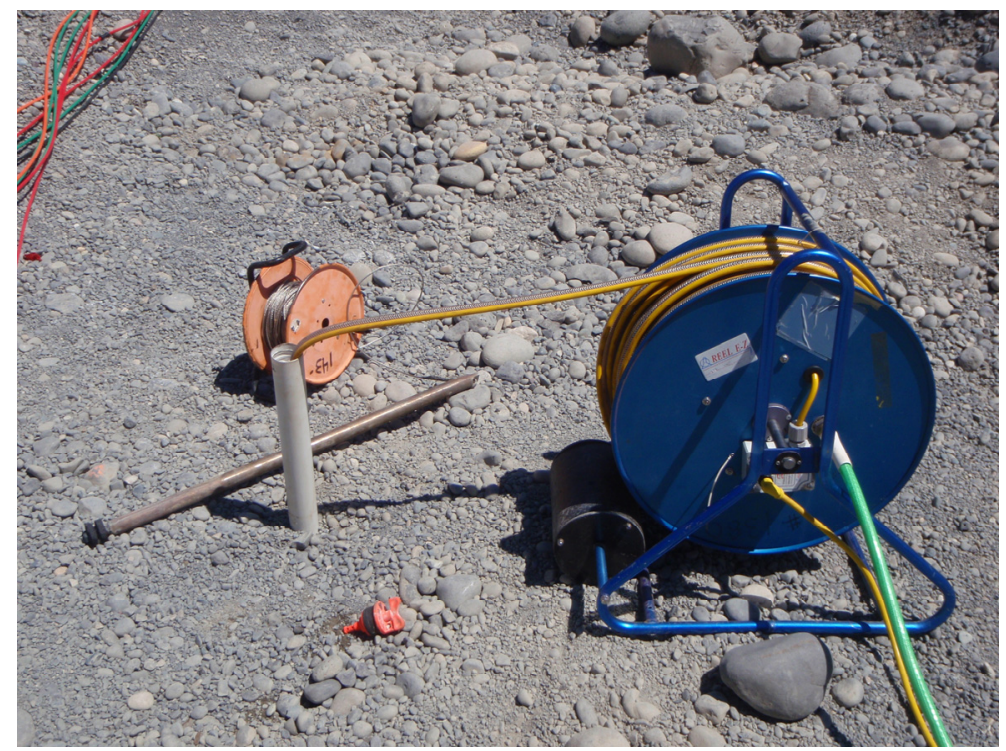

Figure 7. Each well was developed by alternating the use of a dual flange surge block (on the ground by the well in this photo) and Grundfos Redi-Flo2 submersible pump (down-hole in this photo)

\subsubsection{Well Modifications and Final Decommissioning}

After the results of the initial tracer test were evaluated, Electromagnetic Borehole Flow meter (EBF) testing was conducted to evaluate the vertical distribution of horizontal hydraulic conductivity within each well. Based on the results of the EBF testing (see Section 5.4.1), a decision was made to modify the well network by plugging the bottom half of the $3-\mathrm{m}(10-\mathrm{ft})$ screen intervals. A $1.5-\mathrm{m}(5-\mathrm{ft})$ seal was installed in each well using coated bentonite pellets, and then covered with $0.15 \mathrm{~m}(0.5 \mathrm{ft})$ of washed pea gravel to protect downhole equipment from coming into contact with the bentonite. After completion of the final injection tracer test, all wells were decommissioned by backfilling the 5-cm (2-in.) screen and PVC casing with 1-cm (3/8-in.) bentonite chips, and either unthreading and removing the surface joint of 5-cm (2-in.) PVC casing, or cutting the 5-cm (2-in.) PVC casing flush to the ground. No permanent markings were installed because the excavation pit will be backfilled to original ground surface beginning in the fall of 2012. 


\subsection{Hydraulic Testing and Groundwater Flow Direction/Gradient}

Hydrologic characterization activities performed in support of this study are discussed in detail in the following sections.

\subsubsection{Constant-Rate Injection Tests}

A series of constant-rate injection tests were performed in multiple wells in June and August 2012 to estimate local-scale aquifer hydraulic properties beneath the field test site. June testing consisted of a constant-rate injection test in well INJ prior to reconfiguration of the wells (i.e., the test was for a 3-m [10-ft] screened interval). Results from the June tracer injection test and EBF profiles indicated a relatively high permeability interval over the upper portion of the aquifer and significant ambient vertical wellbore flows in the wells (Section 5.4.1). The wells were reconfigured in July by plugging the bottom half of the screens with bentonite to reduce the effective screen interval to the upper $1.5 \mathrm{~m}$ of the original screened interval where the highest permeability materials were indicated. In August 2012, constant-rate injection tests were performed in the reconfigured well network; quantitative analysis of hydraulic test responses focused on these test results because 1) this test interval is consistent with that interrogated during the quantitative tracer testing; and 2) this shallow interval is considered of primary interest for $\mathrm{Cr}(\mathrm{VI})$ transport.

The constant-rate injection tests were designed to maximize the observable pressure response and minimize the surface boundary effects of the ponded water in the nearby excavation, the boundary of which was about $15 \mathrm{~m}$ away. The floor of the excavation was below the water table during the higherwater conditions from May to November (see hydrographs in Section 5.3). During the hydraulic tests in August, there was more than a meter of ponded water covering the excavation floor. Screening calculations indicated that there would be a noticeable effect on the pressure responses within only a few minutes of test initiation and that this boundary effect would need to be accounted for in the analysis. For this reason, the tests were limited to a 40-min injection period, followed by about the same amount of time for pressure recovery.

Ponded water from the excavation was extracted and pumped through filters and into the stressed wells using two 4-in.-diameter submersible pumps in parallel. Injection pressures and flow rates were monitored within the same process trailer equipment used in the tracer injection testing (see Section 4.4). Flow rates of 37 and 42 gpm were held constant during the tests in stress wells INJ and CG1, respectively. Pressure buildup and recovery were monitored in the stress well and nearby observation wells using submersible pressure sensors (model CT2X, Instrumentation Northwest, Kirkland, Washington).

Hydraulic properties were estimated using a type-curve fitting method according to the analytical solution of Neuman $(1972,1974,1975)$ for an unconfined aquifer with delayed gravity response (specific yield). In this analysis, the wells can be either partially or fully penetrating. The analysis assumes the aquifer is homogeneous, of infinite areal extent, of uniform thickness, and ignores well-bore storage effects. The Neuman type-curve analyses were conducted using the aquifer test analysis software AQTESOLV (HydroSOLVE, Inc., Reston, Virginia). Type curves were fit to the pressure recovery data rather than data from the pressure buildup (injection) phase because these data typically have less 
variability, particularly in the early portion of the test response. Prior to analysis, the recovery data were translated to an equivalent pumping test response through the Agarwal (1980) correction method.

The effective aquifer thickness used in the analysis was determined based on the combination of results from EBF vertical profiling and tracer injection tests. EBF results indicated that the upper $1.5 \mathrm{~m}$ of the original 3-m screened interval was most transmissive, with a zone from about 4.88 to $5.49 \mathrm{~m}$ (16 to $18 \mathrm{ft}$ ) below ground surface showing more than an order of magnitude higher relative hydraulic conductivity than deeper in the formation (see Section 5.4.1). Results from an initial scoping-level tracer injection (see Section 4.4) were generally consistent with the EBF results, showing relatively dispersed tracer arrival fronts, which is consistent with the presence of flow system heterogeneities, and no indication of tracer migration below the 3-m test interval (i.e., no tracer arrival was observed in well CG2, which is screened approximately $1.5 \mathrm{~m}$ below the bottom of the test interval). Given this information, the effective test interval for these tests was interpreted to be limited to the saturated material within and above the reconfigured screen interval. The EBF profiles do not extend above the well screen elevation, so the relative permeability of material above the screen is unknown. However, it was assumed that the higher permeability materials indicated for the upper $1.5-\mathrm{m}$ test interval extended to the water table. A partial-penetration model with stress and observation wells having screened-intervals of $1.52 \mathrm{~m} \mathrm{(5 \textrm {ft } )}$ located at the base of a 2.74-m-(9-ft-) thick aquifer was used in the analysis. This conceptual model appears reasonable based on the model fit to the observed data and the agreement of the hydraulic conductivity estimates from this analysis with values obtained independently from the tracer drift analysis (see Section 5.4.3). Conversely, a fully penetrating well configuration that assumes an aquifer thickness

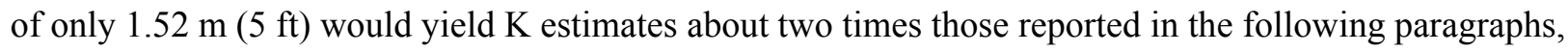
and would not be consistent with tracer test results.

Type curves were fit to the pressure responses in the observation wells using the Neuman solution while adjusting specific yield (Sy) and transmissivity (T) values to improve the goodness of fit. Storativity (S) and anisotropy $(\mathrm{Kz} / \mathrm{Kh})$ were prescribed to values of 0.001 and 0.1 , respectively. Hydraulic conductivity $(\mathrm{K})$ values were calculated from the transmissivity $(\mathrm{T})$ estimates using a prescribed saturated thickness (b) of $2.74 \mathrm{~m}(9 \mathrm{ft})$ according to $\mathrm{T}=\mathrm{K} / \mathrm{b}$.

As noted above, the wells are located within $15 \mathrm{~m}(50 \mathrm{ft})$ of the excavated pit that intersected the aquifer at the time of testing. Surface water was ponded in the pit and created a constant-head boundary condition. The analysis used superposition theory and image-well methods (Ferris et al. 1962) to account for the effects of this boundary.

\subsubsection{Groundwater Flow Direction and Gradient}

Water-level data from nearby wells were used to determine the groundwater flow direction and gradient in the 100-C-7:1 vicinity. The gradients and flow directions were calculated according to the triangulation method described by Devlin (2003). There are a number of existing wells located nearby; however, only three of these wells (199-B4-14, 199-B5-8, and 199-B8-6) were instrumented with pressure transducers as part of CH2M HILL Plateau Remediation Company's Hanford water-level monitoring network (Figure 8). Continuous water-level data for these three wells were extracted from the Automated Water Level Network module within the Virtual Library (http://vlprod.rl.gov). Data are available in the Virtual Library starting in late 2010 and early 2011 for these three wells. Manual waterlevel verifications in these wells taken with a National Institute of Standards and Technology-traceable 
electronic water level indicator (“e-tape"; RST Instruments, Maple Ridge, British Columbia, Canada) agreed with the continuous data to within $\pm 0.02 \mathrm{~m}$. These differences are reasonable given the combined errors associated with depth-to-water measurements, sensor miscalibration (drift/offset), and vertical survey. Well coordinates were extracted from the Well Information and Document Lookup webpage (http://prc.rl.gov/widl/).

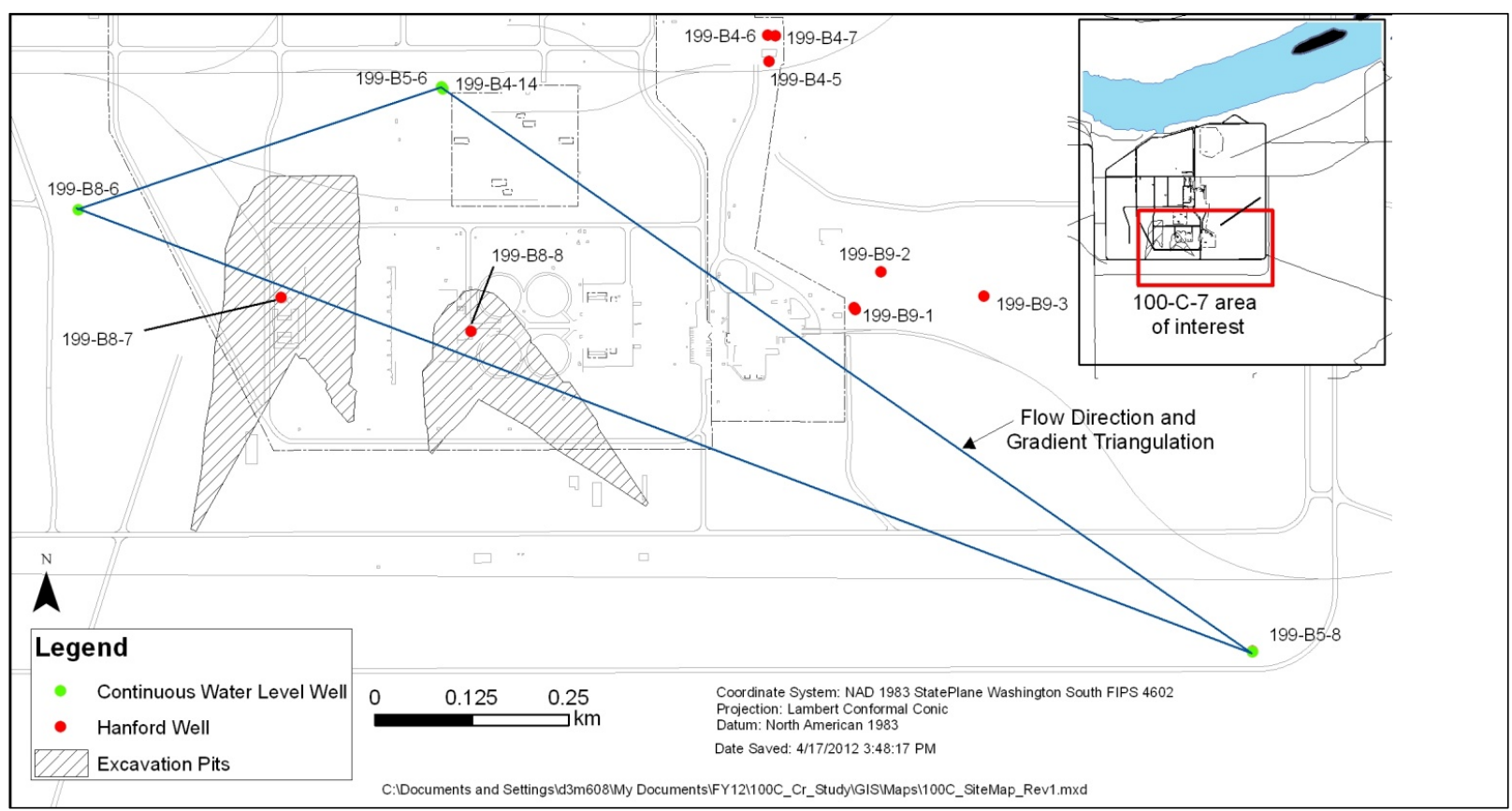

Figure 8. Location of water-level monitoring wells relative to the $100-\mathrm{C}-7$ and 100-C-7:1 sites

\subsubsection{Electromagnetic Borehole Flow Meter}

EBF surveys are effective for measuring the vertical groundwater-flow velocity distribution in wells. The vertical groundwater-flow velocity measurements can be used to infer the distribution of lateral groundwater flow into the well. The objective of EBF surveys is to characterize the ambient (i.e., static) or dynamic (i.e., pump-induced), in-well vertical flow conditions (i.e., vertical flow-velocity magnitude and direction) within the saturated well-screen section. Dynamic EBF survey results corrected for ambient flow conditions can be used to characterize the distribution of vertical flow conditions and inferred vertical hydraulic conductivity distribution.

\subsubsection{Electromagnetic Borehole Flow Meter Field Method}

The theory that governs the operation of the EBF is Faraday's Law of Induction, which states that the voltage induced by a conductor moving at right angles through a magnetic field is directly proportional to the velocity of the conductor moving through the field. In the EBF apparatus, flowing water is the conductor, an electromagnet generates a magnetic field, and electrodes are used to measure the induced voltage. For sign convention, upward flow represents a positive voltage signal and downward flow represents a negative voltage signal. A more detailed description of the EBF instrument system and field test applications are provided in Young et al. (1998). 
The EBF probe consisted of an electromagnet and two electrodes 180 degrees apart inside a hollow cylinder. The inside diameter of the hollow cylinder was $2.5 \mathrm{~cm}$ (1 in.) and the outside diameter of the probe cylinder was just under $5.1 \mathrm{~cm}(2 \mathrm{in}$.). The probe was connected to an electronics box at the surface with a jacketed cable. The electronics attached to the electrodes transmit a voltage signal directly proportional to the velocity of water acting as the conductor. A data logger was used to record the voltage signal, which can be converted to a velocity or flow-rate measurement.

Before the EBF probe was lowered into the well, the probe was fully submersed in a container of water for several minutes and the display reading was adjusted to zero flow using the zero control knob on the electronics display box. After the display readings were stabilized to within approximately $0.00 \pm$ $0.02 \mathrm{~L} / \mathrm{min}$, the probe was lowered to the bottom of the 2 -in. diameter well to begin the survey. Several minutes of inactivity were used to allow re-establishment of stable flow conditions after the disturbances caused by lowering (or raising) of the probe. Stable conditions were determined by observing real-time data logger plots on the computer monitor. After the stable flow measurement was recorded, the probe was raised slowly to the next prescribed depth and the measurement procedure was repeated. After completing the last EBF survey for the day, the EBF probe was fully submersed in the container of water again for several minutes to confirm the display reading had not changed under zero flow conditions.

\subsubsection{Electromagnetic Borehole Flow Meter Analytical Method}

For the EBF survey analysis, it is assumed that the aquifer within the well-screen section is composed of a series of horizontal layers, possessing layer-specific hydraulic properties. Under ambient (i.e., nonpumping) flow conditions, the difference between two successive well screen depth measurements is the portion of ambient flow, $\Delta q_{i}$, entering the well screen between depths where the flow measurements were taken. These two depths are assumed to bound the $i^{\text {th }}$ layer. The portion of flow, $\Delta Q_{i}$, entering the well screen between these successive depths under induced pumping conditions is calculated in the same manner. Ambient flow survey profile information is used to correct dynamic flow meter survey results for background vertical-gradient conditions.

The analytical method used for calculating the vertical distribution of relative hydraulic conductivity from dynamic EBF surveys is summarized in Molz et al. (1989) and Boman et al. (1997). Briefly stated, assuming that a constant pumping rate and pseudo-steady-state conditions are reached during pumping, the normalized relative hydraulic conductivity for the $i^{\text {th }}$ layer within the aquifer can be calculated per Equation (1).

$$
K_{r, i}=\frac{K_{i}}{K_{\text {avg }}}=\frac{\left(\Delta Q_{i}-\Delta q_{i}\right) / \Delta z_{i}}{\sum_{i}\left(\Delta Q_{i}-\Delta q_{i}\right) / \sum_{i} z_{i}} \quad i=1,2, \ldots, n
$$

where $\quad K_{r, i}=$ normalized relative hydraulic conductivity for the $i^{\text {th }}$ layer $(\mathrm{m} / \mathrm{d})$

$K_{i}=$ absolute horizontal hydraulic conductivity of the $i^{\text {th }}$ layer $(\mathrm{m} / \mathrm{d})$

$K_{\text {avg }}=$ average horizontal hydraulic conductivity $(\mathrm{m} / \mathrm{d})$

$\Delta Q_{i}=$ difference in EBF flow measurements at the top and bottom of the $i^{\text {th }}$ layer under pumping conditions

$\Delta q_{i}=$ difference in EBF flow measurements at the top and bottom of the $i^{\text {th }}$ layer under ambient conditions

$\Delta z_{i}=i^{\text {th }}$ layer thickness. 
As indicated in Equation (1), the normalized relative hydraulic-conductivity value can be determined directly from measuring specific depth inflow rates relative to total flow pumped from the entire test interval. An absolute or actual hydraulic-conductivity-value depth profile (i.e., $K_{i}$ versus depth), however, can be developed if an estimate of $K_{\text {avg }}$ has been determined from a standard hydrologic test method (e.g., constant-rate pumping test).

\subsection{Tracer Tests}

Three natural gradient tracer tests, which contributed to a quantitative assessment of the groundwater flow system beneath the 100-C-7:1 pit excavation, were conducted during the summer of 2012. In addition, results from an initial scoping-level test conducted in well INJ (see Figure 5) provided evidence for preferential flow paths that tended to bias flow in the upgradient direction when injecting into well INJ, resulting in very early arrival times in upgradient monitoring locations and limited connectivity to downgradient monitoring locations. Tracer responses observed during this test also suggested the presence of vertical wellbore flow within the monitoring wells, which was confirmed through EBF measurements (see Section 5.4.1). Results from this initial test and subsequent tracer testing indicated that the presence of preferential flow paths was less pronounced in the downgradient direction so the tracer testing experimental design was modified to use the closest downgradient well (DG1) as the injection well for quantitative assessment of upper-zone flow properties. To address the observed vertical wellbore flows and focus testing on the upper portion of the aquifer, which based on EBF profiles was the most transmissive portion of the aquifer, all wells in the monitoring network (except CG2) were reconfigured to shorten the test interval to the upper $5 \mathrm{ft}$ of the original 10 - $\mathrm{ft}$-long screened interval (see Section 4.0). Two natural gradient tracer tests were conducted in this reconfigured well field using well DG1 as the injection well and a third tracer test was conducted deeper in the formation in well CG2. All three tests were conducted using the same process control and monitoring equipment.

Supply water for the tracer tests was extracted from the shallow pond that formed in the bottom of the excavation when the water table rose above the elevation of the excavation floor. Water was extracted with a submersible well pump (model 16S, Grundfos Pumps Corp., Colvis, California) placed inside of a pump shroud and laid on the side of the pond. The water was pumped through a bag filter ( 85 micron), through a turbine flow meters (model FT series, Flow Technology Inc., Tempe, Arizona), and into the injection well through a perforated drop hose. This configuration was used for both the hydraulic testing and the tracer tests. A concentrated tracer solution was added to the injection stream for the first two tracer tests. Nominally, a $5000 \mathrm{mg} / \mathrm{L}\left(\mathrm{Br}^{-}\right)$concentrated stock solution was added to the injection stream at mixing ratio of 0.02 to produce the targeted $100 \mathrm{mg} / \mathrm{L}\left(\mathrm{Br}^{-}\right)$tracer injection concentration. The concentrated tracer solution was added to the injection stream using a centrifugal pump to drive the solution through a Y-strainer (75 micron) and a turbine flow meter (model FT series, Flow Technology Inc., Tempe, Arizona) and into the process piping system. For the third tracer test, $757 \mathrm{~L}$ of the pond water was pumped into a storage tank, and $0.25 \mathrm{~kg}$ of $\mathrm{N}$ sodium bromide was added to create a tracer solution of approximately $250 \mathrm{mg} / \mathrm{L} \mathrm{Br}^{-}$.

Tracer concentrations within the formation were inferred from specific conductance probes installed within each well. The change in specific conductance was proportional to the concentration of tracer solution in groundwater. The probes used (model CT2X, Instrumentation Northwest, Kirkland, Washington) recorded temperature, pressure, and specific conductance at a frequency ranging from 4 hertz (i.e., $4 / \mathrm{sec}$ ) to hourly, depending on the test requirements. Probe calibration was checked prior to 
the start of each test using a two-point check. If the probe required recalibration, this was accomplished using the manufacture's two-point field calibration method.

Aqueous samples were collected from the wells for the initial scoping test and during the first quantitative tracer test (Table 4 and Table 5). Dedicated "Mega Typhoon" sampling pumps (Proactive Pumps, Trenton, New Jersey), capable of delivering flows up to $7.6 \mathrm{~L} / \mathrm{min}$, were installed in all site monitoring wells. The sample tubing $(1.5 \mathrm{~cm}$ vinyl $)$ from each of these sampling pumps was routed inside a mobile laboratory and connected to a sampling manifold. A single DC power supply (model 1688A, B+K Precision Corp., Yorba Linda, California) provided power for the sampling pumps. A multi-channel interface (pump switch box) was used to allow a single power supply/controller arrangement to provide power to each sampling pump. A multi-position rotary switch on the switch box eliminated the possibility of powering more than one pump at a time. A sampling manifold was used in the collection of samples from monitoring wells. This approach routes all sample streams into a central manifold for monitoring field parameters and collecting groundwater samples (Figure 9). The advantage of this type of system is that all field parameter measurements are made using a single instrument, which improves data quality and comparability of spatially distributed measurements. To reduce the potential for collecting sample from the wrong well, the pump switch box was wired to a series of low-voltage light-emitting diode indicator lights on the sample manifold. When a pump was turned on, a light came on to indicate which pump was operating, and which valve on the manifold should be opened. For the tracer tests, only specific conductance was recorded as an indication parameter; it was measured using a Myron L multi-parameter probe (Myron L Co., Carlsbad, California) to measure the specific conductance of the water at the sampling port. Aqueous samples were not collected during tracer test 2 and 3 because of pumping induced sampling artifacts identified during the first test. Instead, these tests relied exclusively on the downhole probe data.

Table 4. Sample collection requirements for aqueous tracer test samples

\begin{tabular}{|c|c|c|c|c|}
\hline Parameter & Media/Matrix & Sampling Frequency & Volume/Container & Preservation \\
\hline $\begin{array}{l}\text { Anions: } \\
\mathrm{Br}^{-}\end{array}$ & Water & $\begin{array}{l}\text { As required to define } \\
\text { arrival and elution curves }\end{array}$ & 25-mL plastic vial & $\begin{array}{l}\text { Filtered } \\
\text { Hold Time: } 45 \mathrm{~d}\end{array}$ \\
\hline Specific Conductance & Water & Continuous, downhole & Field measurement & None \\
\hline
\end{tabular}

Table 5. Analytical requirements for aqueous tracer test samples

\begin{tabular}{|c|c|c|c|c|}
\hline Parameter & Analysis Method & Detection Limit & $\begin{array}{c}\text { Typical } \\
\text { Precision/Accuracy }\end{array}$ & $\begin{array}{l}\text { Quality Control } \\
\text { Requirements }\end{array}$ \\
\hline $\begin{array}{l}\text { Anions: } \\
\mathrm{Br}^{-}\end{array}$ & $\begin{array}{l}\text { Ion Chromatography } \\
\text { (EPA Method 300.0) } \\
\text { (EPA 1993) }\end{array}$ & $240 \mu \mathrm{g} / \mathrm{L}$ & $\pm 15 \%$ & $\begin{array}{l}\text { Daily calibration; } \\
\text { blanks } 10 \% \text { level }\end{array}$ \\
\hline Specific Conductance & Electrode & Not applicable & $\pm 10 \%$ & For indication only \\
\hline
\end{tabular}




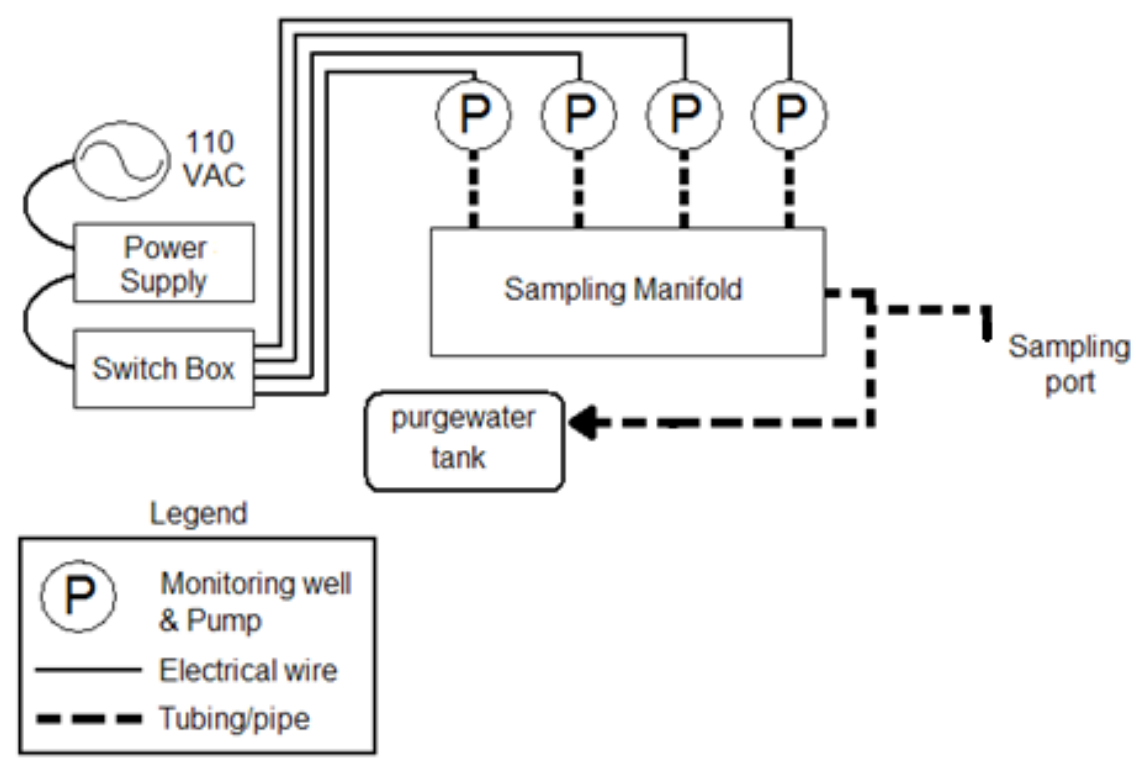

Figure 9. Schematic drawing of the groundwater sample acquisition system

\subsection{Modeling Configuration}

A numerical model was constructed to assess the data from the injection/elution tracer test. The three dimensional numerical model was constructed within the Groundwater Modeling System software (Brigham Young University, Provo, Utah; commercially available through Aquaveo, LLC, www.aquaveo.com), which uses MODFLOW (McDonald and Harbaugh 1988; Harbaugh et al. 2000) for the flow calculation engine. For this work, RT3D (Clement 1997; Clement et al. 1998; Clement and Johnson 2002) was used as the solute transport engine. This section describes the configuration of the numerical model.

Configuring the numerical model consists of defining a conceptual model, then constructing the specifics of the numerical model (model grid size/discretization, nature of the aquifer, tracer injection parameters) based on that conceptual model. For this work, a simplified conceptual model was applied. The aquifer is conceptualized as a $1.5-\mathrm{m}(5-\mathrm{ft})$ thick zone of uniform properties (hydraulic conductivity, porosity, etc.) with a constant hydraulic gradient for the duration of the tracer test. A transient model is required to represent the periods of tracer injection and subsequent solute transport under non-pumping conditions (i.e., "drift"). The model does not represent any surface water features, such as the nearby pond. No recharge was applied to the model, which is appropriate for the time frame during which the tracer tests were conducted.

The grid for the numerical model is described in Table 6. A single layer was used to represent the homogenous aquifer. The extent of the square model grid was selected to avoid any edge effects and is nominally three times the distance between wells UG1 and DG2. A uniform lateral grid resolution of $0.25 \mathrm{~m}$ was selected to provide a relatively fine discretization between monitoring wells (which is important for the solute transport). The coordinate system for the model grid is an arbitrary model system. However, the monitoring well locations were overlaid on the model grid such that well DG1 was 
located at the center of the model grid and the direction of groundwater flow (Section 5.3) was parallel to the left-right rows of the grid. Figure 10 shows a plan view of the model grid.

Table 6. Descriptive parameters for the numerical model grid

\begin{tabular}{lcccc}
\hline \multicolumn{1}{c}{ Grid Information } & Units & $\begin{array}{c}\text { X direction } \\
\text { (columns) }\end{array}$ & $\begin{array}{c}\text { Y direction } \\
\text { (rows) }\end{array}$ & $\begin{array}{c}\text { Z direction } \\
\text { (layers) }\end{array}$ \\
\hline Number of cells & - & 121 & 121 & 1 \\
Total grid length & $\mathrm{m}$ & 30.25 & 30.25 & 1.524 \\
$\begin{array}{l}\text { Grid cell size } \\
\text { (i.e., width, thickness) }\end{array}$ & $\mathrm{m}$ & 0.25 & 0.25 & 1.524 \\
Origin coordinates $^{(\mathrm{a})}$ & $\mathrm{m}$ & 0.0 & 0.0 & 0.0 \\
\hline
\end{tabular}

(a) The origin is at the lower left bottom corner of the three-dimensional model grid. Local coordinates for well locations were rotated and translated such that well DG1 was located at the center of the model grid (indices of $61,61,1$ ) and the nominal groundwater gradient azimuth of $44.7^{\circ}$ was parallel to the left-right direction of the model grid. Note that the line of wells UG1, INJ, DG1, and DG2 lie along an azimuth of $35^{\circ}$.

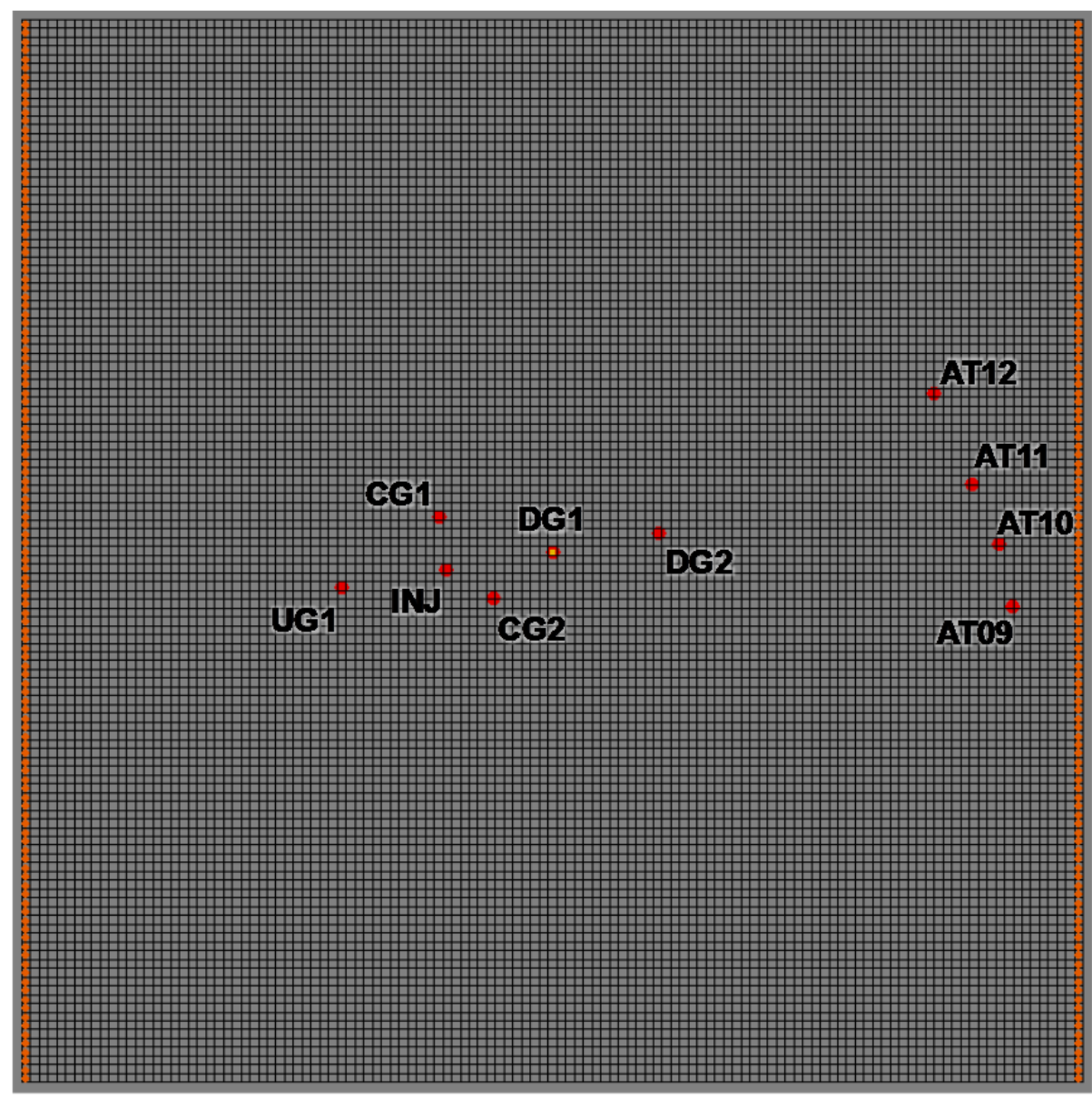

Figure 10. Plan view of the numerical model grid showing boundary condition cells (left and right sides), the injection well (yellow square in the center of the grid), and locations of wells and nearby aquifer tubes (labeled red dots) 
The key aquifer properties that must be defined for a MODFLOW model in the layer property flow (LPF) package include the nature of the aquifer (confined, under the assumption that flow only moves laterally), hydraulic conductivity, lateral anisotropy, and specific storage. The hydraulic conductivity was a fitting parameter and is discussed further in Section 5.4. The lateral anisotropy was left at the default value of 1.0. A specific storage value of $0.00001 \mathrm{~m}^{-1}$ was applied. The porosity and dispersivity must also be defined for simulation of solute transport, but these parameters were also used as fitting parameters and are discussed in Section 5.4. The ratios of transverse to longitudinal and vertical to longitudinal dispersivity were, however, fixed at the default $10 \%$ and $1 \%$, respectively (note, though, that the vertical dispersivity is irrelevant to this one-layer model).

Initial and boundary conditions were defined for the model based on site hydraulic data for the time period of the tracer tests (Section 5.4.3). A hydraulic head elevation of $122.3 \mathrm{~m}$ was selected for the initial conditions in all non-boundary-condition grid cells based on typical historical data. Constant head boundary conditions were calculated for the upgradient and downgradient model sides, taking the head at the center of the model domain to be $122.3 \mathrm{~m}$ under unstressed conditions and applying the average gradient across the 15-m span in each direction (cell center to cell center). The average gradient for each tracer test was calculated based on hourly data spanning the duration of the test. The timeframes, gradients, and boundary conditions are listed in Table 7 . Where constant head boundary conditions are specified, the boundary condition is also the initial condition. The top and bottom sides of the grid were defined as no-flow boundary conditions because flow is parallel to those sides.

Table 7. Information about the tracer tests (dates/durations, flow rates, gradient, etc.) and numerical model configuration (boundary conditions, temporal discretization)

\begin{tabular}{|c|c|c|c|}
\hline Parameter & Units & Tracer Test 2 & Tracer Test 3 \\
\hline Injection start time & - & $8 / 22 / 2012 \quad 10: 33: 30 \mathrm{AM}$ & 8/23/2012 10:12:30 AM \\
\hline Injection end time & - & 8/22/2012 03:40:30 PM & 8/23/2012 10:34:30 AM \\
\hline Average injection flow rate & $\mathrm{m}^{3} / \mathrm{d}(\mathrm{gpm})$ & $59.04(10.8)$ & $24.78(4.55)$ \\
\hline Extraction start time & - & - & 8/24/2012 06:19:00 AM \\
\hline Extraction pumping change time & - & - & 8/24/2012 08:45:00 AM \\
\hline Extraction end time & - & - & 8/24/2012 09:41:00 AM \\
\hline Average extraction flow rate (initial) ${ }^{(a)}$ & - & - & $21.80(4.0)$ \\
\hline Average extraction flow rate (final) ${ }^{(a)}$ & - & - & $39.52(7.25)$ \\
\hline Data collection end time & - & 8/24/2012 08:39:30 PM & 8/24/2012 09:45:24 AM \\
\hline Start time for average gradient calc. & - & 8/21/2012 11:00:00 AM & 8/22/2012 11:00:00 AM \\
\hline End time for average gradient calc. & - & 8/24/2012 08:00:00 PM & 8/24/2012 10:00:00 AM \\
\hline Average gradient & $\mathrm{m} / \mathrm{m}$ & $1.10227 \mathrm{E}-04$ & $1.09029 \mathrm{E}-04$ \\
\hline Average flow direction (azimuth) & deg. & 44.7 & 44.7 \\
\hline Upgradient constant head & $\mathrm{m}$ & 122.30165 & 122.30164 \\
\hline Downgradient constant head & $\mathrm{m}$ & 122.29835 & 122.29836 \\
\hline Number of stress periods & - & 3 & 5 \\
\hline Num. time steps in each stress period & - & $20,20,48^{(\mathrm{b})}$ & $10,79,10,4,25^{(\mathrm{b})}$ \\
\hline Duration of each stress period & $\min$ & $307,299,2880^{(\mathrm{b})}$ & $22,1185,146,56,1471^{(\mathrm{b})}$ \\
\hline \multicolumn{4}{|c|}{$\begin{array}{l}\text { (a) The extraction flow rate was increased part-way through the extraction. Tracer test } 2 \text { did not include an } \\
\text { extraction phase. }\end{array}$} \\
\hline
\end{tabular}


The final aspect of the model configuration is specifying information pertaining to the injection of tracer. The model was configured to include multiple stress periods to accommodate the duration of pumping and drift activities. Each stress period includes multiple time steps for calculation of the flow conditions over time. The stress period and time step configurations are shown in Table 7. As an ancillary consideration, the temporal discretization was also designed for convenience in specifying when model output was to be recorded.

A chemical species named "Tracer" was defined for describing the solute injection and transport in RT3D. The tracer was defined as non-sorbing and non-reacting. The injection concentration was specified as 100 concentration units for ease of interpreting output (e.g., a concentration of "50" equates to $50 \%$ of the input concentration).

The default PCG2 Solver parameters and MODFLOW output scheme (at the end of each flow time step) were retained. For solute transport simulation with RT3D, the default total variation diminishing advection solver and the generalized conjugate gradient (GCG) implicit solver were applied. The GCG solver used the default settings, including Jacobi preconditioning. The transport time step size was set to be automatically determined by RT3D for the injection stress period, but was specified as $0.0001 \mathrm{~d}$ for subsequent stress periods to improve the simulation run time.

\subsection{Results}

As discussed in Section 4.0, spatially and temporally distributed $\mathrm{Cr}(\mathrm{VI})$ data and hydrologic data were collected as part of this site investigation. These efforts enabled monitoring of elevated $\mathrm{Cr}(\mathrm{VI})$ concentrations that were mobilized as the water table came into contact with excavation bottom sediments, and the project-installed aquifer tube network was routinely monitored over the duration of the project.

A temporary, small-diameter monitoring well network was installed (by direct-push drilling methods) for determination of local-scale hydraulic and transport property estimation. The well network was originally designed to focus interrogation on a 3-m interval of the Hanford formation, the top of which was the approximate elevation of the excavation floor. Results from initial hydraulic and tracer testing in this well network demonstrated that the wellbore flows significantly impacted the concentration of tracers measured in the monitoring wells and limited the ability to quantitatively assess natural gradient tracer drift response data. Therefore, the wells were reconfigured using bentonite fill material to decrease the test interval to the upper $1.5 \mathrm{~m}$ of each $3-\mathrm{m}$ well screen. This reconfigured well network, which effectively mitigated the ambient wellbore flow problem and focused hydrologic interrogation on the upper 1.5-m test interval, was used to perform both hydraulic and tracer injection and natural gradient drift tests. Results from these tests, along with the hydraulic gradient calculated from hydraulic head data at wells in the vicinity of the site, were used to characterize properties controlling local-scale groundwater flow and contaminant transport.

Results for the study elements are presented in the following sections. 


\section{1 $\mathrm{Cr}(\mathrm{VI})$ Concentration, Mass, and Flux}

\subsubsection{Vertical Profiling}

Cr(VI) concentration data collected during vertical profiling on May 10, 2012, is shown in Figure 11. At the time of this profiling activity, location AT-1 (located near the D7 soil sampling point) was flooded with 10-plus centimeters of water and the yellow stain observed previously on the sediment had dissipated. Water was just appearing at the surface at location AT-3 (located near the D5 soil sampling point) and the area was stained yellow. The area around location AT-6 (downgradient location) was not yet flooded and there was no yellow staining. Yellow staining is taken as an indication of high $\mathrm{Cr}(\mathrm{VI})$ concentrations associated with the sediment.

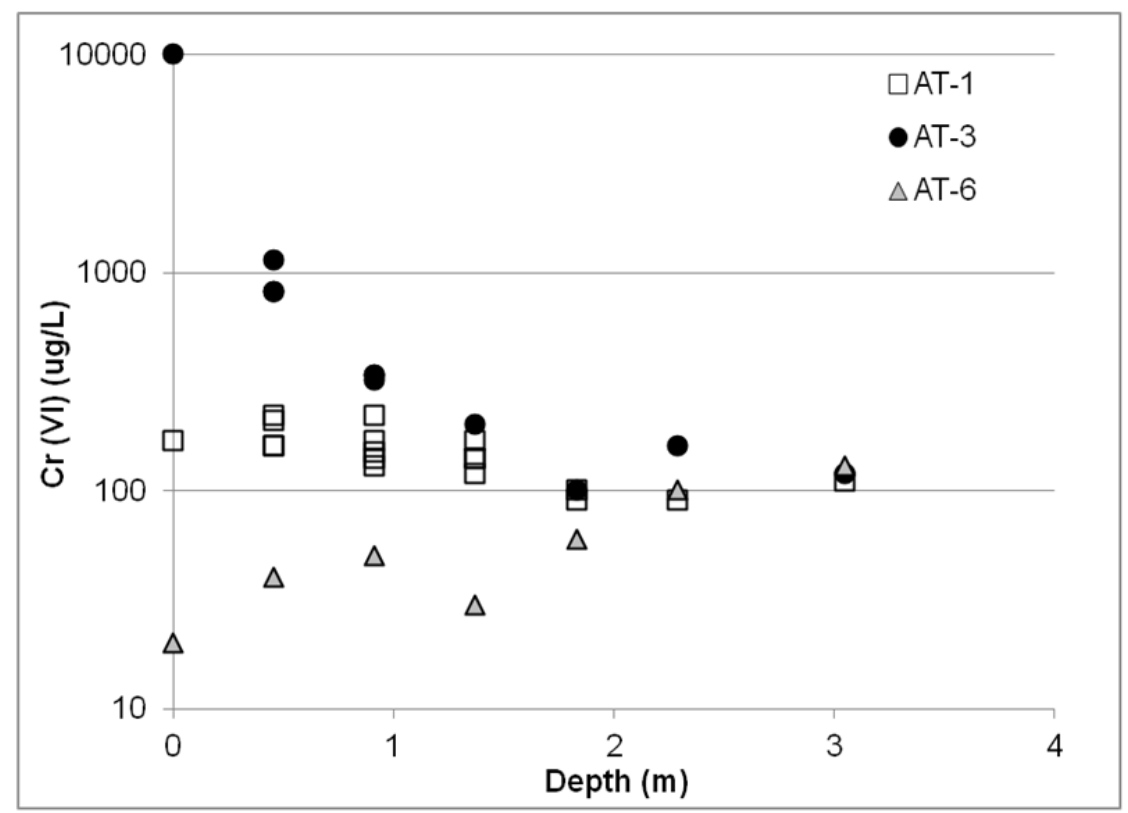

Figure 11. Vertical profiling data from May 10, 2012. Note the log scale for $\mathrm{Cr}(\mathrm{VI})$ concentration $(\mu \mathrm{g} / \mathrm{L})$.

The near-surface $\mathrm{Cr}(\mathrm{VI})$ concentration results during vertical profiling were highly transient because of flooding over time. Figure 12 shows a comparison of the May 8 and May $10 \mathrm{Cr}(\mathrm{VI})$ profiling results at location AT-1. Good agreement is generally observed, except near the surface, where surface flooding rapidly dissipated/diluted the $\mathrm{Cr}(\mathrm{VI})$ concentrations. These data demonstrate the rapid mobilization of $\mathrm{Cr}(\mathrm{VI})$ from sediments when contacted by water, similar to the observation on a larger scale for the full study data set for temporal $\mathrm{Cr}(\mathrm{VI})$ concentration trends presented below. 


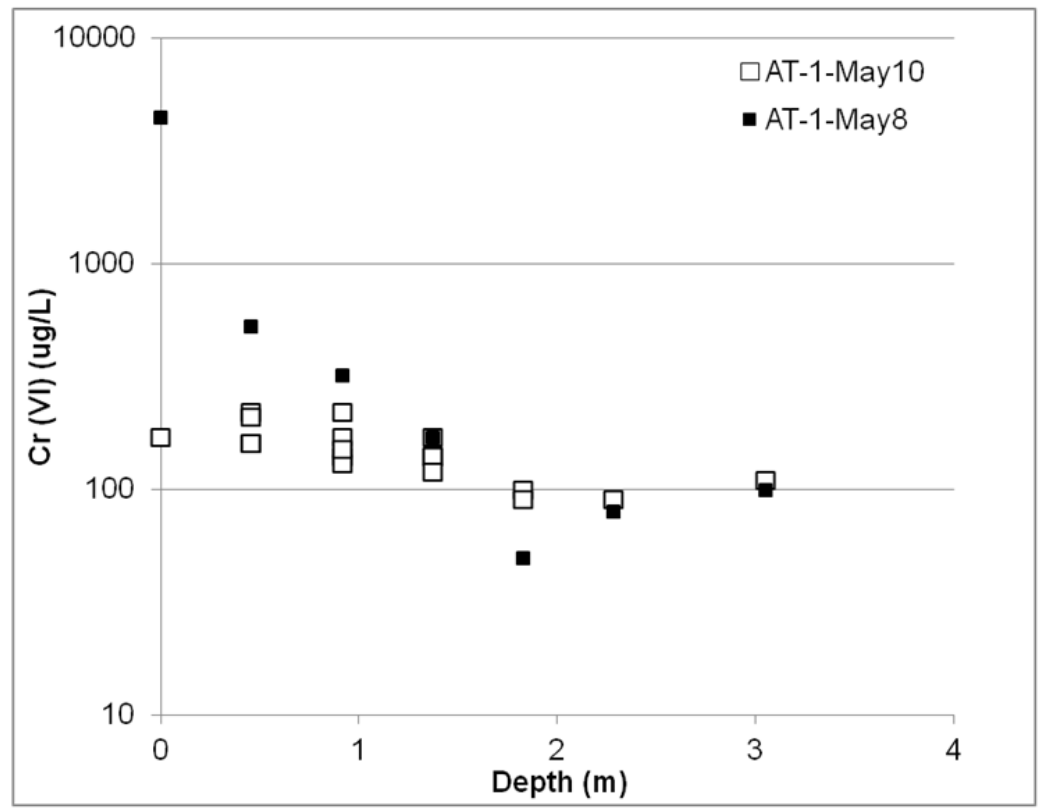

Figure 12. Comparison of May 8 and May 10, 2012, vertical profiling data for $\mathrm{Cr}(\mathrm{VI})$. Note the $\log$ scale for $\mathrm{Cr}(\mathrm{VI})$ concentration in $(\mu \mathrm{g} / \mathrm{L})$.

\subsubsection{Temporal Cr(VI) Data}

Routine monitoring of aqueous Cr(VI) concentrations began in May 2012. Overall, 10 sampling events occurred, with 187 samples collected from aquifer tubes (Figure 3, Table 8). In addition, 11 samples of the ponded water in the excavated pit were collected and analyzed for $\mathrm{Cr}(\mathrm{VI})$. The groundwater $\mathrm{Cr}(\mathrm{VI})$ concentrations decreased over the course of the study time frame (Figure 13). The equally weighted average concentration data indicated that the concentration decreased from near $50 \mu \mathrm{g} / \mathrm{L}$ in early May to less than $5 \mu \mathrm{g} / \mathrm{L}$ by the end of August (Table 9).

A sub-set of filtered samples was analyzed for both total chromium (ICP-MS, Figure 14) and $\mathrm{Cr}(\mathrm{VI})$. The results of these split samples indicated that the $\mathrm{Cr}(\mathrm{VI})$ and total chromium concentrations were essentially the same, providing confirmation that all of the soluble chromium was present as $\mathrm{Cr}(\mathrm{VI})$ (Figure 14). An additional sub-set of unfiltered samples was analyzed via ICP-MS; these results were compared with results for filtered samples analyzed with ICP-MS for total chromium (Figure 14) and showed no measureable difference between the filtered and unfiltered concentrations, indicating that the samples did not contain colloidal Cr(VI) contamination. Collectively, these results indicate that all the chromium present in the samples was soluble and present as $\mathrm{Cr}(\mathrm{VI})$.

$\mathrm{Cr}(\mathrm{VI})$ concentration measurements in samples collected from near-field aquifer tubes AT-9, AT-10, AT-11, and AT-12 on June 25, 2012, were 10, non-detect, 10, and $20 \mu \mathrm{g} / \mathrm{L}$, respectively. These results are comparable to the concentrations measured at aquifer tubes AT-2 and AT-8, the two primary monitoring locations closest to the four near-field aquifer tubes installed to support hydrologic testing. Low to non-detectible $\mathrm{Cr}(\mathrm{VI})$ concentrations measured at these aquifer tube locations and during installation of the nearby well network provide evidence that this location is upgradient of $\mathrm{Cr}(\mathrm{VI})$ contamination areas. 
$\mathrm{Cr}(\mathrm{VI})$ concentrations in the ponded water covering the excavation floor also decreased throughout the monitoring period (Table 8). Concentrations in the ponded water were generally very high in yellow stained areas when ponding was first occurring (puddles) but then decreased significantly as the water table continued to rise and the surface became more flooded.

Table 8. $\mathrm{Cr}(\mathrm{VI})$ concentrations $(\mu \mathrm{g} / \mathrm{L})$ based on aquifer tube sampling and field analyses performed from May through August 2012

\begin{tabular}{|c|c|c|c|c|c|c|c|c|c|c|c|}
\hline \multirow[b]{2}{*}{$\begin{array}{l}\text { Aquifer } \\
\text { Tube } \\
\text { Location }\end{array}$} & \multirow[b]{2}{*}{$\begin{array}{c}\text { Screen } \\
\text { Center } \\
\text { Depth } \\
(\mathrm{m} \text { bgs }) \\
\end{array}$} & \multicolumn{10}{|c|}{$\mathrm{Cr}(\mathrm{VI})$ Concentration $^{(\mathrm{a})}(\mu \mathrm{g} / \mathrm{L})$ for Samples Collected on the Indicated Date } \\
\hline & & 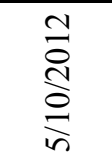 & $\underset{\substack{N \\
\stackrel{N}{\infty}}}{\stackrel{N}{n}}$ & $\begin{array}{c}\stackrel{N}{\delta} \\
\stackrel{N}{J} \\
\stackrel{J}{n}\end{array}$ & $\begin{array}{l}\stackrel{1}{c} \\
\stackrel{i}{1} \\
\stackrel{m}{n} \\
i n\end{array}$ & $\begin{array}{l}\frac{1}{0} \\
\frac{1}{0} \\
0\end{array}$ & 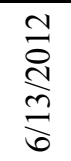 & 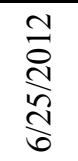 & $\begin{array}{l}\stackrel{N}{o} \\
\stackrel{d}{\Xi} \\
\equiv\end{array}$ & $\frac{\mathfrak{c}}{\stackrel{i}{\infty}}$ & 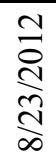 \\
\hline AT-1 & 1 & 170 & 50 & 40 & 100 & 10 & 30 & 20 & 20 & 10 & 0 \\
\hline AT-1 & 2 & 90 & 50 & 30 & 30 & 20 & 40 & 20 & 10 & 10 & 0 \\
\hline AT-1 & 3 & 110 & 40 & 40 & 30 & 20 & 20 & 20 & 20 & 10 & 0 \\
\hline AT-2 & 1 & NS & 40 & 30 & 20 & 20 & 20 & 10 & 0 & 0 & 0 \\
\hline AT-2 & 3 & NS & 50 & 60 & 30 & 30 & 30 & 20 & 0 & 0 & 0 \\
\hline AT-3 & 1 & 320 & 120 & 110 & 90 & 200 & 150 & 120 & 60 & 0 & 0 \\
\hline AT-3 & 3 & 120 & 50 & 80 & 80 & 70 & 80 & 60 & 50 & 10 & 0 \\
\hline AT-4 & 1 & NS & 30 & 40 & 40 & 40 & 30 & 20 & 0 & 10 & 0 \\
\hline AT-4 & 3 & NS & 30 & 30 & 40 & 50 & 30 & 20 & 0 & 10 & 0 \\
\hline AT-5 & 1 & NS & 20 & 20 & 10 & 10 & 10 & 10 & 0 & 0 & 0 \\
\hline AT-5 & 3 & NS & 30 & 20 & 20 & 20 & 30 & 0 & 0 & 10 & 0 \\
\hline AT-6 & 1 & 50 & 10 & 20 & 10 & 10 & 20 & 10 & 0 & 10 & 0 \\
\hline AT-6 & 2 & 60 & 40 & 50 & 50 & 30 & 30 & 20 & 0 & 10 & 0 \\
\hline AT-6 & 3 & 130 & 20 & 30 & 30 & 20 & 30 & 20 & 0 & 10 & 10 \\
\hline AT-7 & 1 & NS & 30 & 30 & 20 & 20 & 20 & 10 & 0 & 20 & 10 \\
\hline AT-7 & 2 & NS & 110 & 70 & 40 & 20 & 20 & 20 & 0 & 20 & 10 \\
\hline AT-7 & 3 & NS & 40 & 30 & 30 & 20 & 10 & 30 & 0 & 20 & 20 \\
\hline AT-8 & 1 & NS & 10 & 10 & 10 & 0 & 10 & 0 & 0 & 0 & 0 \\
\hline AT-8 & 2 & NS & 0 & 20 & 10 & 10 & 10 & 10 & 0 & 0 & 0 \\
\hline AT-8 & 3 & NS & 10 & 10 & 10 & 10 & NS & 10 & 0 & 10 & 0 \\
\hline $\begin{array}{l}\text { Surface } \\
\text { Water }^{(b)}\end{array}$ & 0 & 10000 & NS & 30 & NS & 20 & 20 & 10 & NS & 10 & NS \\
\hline
\end{tabular}

(a) A numerical concentration value of zero indicates an assay result that was below the detection limit of $10 \mu \mathrm{g} / \mathrm{L}$. A value of "NS" indicates that no sample was collected.

(b) At a location near AT-3 for the first two sampling dates, and subsequently at the edge of the pond in the excavation. 

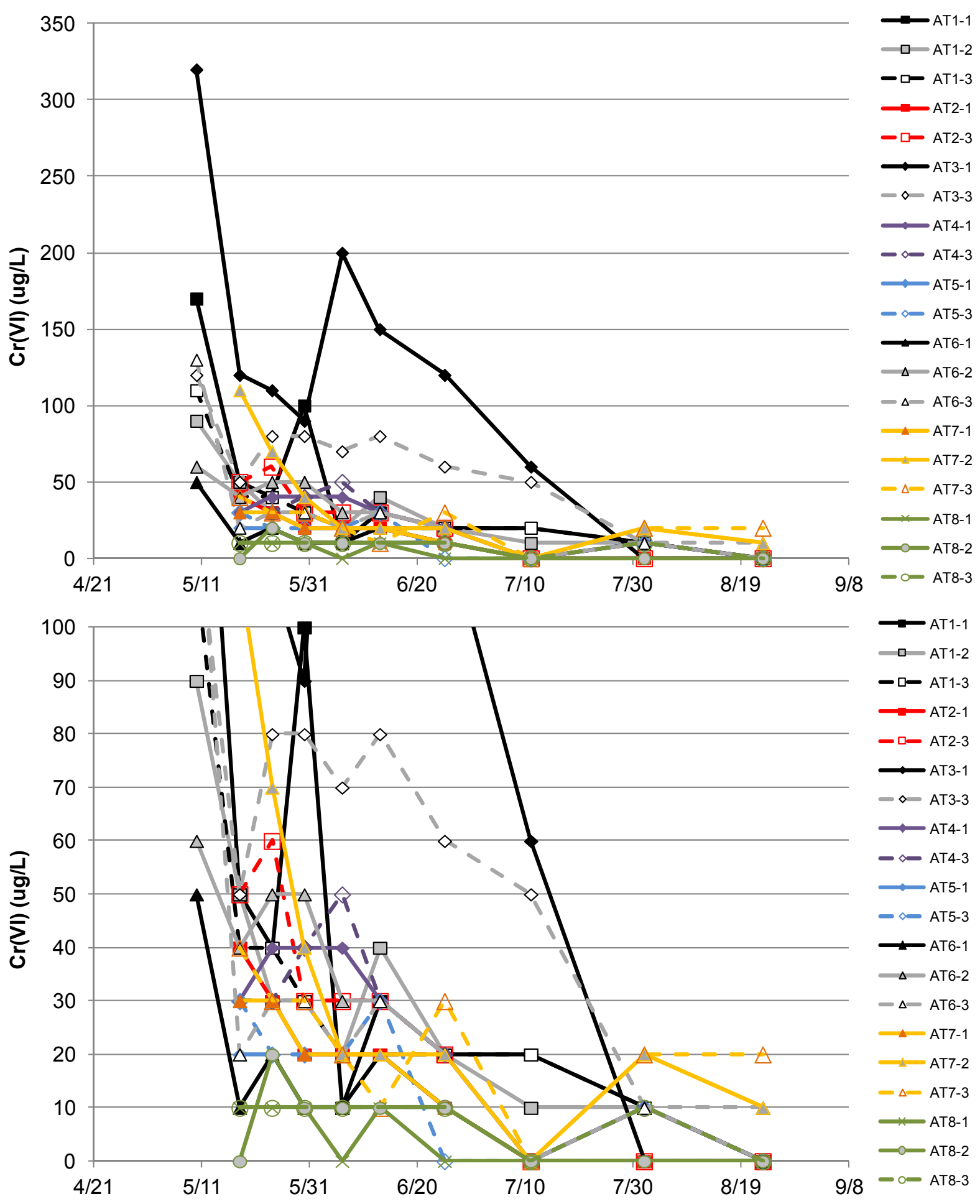

Figure 13. $\mathrm{Cr}(\mathrm{VI})$ concentrations measured at aquifer tubes during sampling from May through August 2012. A numerical value of zero indicates a result below the detection limit $(<10 \mu \mathrm{g} / \mathrm{L})$.

Top and bottom plots are the same except that the lower plot zooms in on the y-axis to better show detail at low concentrations. In the legend, the final number indicates the sample collection depth in meters. 
Table 9. Average of AT-1 through AT-7 Cr(VI) concentrations $(\mu \mathrm{g} / \mathrm{L})$ at specific sampling depths

\begin{tabular}{cccc}
\hline \multirow{2}{*}{$\begin{array}{c}\text { Sample Collection } \\
\text { Date }\end{array}$} & \multicolumn{3}{c}{ Average $\operatorname{Cr}(\mathrm{VI})(\mu \mathrm{g} / \mathrm{L})$ at Indicated Depth } \\
\cline { 2 - 4 } 5/18/2012 & 42.9 & 37.1 & All Depths $^{(\mathrm{a})}$ \\
$5 / 24 / 2012$ & 41.4 & 41.4 & 48.9 \\
$5 / 30 / 2012$ & 41.4 & 37.1 & 44.3 \\
$6 / 6 / 2012$ & 44.3 & 32.9 & 39.5 \\
$6 / 13 / 2012$ & 40.0 & 32.9 & 33.5 \\
$6 / 25 / 2012$ & 28.6 & 24.3 & 34.3 \\
$7 / 11 / 2012$ & 11.4 & 10.0 & 24.3 \\
$8 / 1 / 2012$ & 7.1 & 10.0 & 8.3 \\
$8 / 23 / 2012$ & 1.4 & 4.3 & 10.2 \\
\hline
\end{tabular}

(a) Includes 2-m depth results for AT-1, AT-6, and AT-7.
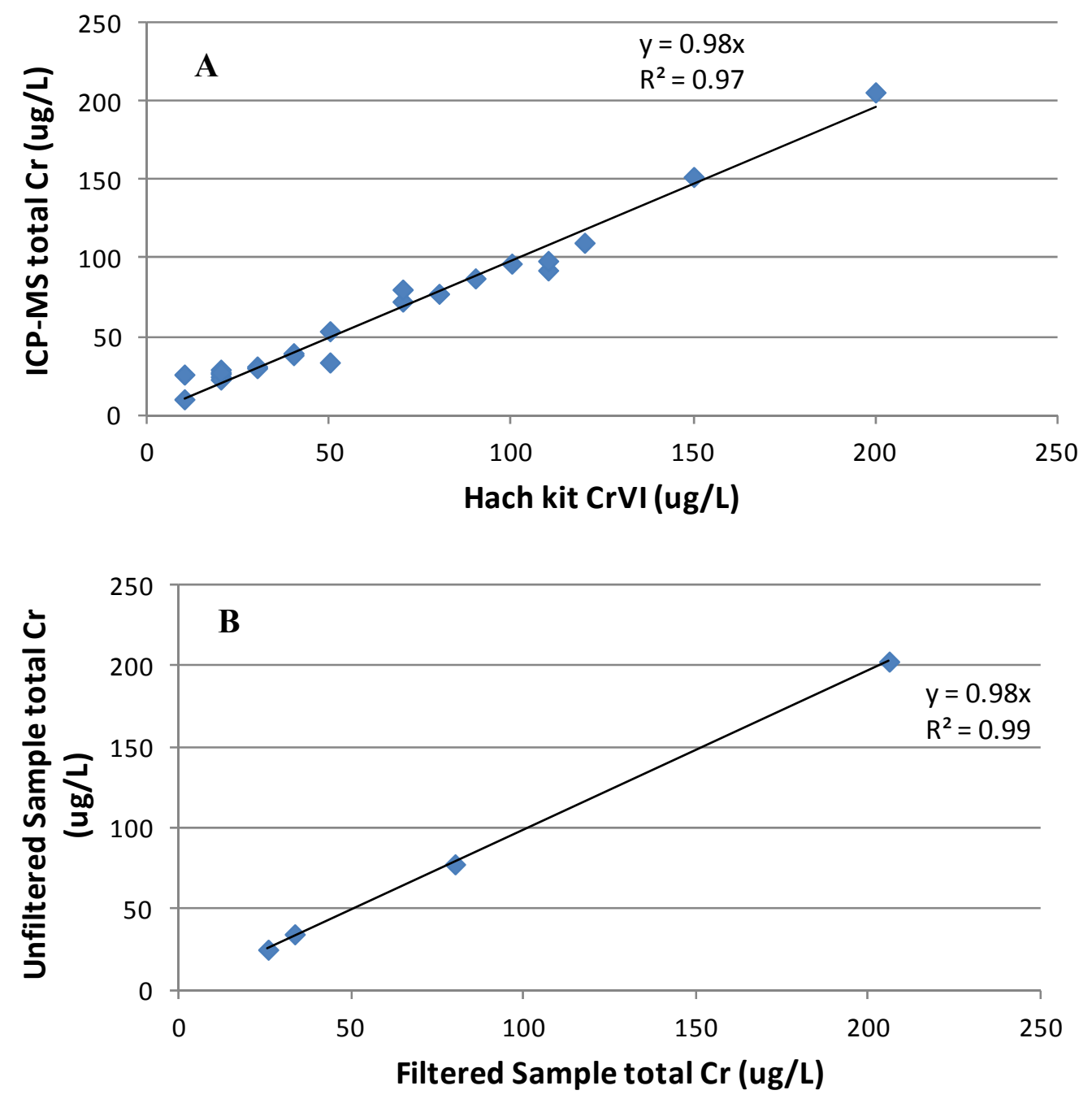

Figure 14. Correlation of total chromium concentration results $(\mu \mathrm{g} / \mathrm{L})$ between laboratory and Hach $\mathrm{Cr}(\mathrm{VI})$ assays (A) and between filtered and unfiltered laboratory assays (B) 


\subsection{Geology}

Generalized stratigraphy at the site is based on previous investigations of regional data (Khaleel and Williams 2011), including wells drilled in and adjacent to the 100-C-7 excavations, and sediments exposed during excavation activities. The test site is located within coarse-grained Hanford formation sediments exposed in the 100-C-7:1 excavation pit, and is approximately $26 \mathrm{~m}(85 \mathrm{ft})$ below the original surface grade. The sedimentary sequence beneath the test site can be divided into two main hydrogeologic units: the Ringold Formation and the Hanford formation (Figure 15). The contact with the underlying Ringold Formation is an erosional surface that is interpreted as buried paleoflood or river channels.

No sediment samples were collected during drilling operations; however, because DPT drilling methods are generally not successful at penetrating the consolidated Ringold Formation sediments, one borehole (DG2) was advanced to the point of refusal in an effort to better define the Hanford/Ringold contact. During the push, the drilling rate appeared to slow down a little at $17.4 \mathrm{~m}(57 \mathrm{ft}) \mathrm{bgs}$, but then significant resistance was encountered at $18.3 \mathrm{~m}(60 \mathrm{ft})$ bgs. Drilling continued at a very slow rate for an

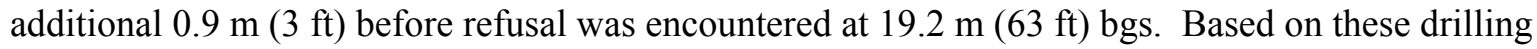
observations, the depth to the top of the Ringold Formation was estimated to be approximately $18.3 \mathrm{~m} \mathrm{bgs}$ (108 m msl).

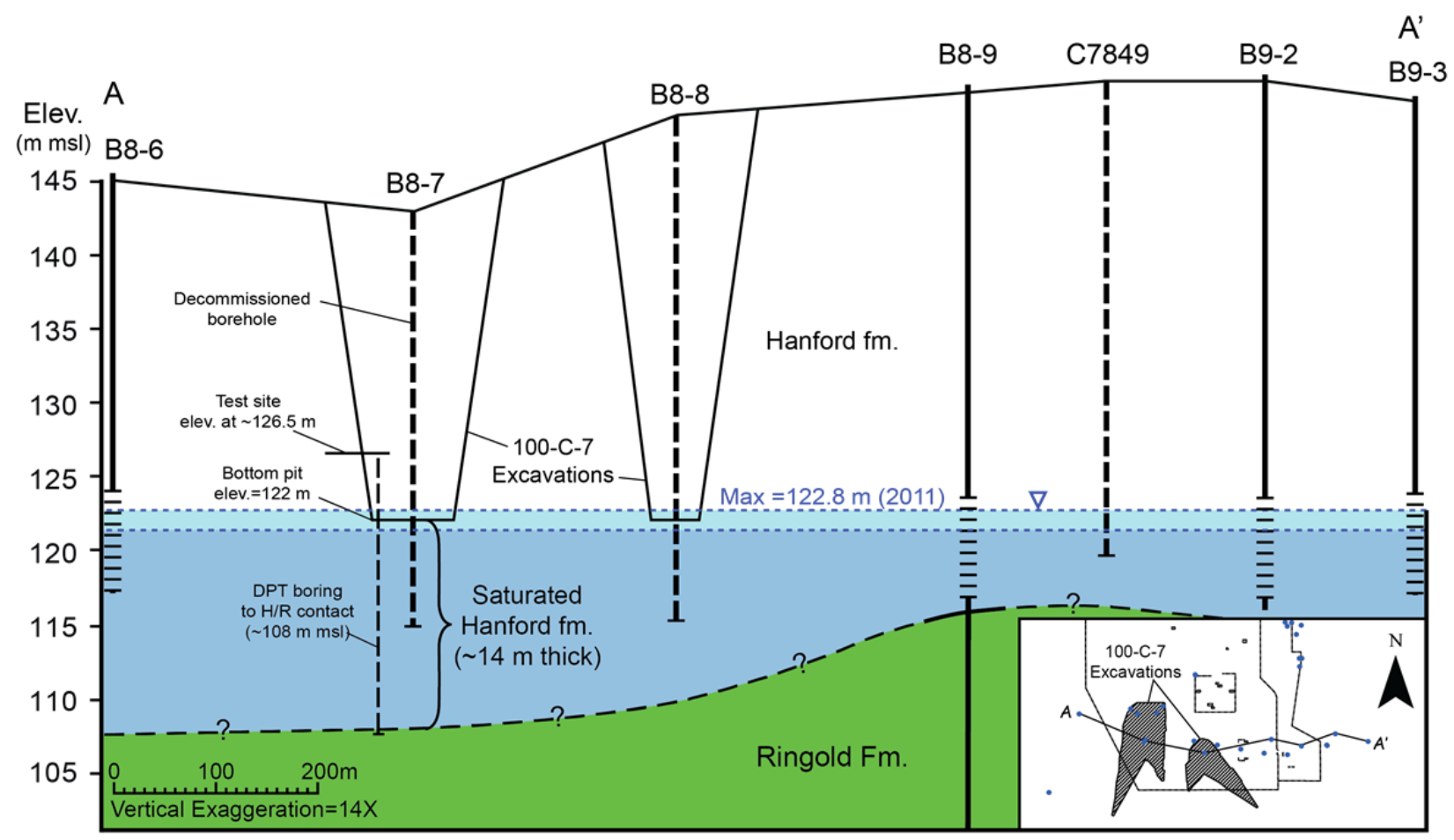

Figure 15. East-west transect showing the water table and the Hanford/Ringold Formation contact 


\subsection{Groundwater Flow Direction and Gradient}

Groundwater levels, flow direction, and gradients triangulated from water levels in wells 199-B4-14, 199-B5-8, and 199-B8-6 (Figure 8) from April 13, 2011, through August 30, 2012, show a strong seasonal variation related to stage changes in the Columbia River. During this data record, groundwater levels reached a minimum elevation of about $121.8 \mathrm{~m}$ in the winter months and began rising in the spring, reaching a maximum of about $123 \mathrm{~m}$ in late July and early August (Figure 16). Groundwater flows primarily in a northerly direction during the fall, winter, and early spring months. As the water table rises in the late spring and summer, the flow direction shifts as much as 60 degrees towards the east (Figure 17 and Figure 18). The hydraulic gradient varies from a low of about $5.0 \times 10^{-5}$ in the winter months to a maximum of about $2.0 \times 10^{-4}$ in the late summer months when the water table is at its maximum.

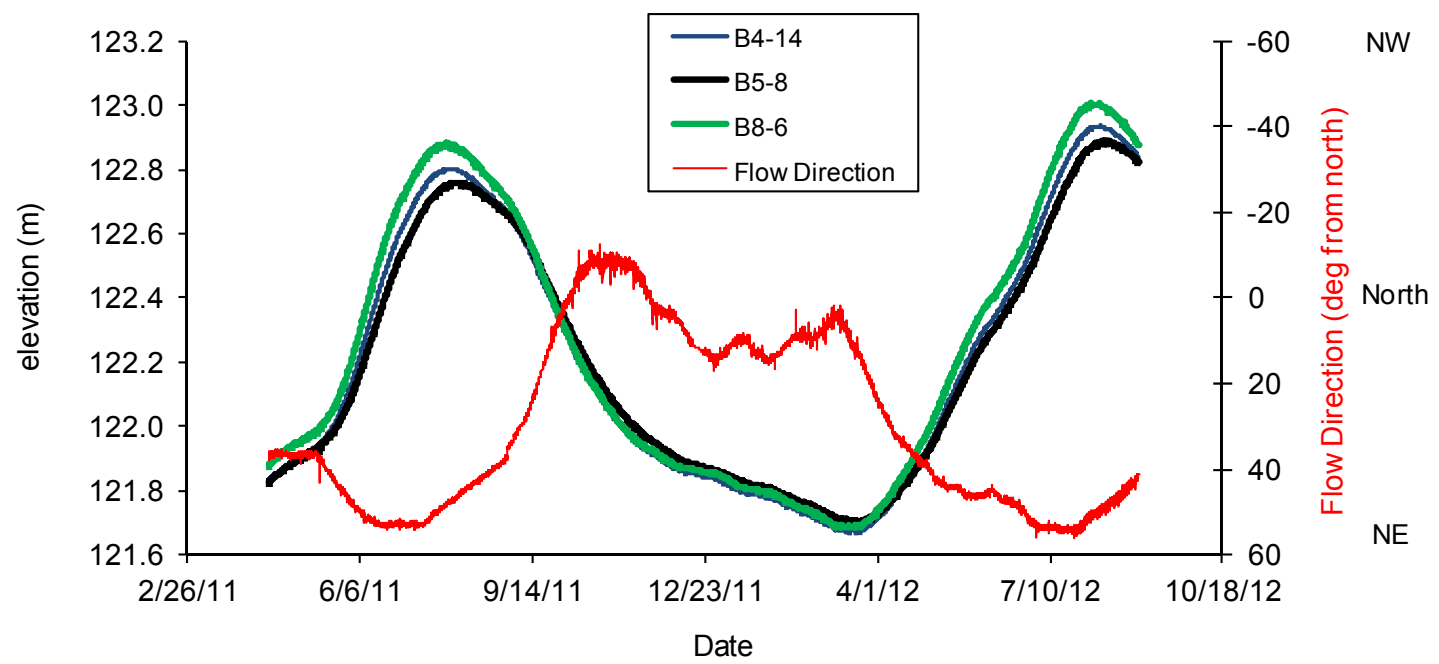

Figure 16. Hydraulic head data for wells 199-B4-14, 199-B5-8, and 199-B8-6 along with the corresponding groundwater flow direction (azimuth) calculated from the head data using "three-point problem" techniques

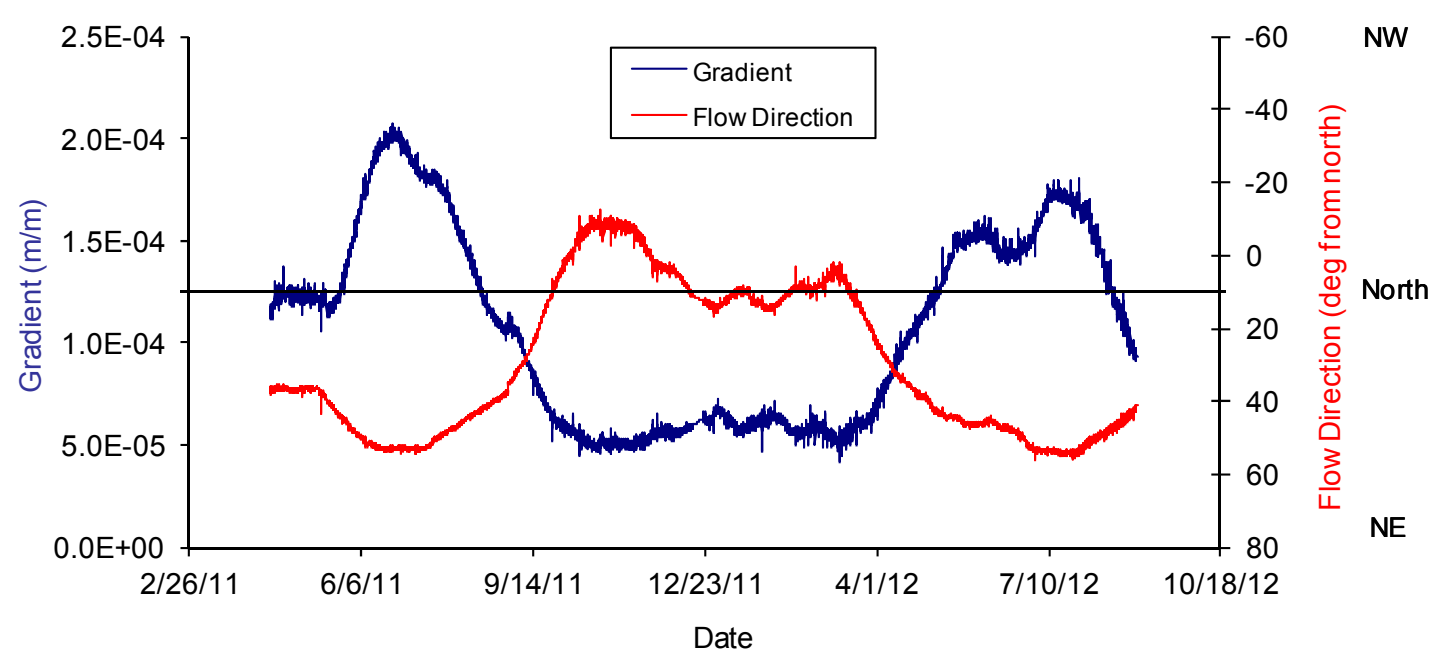

Figure 17. Groundwater flow direction (azimuth) and hydraulic gradient calculated from the hydraulic head data for wells 199-B8-6, 199-B4-14, and 199-B5-8 using "three-point problem" techniques 


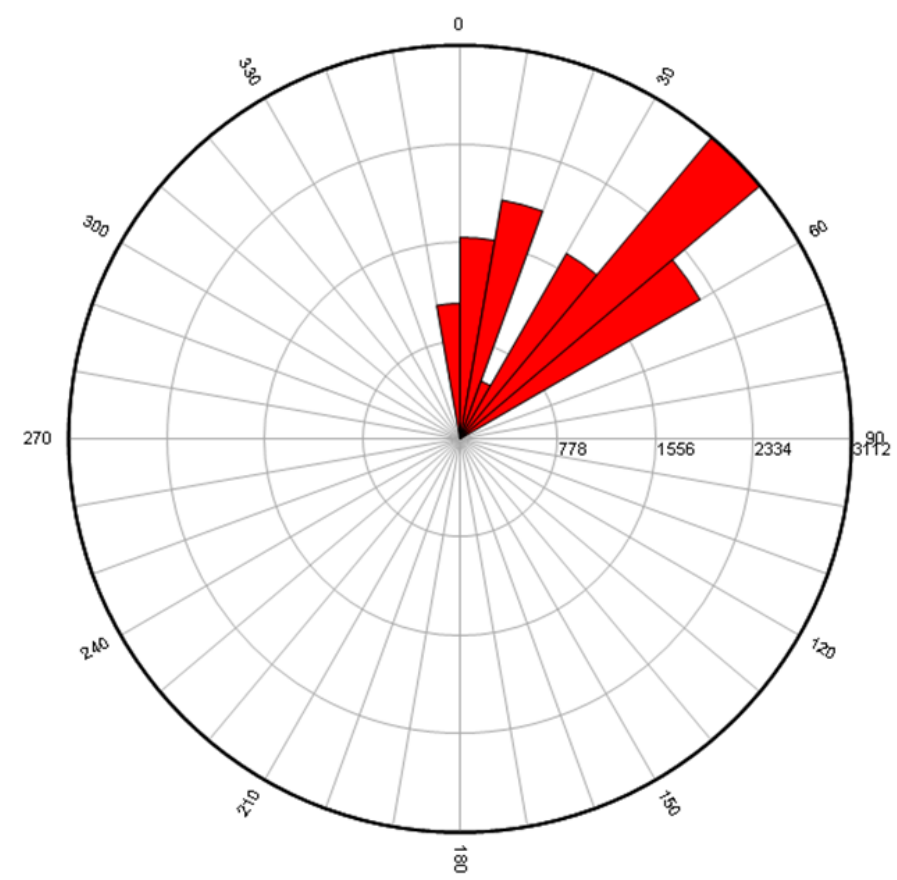

Figure 18. Radial frequency histogram depicting the groundwater flow direction (azimuth) in $10^{\circ}$ bins as calculated from the hourly hydraulic head data for wells 199-B8-6, 199-B4-14, and 199-B5-8

Flow direction became more northward and the gradient was declining during the August 2012 tracer tests (Figure 19). The flow direction azimuth was about 50 degrees during tracer test 1 and 45 degrees (northeasterly) during tracer tests 2 and 3. Hydraulic gradients were about $1.5 \times 10^{-4}$ during tracer test 1 and $1.0 \times 10^{-4}$ during tracer tests 2 and 3 .

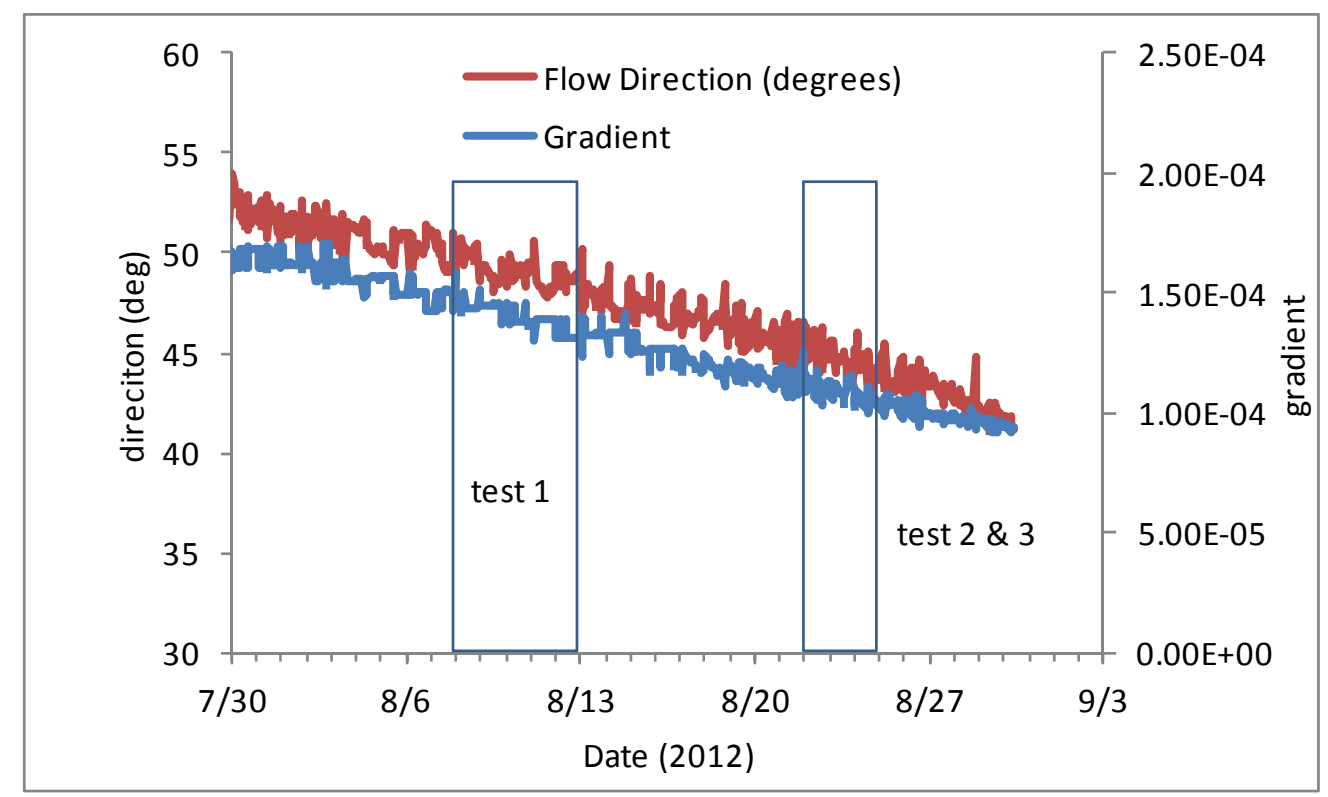

Figure 19. Calculated hydraulic gradient and groundwater flow direction (azimuth) from hydraulic head data at wells 199-B8-6, 199-B4-14, and 199-B5-8 during the study period 
Estimates of groundwater velocity for the Hanford formation beneath the 100-C-7:1 study area over time based on the observed hydraulic head data and the hydraulic properties estimated from the hydraulic and tracer tests $(\mathrm{K}=6,096 \mathrm{~m} /$ day and effective porosity $=0.18)$ vary from about 2 (winter months) to $7 \mathrm{~m} /$ day (summer months) (Figure 20). Note that the gradients and flow groundwater levels, flow direction, and gradients reported here are local-scale values that are representative within the triangulated area (Figure 8). This study did not examine these values at a larger-scale spatial variation (e.g., entire $100-\mathrm{BC}$ Area region or near the Columbia River).

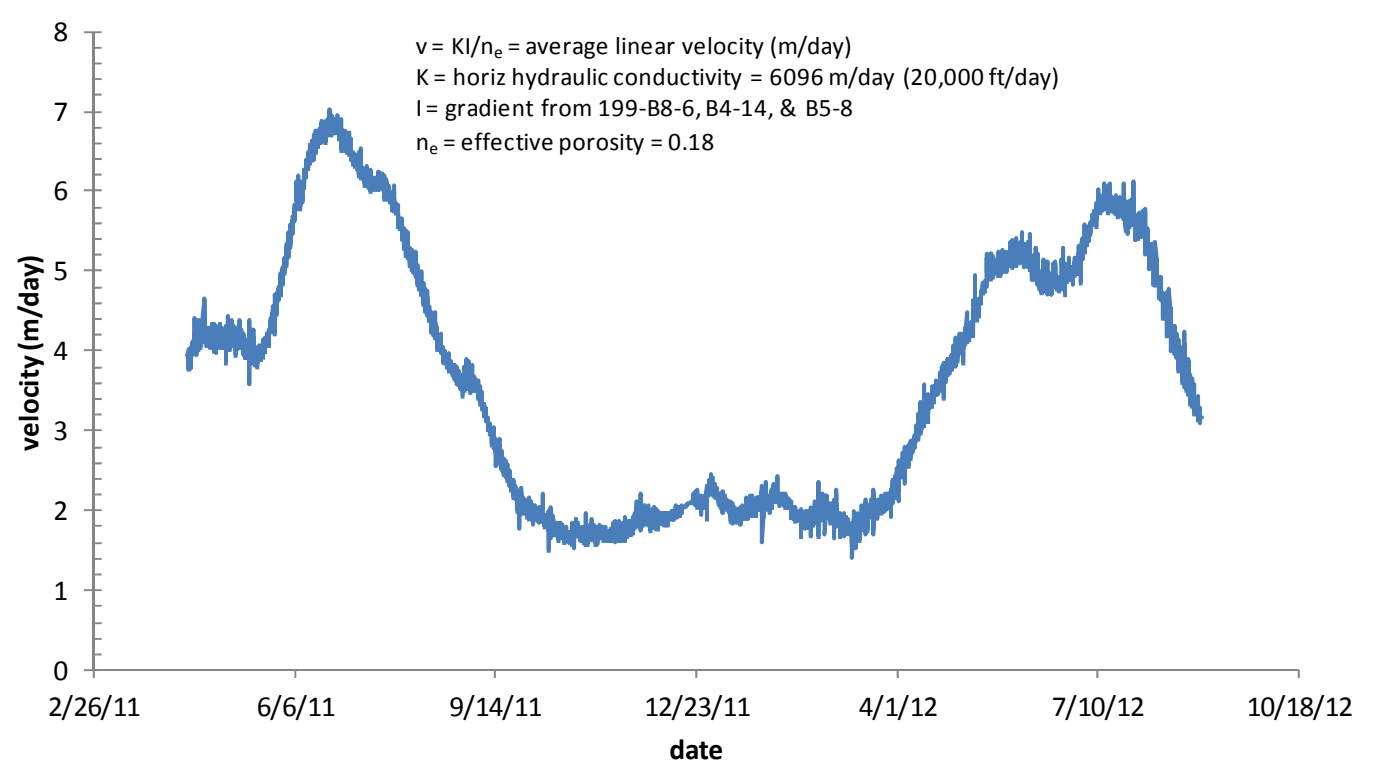

Figure 20. Estimated groundwater velocities in the Hanford formation beneath the $100-\mathrm{C}-7$ and 100-C-7:1 excavations based on calculated hydraulic gradients and hydraulic property estimates

\subsection{Local-Scale Hydrologic Characterization}

Results from the hydrologic characterization activities performed in support of this study are discussed in detail in the following sections.

\subsubsection{Electromagnetic Borehole Flow Meter Results}

Both ambient (i.e., static) and dynamic (i.e., pump-induced) EBF surveys were performed in five wells at the 100-C-7:1 excavation site. EBF surveys were conducted June 26-28, 2012, before the wells were reconfigured with a bentonite seal. A second set of surveys was performed July 24-25, 2012, after the wells were reconfigured. The wells and pertinent EBF survey information are listed in Table 10. Flow meter measurements were generally acquired every $0.5 \mathrm{ft}(0.15 \mathrm{~m})$ over the saturated well-screen sections, but were reduced to every $0.25 \mathrm{ft}(0.08 \mathrm{~m})$ at depths where significant changes in flow were observed in the field. For the pre-reconfiguration surveys, the EBF test interval was slightly less than the well-screen section. This difference was assumed to be associated with sediment on the bottom portion of the well-screen section. All flow meter measurement depths were referenced to the top of the casing during testing and then converted to depths below ground surface for the analyses. 
Table 10. Summary of pertinent EBF test information

\begin{tabular}{ccccc}
\hline $\begin{array}{c}\text { Well } \\
\text { Number }\end{array}$ & $\begin{array}{c}\text { Date of } \\
\text { Survey }\end{array}$ & $\begin{array}{c}\text { Well-Screen Interval } \\
\text { (ft bgs) }\end{array}$ & $\begin{array}{c}\text { EBF Test Interval } \\
\text { (ft bgs) }\end{array}$ & $\begin{array}{c}\text { Pre-Survey Depth to } \\
\text { Water (ft bgs) }\end{array}$ \\
\hline CG-1 & $6 / 28 / 2012$ & $16.0-26.0$ & $16.0-25.6$ & 13.3 \\
DG-1 & $6 / 26 / 2012$ & $14.3-24.3$ & $14.3-23.8$ & 12.5 \\
DG-2 & $6 / 27 / 2012$ & $13.8-23.8$ & $13.8-23.3$ & 11.5 \\
INJ & $6 / 26 / 2012$ & $15.7-25.7$ & $15.7-25.5$ & 13.3 \\
UG-1 & $6 / 28 / 2012$ & $16.8-26.8$ & $16.8-26.6$ & 14.2 \\
CG-1 & $7 / 25 / 2012$ & $16.0-26.0$ & $16.0-20.7$ & 12.2 \\
DG-1 & $7 / 25 / 2012$ & $14.3-24.3$ & $14.3-19.0$ & 11.3 \\
DG-2 & $7 / 25 / 2012$ & $13.8-23.8$ & $13.8-18.5$ & 10.2 \\
INJ & $7 / 24 / 2012$ & $15.7-25.7$ & $15.7-20.7$ & 12.1 \\
UG-1 & $7 / 24 / 2012$ & $16.8-26.8$ & $16.8-21.5$ & 13.1 \\
\hline
\end{tabular}

(a) Data in this table are shown in feet because the root data from the EBF measurement equipment are in feet. Multiply values in feet times $0.3048 \mathrm{~m} / \mathrm{ft}$ to obtain values in meters.

During the dynamic flow meter tests, groundwater was extracted from the well using a peristaltic pump at maximum pump capacity and discharged to a purge water tank. The discharge rate was held constant during each individual dynamic test. The discharge rates for the five wells ranged from 4.14 to $4.64 \mathrm{~L} / \mathrm{min}$ for the pre-reconfiguration tests and ranged from 4.67 to $5.12 \mathrm{~L} / \mathrm{min}$ for the postreconfiguration tests. Each well was pumped $\sim 15 \mathrm{~min}$ to allow flow conditions to reach near-equilibrium conditions before starting each dynamic survey. After near-equilibrium conditions were established, electromagnetic borehole flow meter measurements were made in succession from bottom to top of the saturated well-screen section. The discharge rate was measured and recorded periodically with an in-line pitot tube and was also measured by timing the manual filling of a graduated cylinder at the beginning and end of each survey. The pump-induced water level in the wells changed by only $0.003 \mathrm{~m}(0.01 \mathrm{ft})$ or less during the dynamic surveys.

\subsubsection{Ambient Survey Results}

Ambient EBF survey results indicate predominantly upward vertical wellbore flow in the saturated well screens, as shown by the positive ambient flow rate plots in Figure 21 through Figure 25. At depths where ambient flow is increasing from the bottom up, groundwater flow is entering into the well screen. Where ambient flow is not changing with depth, water flows vertically and does not enter or exit the well. Water exits the portion of the well screen where ambient flow decreases. Maximum upward ambient flows ranged from +0.36 to $+1.66 \mathrm{~L} / \mathrm{min}$ (LPM) over the full saturated well screen sections (i.e., before well reconfiguration), but were significantly reduced to levels not exceeding +0.15 LPM following well reconfiguration (Table 11). The most pronounced reduction in vertical wellbore flow occurred in upgradient well UG-1, where maximum ambient flow was reduced from +1.66 to +0.06 LPM as a result of the well reconfiguration (Figure 21 through Figure 25). 


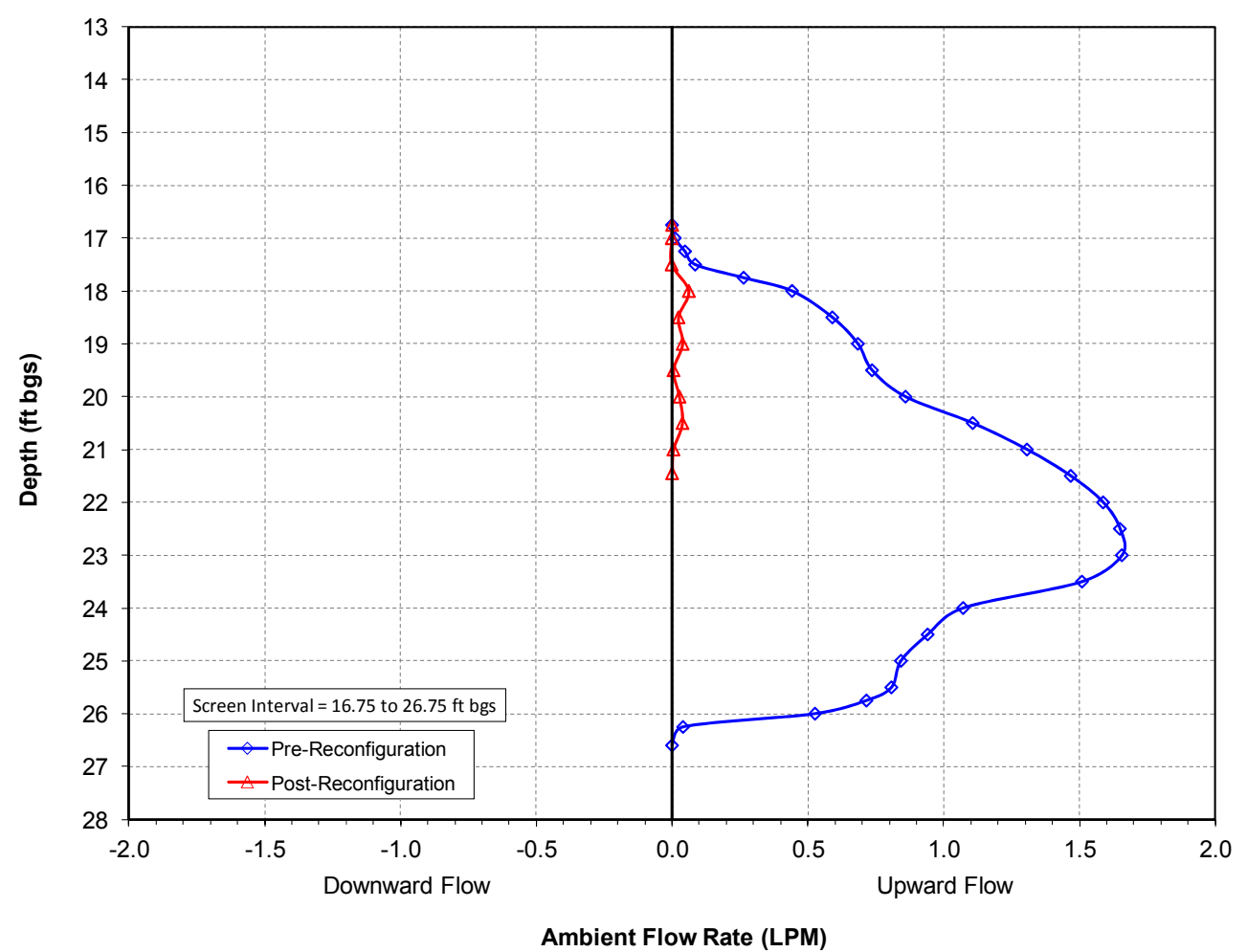

Figure 21. Ambient vertical wellbore flow profiles for well UG1 before and after well reconfiguration

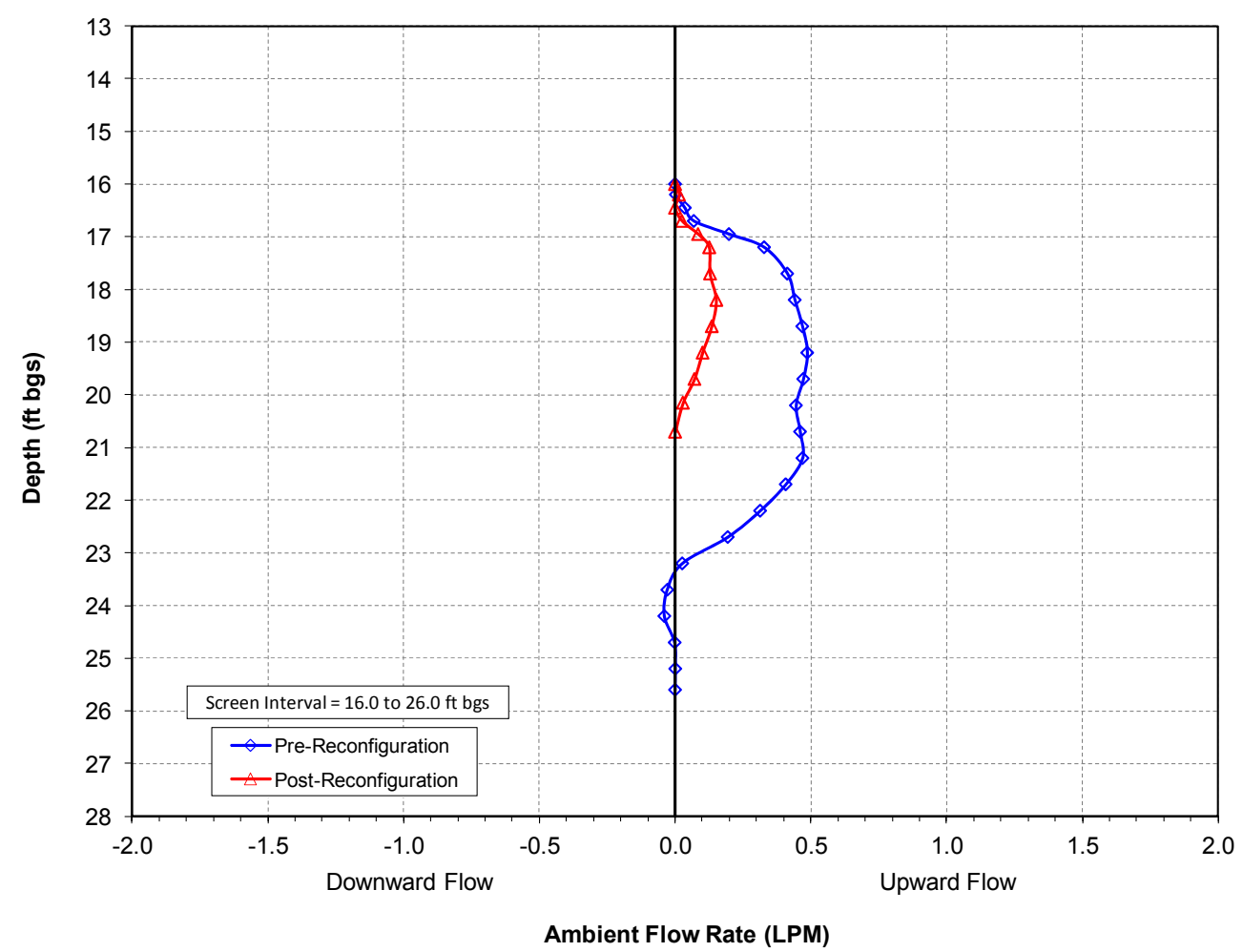

Figure 22. Ambient vertical wellbore flow profiles for well CG1 before and after well reconfiguration 


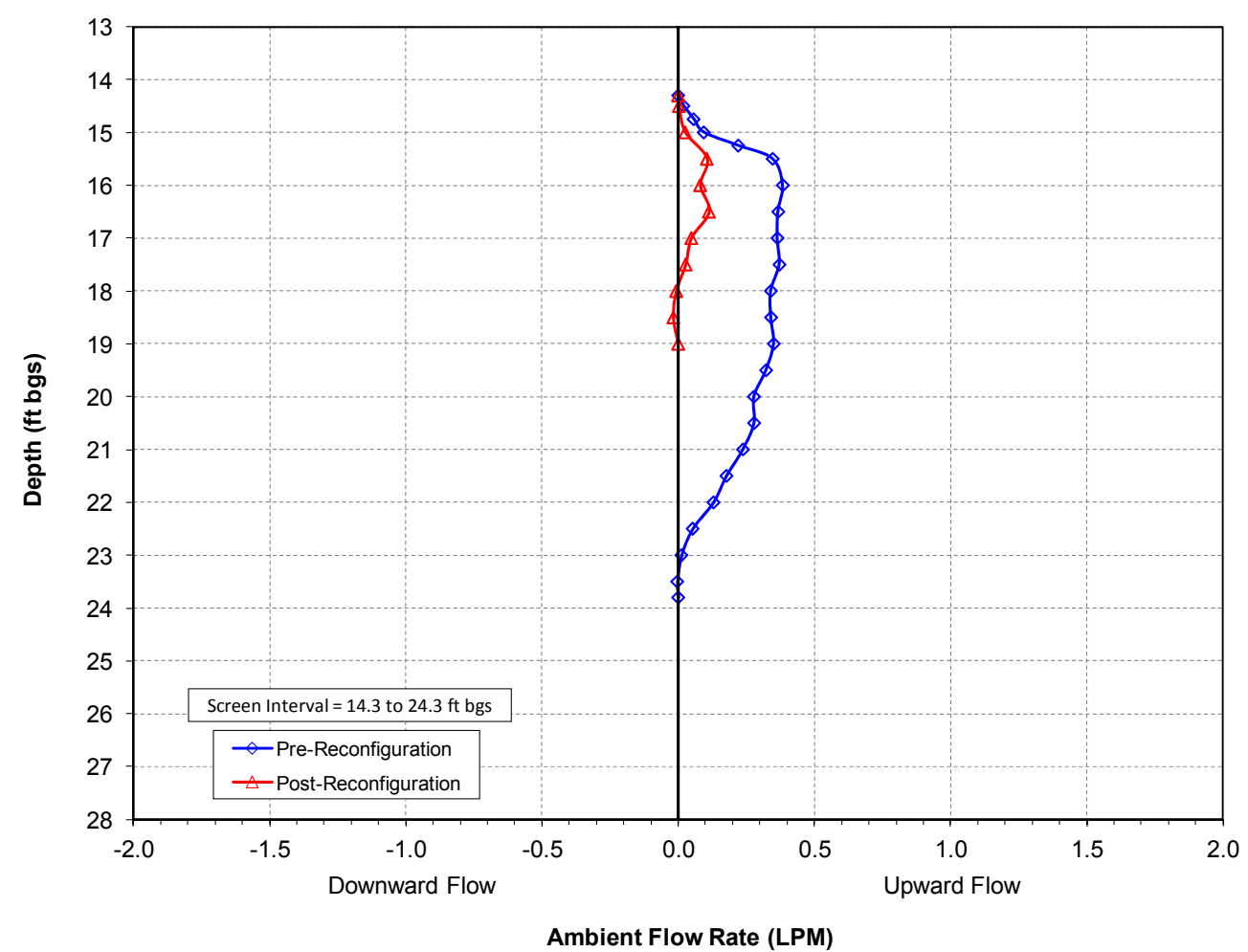

Figure 23. Ambient vertical wellbore flow profiles for well DG1 before and after well reconfiguration

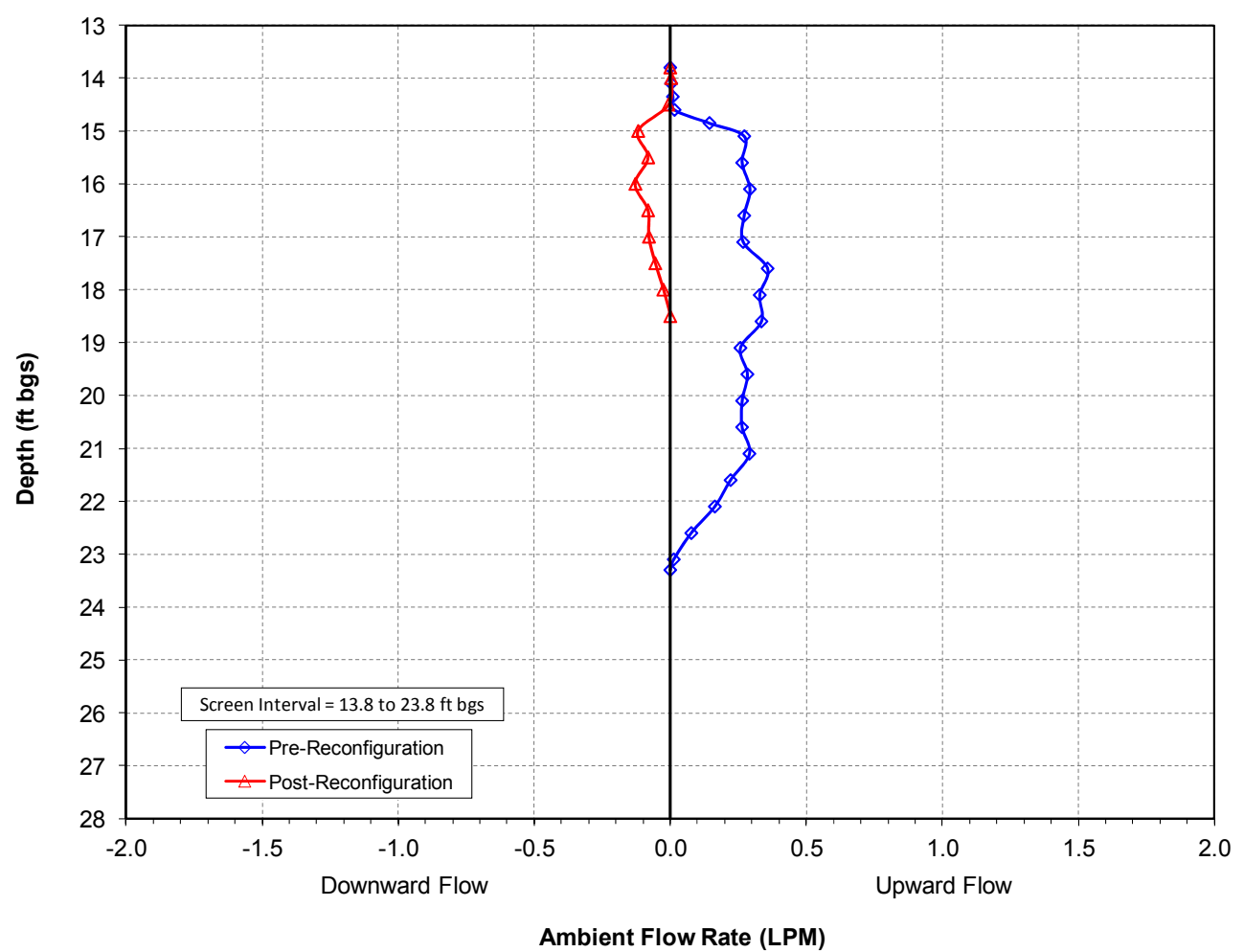

Figure 24. Ambient vertical wellbore flow profiles for well DG2 before and after well reconfiguration 


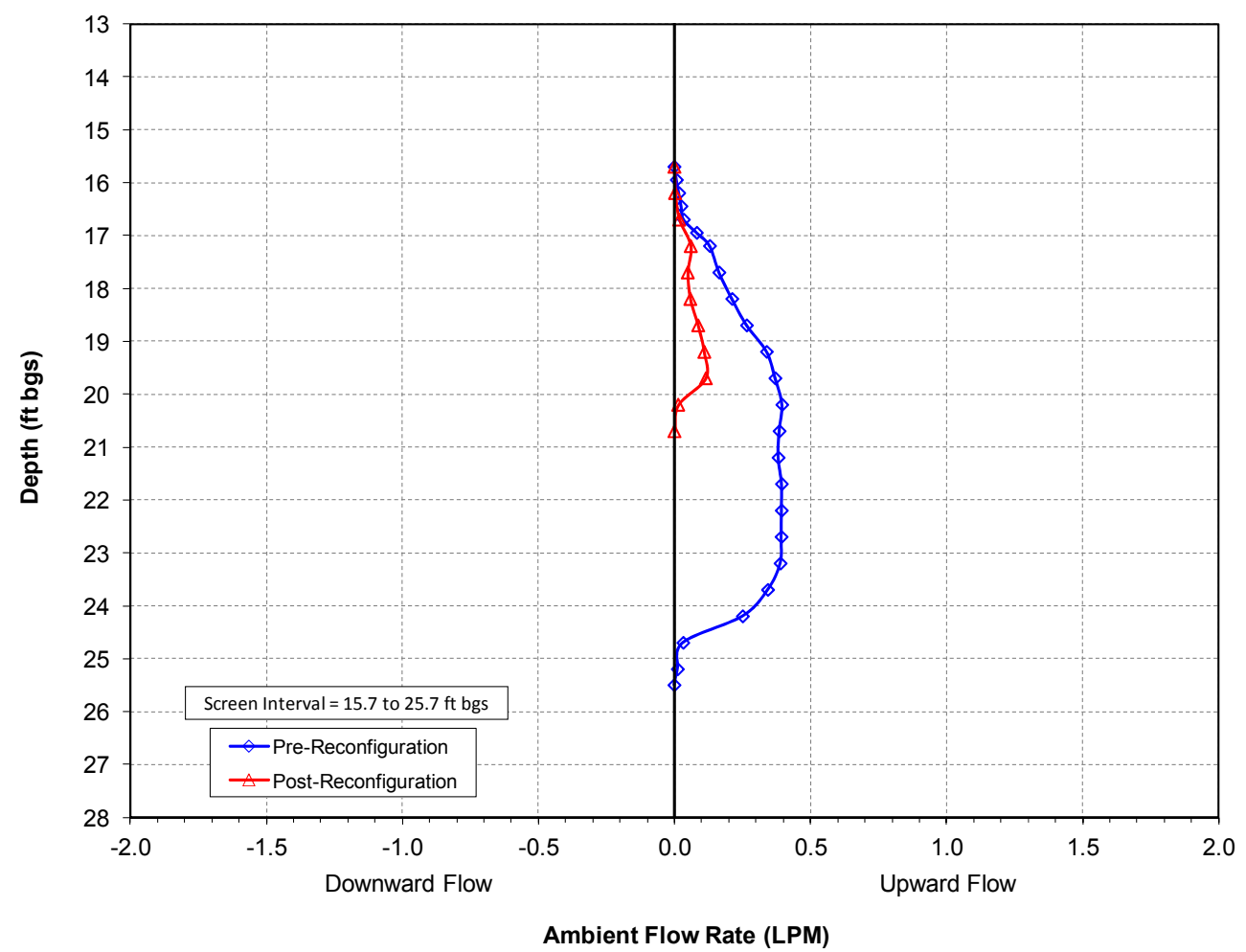

Figure 25. Ambient vertical wellbore flow profiles for well INJ before and after well reconfiguration

Table 11. Summary of ambient EBF survey results

\begin{tabular}{ccc}
\hline $\begin{array}{c}\text { Well } \\
\text { Number }\end{array}$ & $\begin{array}{c}\text { Pre-Reconfiguration Ambient Flow } \\
\text { Range }(\mathrm{L} / \mathrm{min})\end{array}$ & $\begin{array}{c}\text { Post-Reconfiguration Ambient Flow } \\
\text { Range }(\mathrm{L} / \mathrm{min})\end{array}$ \\
\hline CG-1 & -0.04 to +0.49 & 0.0 to +0.15 \\
DG-1 & 0.0 to +0.38 & 0.0 to +0.11 \\
DG-2 & 0.0 to +0.36 & -0.13 to 0.0 \\
INJ & 0.0 to +0.40 & 0.0 to +0.11 \\
UG-1 & 0.0 to +1.66 & 0.0 to +0.06 \\
\hline
\end{tabular}

\subsubsection{Dynamic Survey Results}

Immediately following each ambient flow survey, a dynamic test was conducted over the same test interval and EBF measurements were repeated at the same depths. Dynamic EBF survey results adjusted for ambient flow conditions indicate non-uniform inferred relative hydraulic conductivity distributions for the five wells tested (Figure 26 through Figure 30). The EBF profiles show a thin zone of high relative hydraulic conductivity with $>0.4$ normalized hydraulic conductivity near the top of the test interval for all five wells tested. This thin zone has a uniform thickness of $0.25 \mathrm{ft}$ or less. All other depths tested indicate low relative hydraulic conductivity with normalized hydraulic conductivity generally $<0.1$. Dynamic surveys performed in the upper half of the well-screen section (not shown) confirmed the presence of the thin, high relative hydraulic conductivity zone following well reconfiguration. The high permeability zone is at an elevation of about $121 \mathrm{~m} \mathrm{msl}$, within the elevation of seasonal water table variation. 


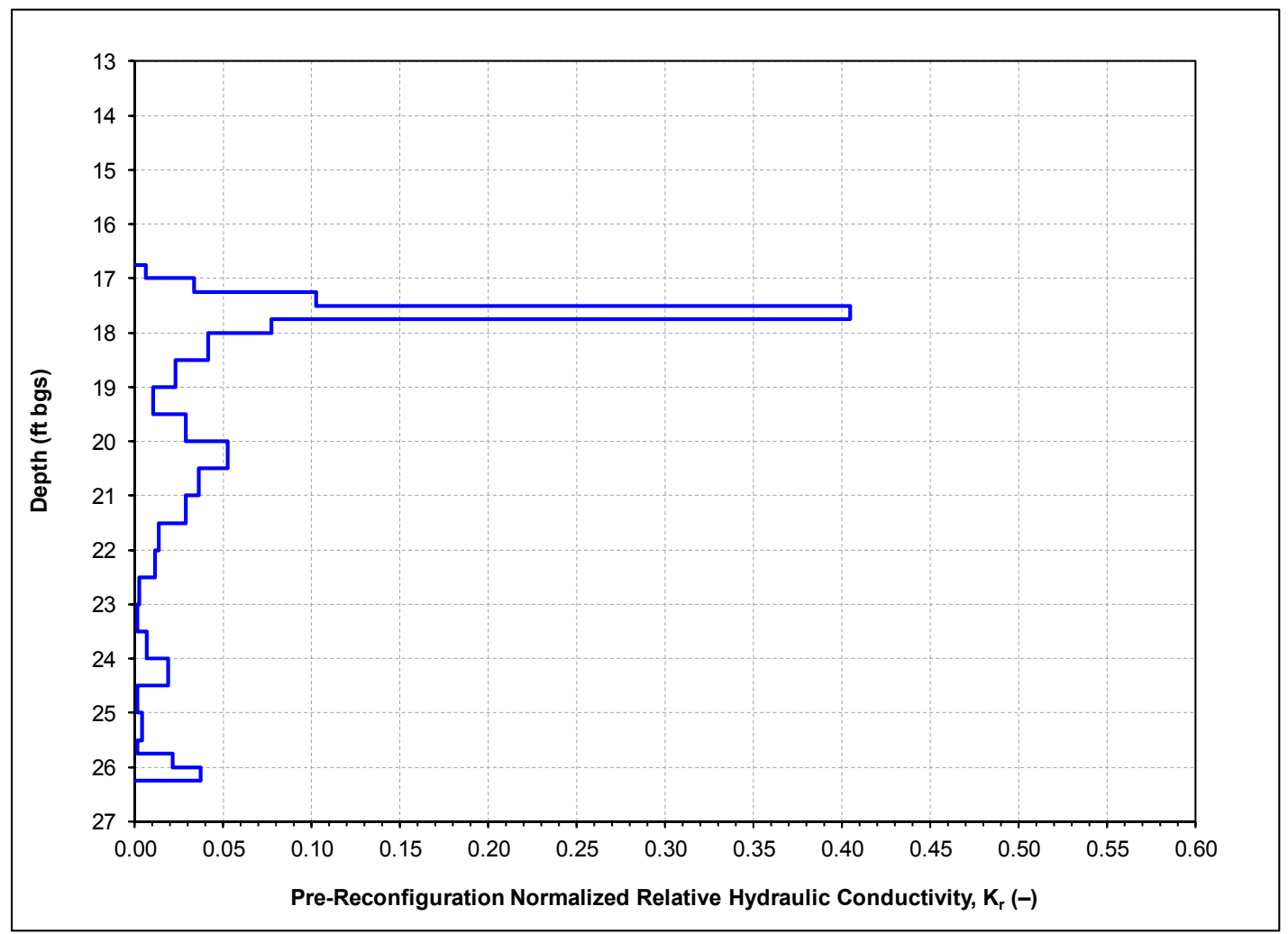

Figure 26. Normalized hydraulic conductivity profile for well UG1 prior to well reconfiguration

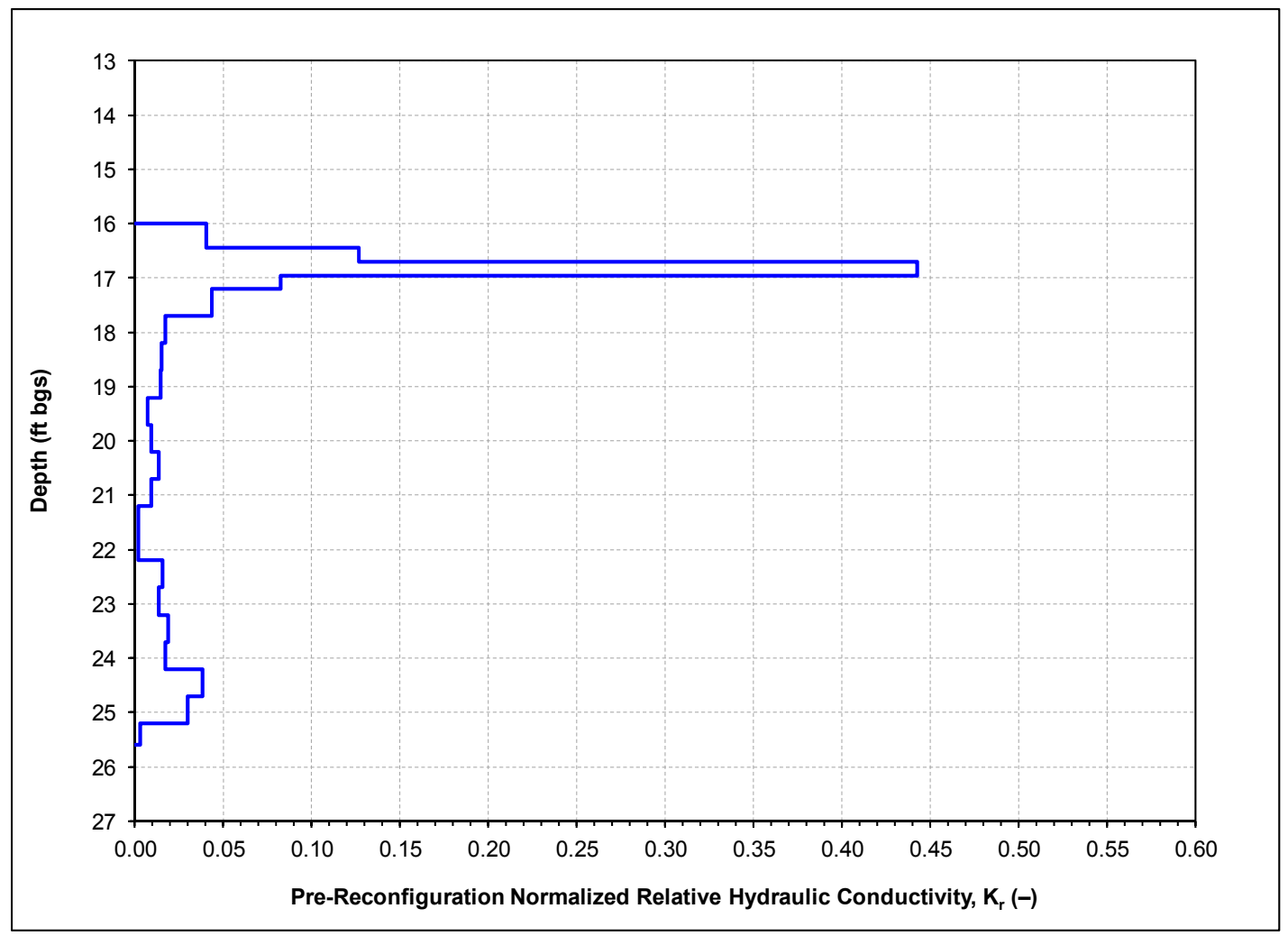

Figure 27. Normalized hydraulic conductivity profile for well CG1 prior to well reconfiguration 


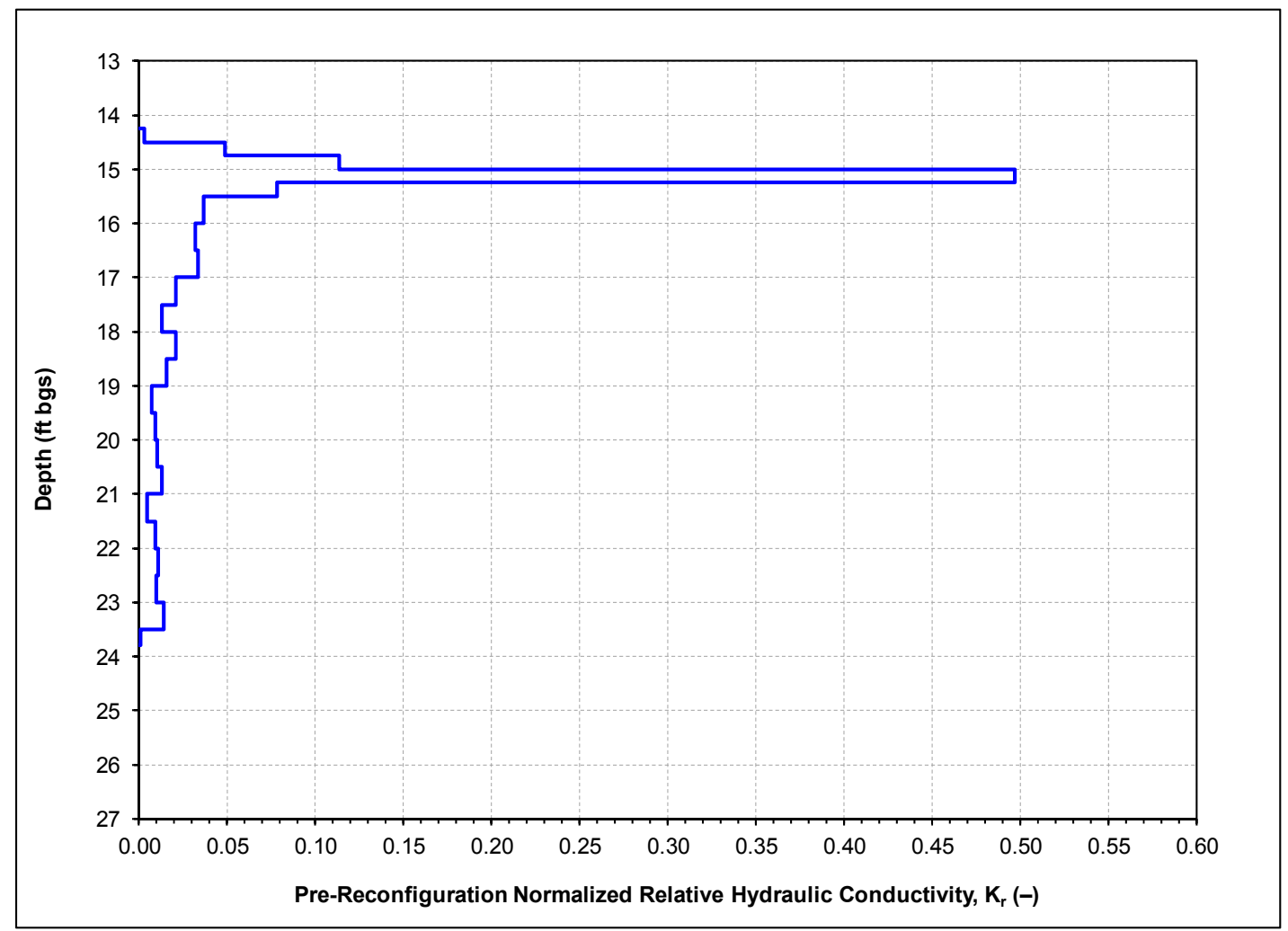

Figure 28. Normalized hydraulic conductivity profile for well DG1 prior to well reconfiguration

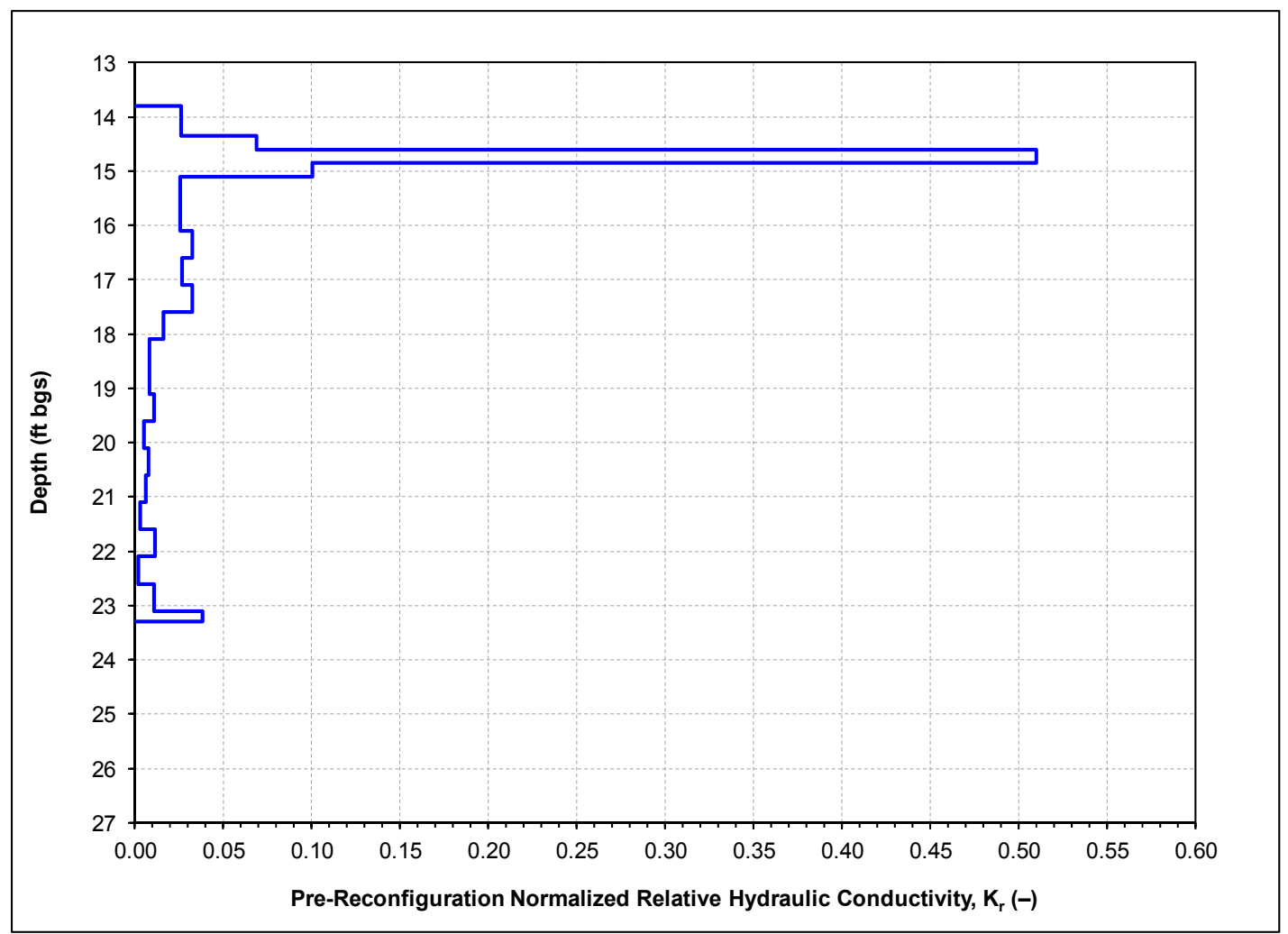

Figure 29. Normalized hydraulic conductivity profile for well DG2 prior to well reconfiguration 


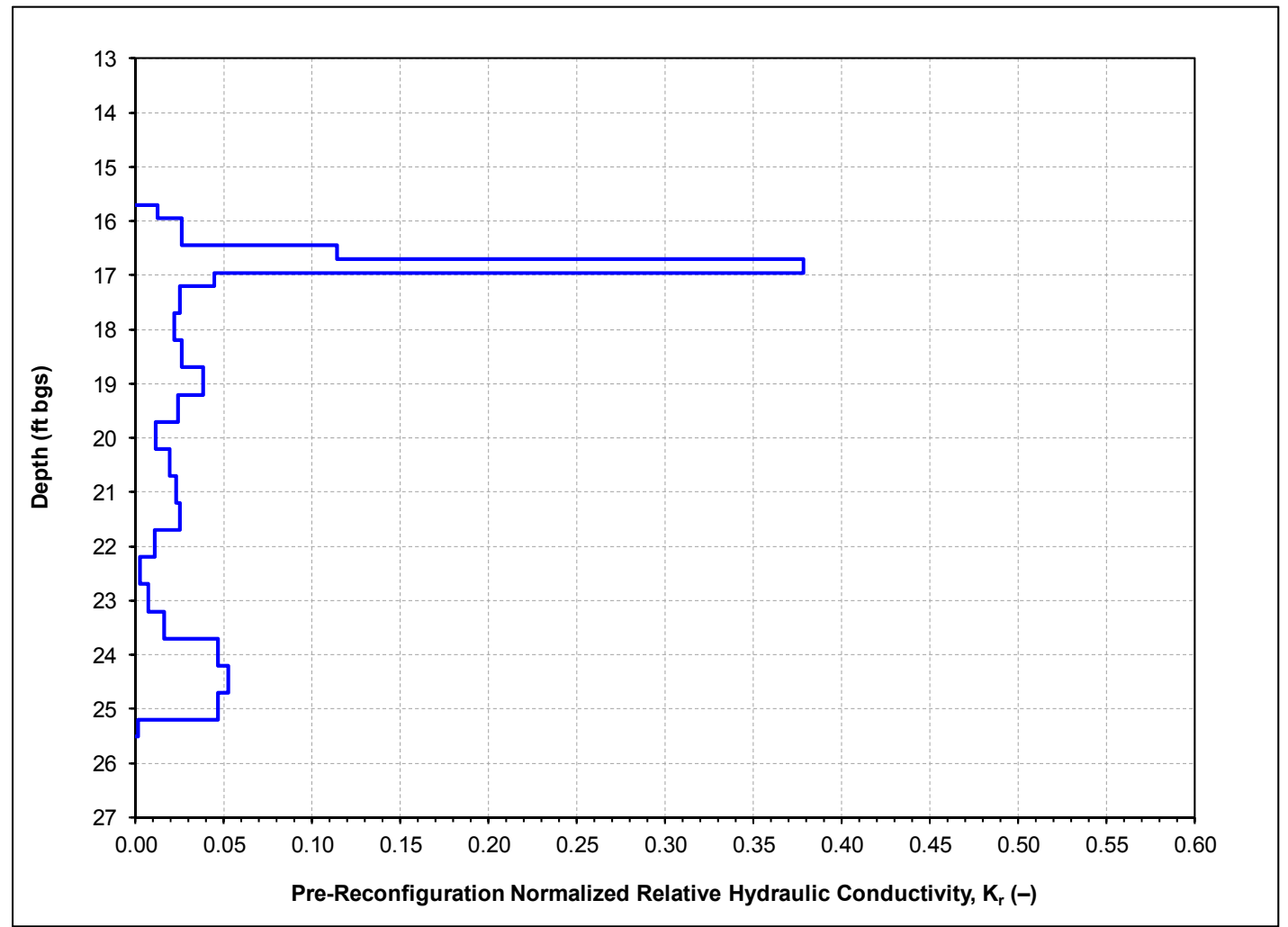

Figure 30. Normalized hydraulic conductivity profile for well INJ prior to well reconfiguration

\subsubsection{Hydraulic Testing}

The amount of pressure buildup/recovery in the constant-rate injection tests was relatively low in magnitude, indicating a very permeable test interval. Stress and observation wells displayed less than 0.120 and $0.012 \mathrm{~m}(0.4$ and $0.04 \mathrm{ft})$ of pressure head response, respectively. As a result, only the closest observation wells exhibited a discernible and analyzable pressure response. Unfortunately, there were no observation wells with an analyzable response for the test performed in well DG1.

For the three test responses that were analyzable, hydraulic conductivity $(\mathrm{K})$ estimates range in value from $5.2 \times 10^{3}$ to $7.3 \times 10^{3} \mathrm{~m} / \mathrm{d}$ (Table 12 ). Figure 31 and Figure 32 show the observed pressure responses and Neuman type-curve fits for the test in stress well INJ, as observed in observation wells CG1 and DG1. Figure 33 contains the observed response and curve fit in well INJ when stressing in well CG1. The K estimates from data at wells INJ and CG1 were very similar (about a 5\% difference), regardless of which well was the stressed well or the observation well. Specific yield (Sy) values obtained from the type-curve fits were between 0.01 and 0.16 . These Sy estimates are lower than estimates of effective porosity, although the upper end of this range is only slightly lower. The lower Sy estimates are likely the result of non-ideal test conditions or the nearby constant-head boundary effects. Overall, the hydraulic results are consistent with other analytical analysis techniques and results from numerical modeling of the tracer test. 
Table 12. Summary of hydraulic conductivity estimates from constant-rate injection tests in 100-C-7:1 wells conducted in August 2012

\begin{tabular}{|c|c|c|c|c|}
\hline Stress Well & Observation Well & $\begin{array}{l}\text { Transmissivity, } \\
\mathrm{T}\left(\mathrm{m}^{2} / \text { day }\right)\end{array}$ & $\begin{array}{c}\text { Hydraulic Conductivity, } \mathrm{K} \\
\text { (m/day) }\end{array}$ & Specific Yield, $\mathrm{S}_{\mathrm{y}}$ \\
\hline \multirow{2}{*}{ INJ } & CG1 & $1.4 \times 10^{4}$ & $5.2 \times 10^{3}$ & $1.0 \times 10^{-2}$ \\
\hline & DG1 & $2.0 \times 10^{4}$ & $7.3 \times 10^{3}$ & $1.6 \times 10^{-1}$ \\
\hline CG1 & INJ & $1.5 \times 10^{4}$ & $5.5 \times 10^{3}$ & $1.0 \times 10^{-2}$ \\
\hline \multicolumn{2}{|c|}{ Average } & $1.6 \times 10^{4}$ & $6.0 \times 10^{3}$ & $7.3 \times 10^{-2}$ \\
\hline
\end{tabular}

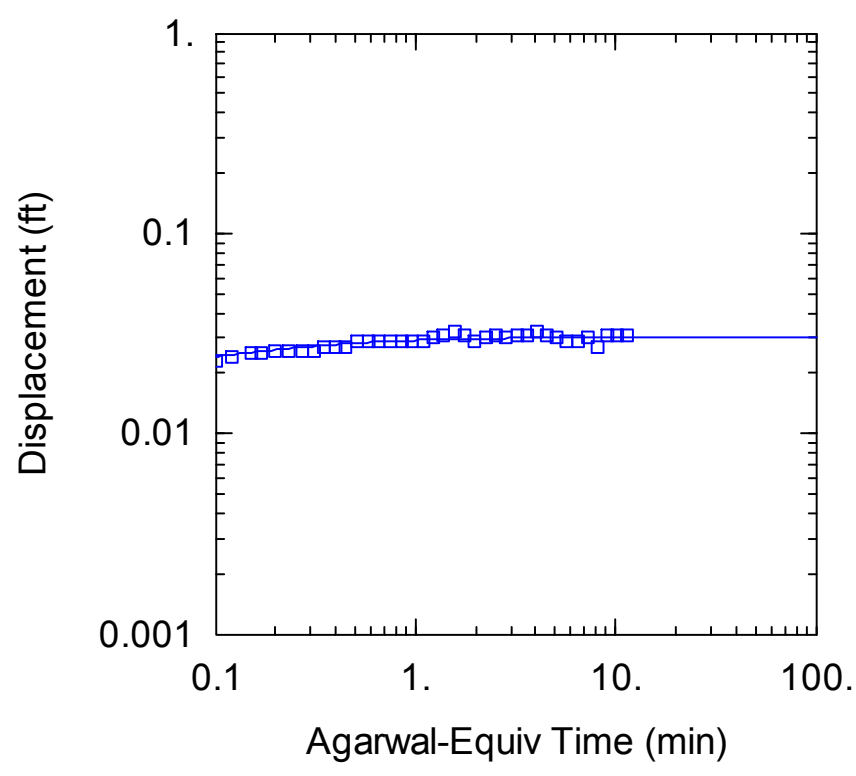

Obs. Wells

口 CG1 Recovery Data

Aquifer Model

Unconfined

Solution

Neuman

Parameters

$T=1.5 \mathrm{E}+5 \mathrm{ft}^{2} / \mathrm{day}$

$S \quad=0.001$

Sy $=0.01$

$\mathrm{Kz} / \mathrm{Kr}=0.1 \mathrm{ft}$

$\mathrm{K}=17,000 \mathrm{ft} / \mathrm{day}$

$\mathrm{Q} \quad=37 \mathrm{gpm}$

$\mathrm{r}_{\text {obs }}=4.91 \mathrm{ft}$

Agarwal-Equiv Time (min)

Figure 31. Observed pressure response (blue squares) in observation well CG1 for test in stress well INJ, with fitted Neuman type-curve (solid blue line)
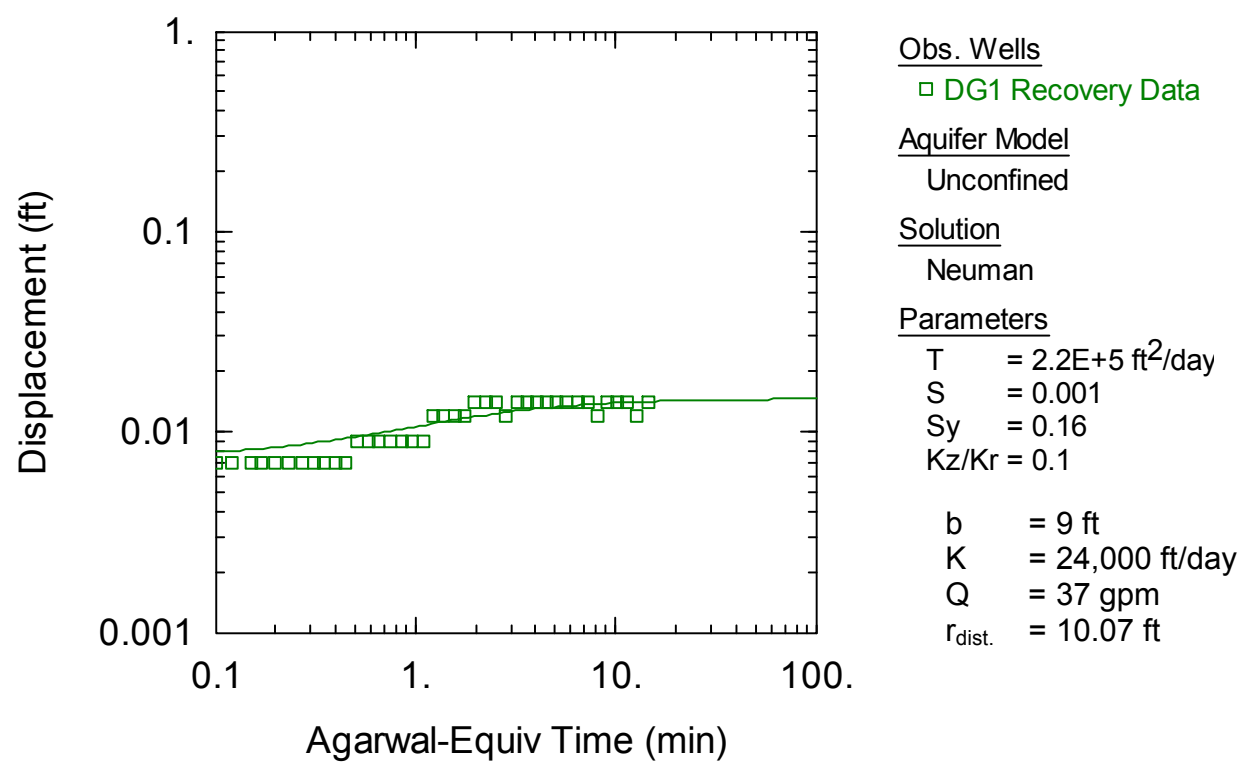

Figure 32. Observed pressure response (green squares) in observation well DG1 for test in stress well INJ, with fitted Neuman type-curve (solid green line) 

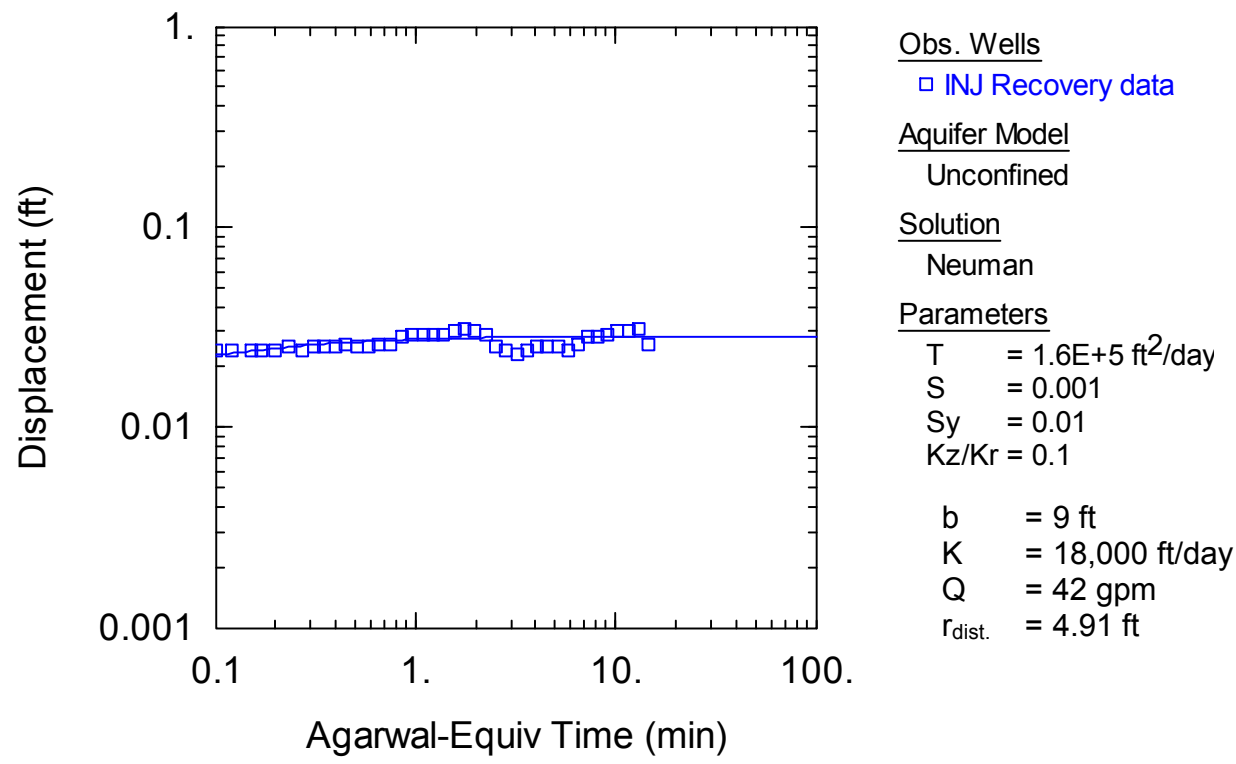

Figure 33. Observed pressure response (blue squares) in observation well INJ for test in stress well CG1, with fitted Neuman type-curve (solid blue line)

\subsubsection{Tracer Tests}

Three tracer injection and natural gradient drift tests were conducted between August 8 and August 23, 2012. The first two tests were conducted in the reconfigured well field, which focused interrogation on a $1.5-\mathrm{m}(5-\mathrm{ft})$ test interval within the uppermost, high permeability portion of the aquifer. It is assumed that the tracer transport occurred primarily within this test interval over the scale represented by the monitoring well network. While a definitive assessment of vertical tracer spread (i.e., above and below the 1.5-m test interval) is not possible, this assumption is supported by 1) EBF results that show lower relative hydraulic conductivities below the 1.5 -m test interval; 2) tracer test interpretations that, based on an assumed test interval thickness of $1.5 \mathrm{~m}$, resulted in effective porosity estimates within the expected range; and 3) observed tracer and pressure responses during the initial scoping test conducted in the longer 3-m (10-ft) test interval that showed no indication of tracer or pressure response in the one deep monitoring well (CG2) screened below the test interval. Given the assumption that tracer transport was effectively constrained within the $1.5-\mathrm{m}$ test interval thickness, the tracer test response data could be quantitatively analyzed to provide estimates of effective porosity and groundwater velocity. When coupled with available gradient data, estimates of hydraulic conductivity based on tracer drift could also be made.

\subsubsection{Tracer Test 1}

For tracer test 1 , a total of $10,527 \mathrm{~L}$ of tracer solution was injected into well DG1. The injection period lasted for $275 \mathrm{~min}$, with an average injection rate of $38.2 \mathrm{~L} / \mathrm{min}$ (Figure 34). The average tracer concentration was $107 \mathrm{mg} / \mathrm{L}$ of bromide.

During the injection phase of tracer test 1 , it became apparent that the collection of aqueous samples from the monitoring wells was impacting the tracer concentration measured by the downhole probes, particularly in the two wells closest to the injection well (DG2 and INJ) (Figure 35). The observed 
downhole probe response is consistent with a dilution effect caused by waters of low or no tracer concentration being pulled into the wellbore during sampling events (Figure 36). This type of sampling-related variability can result when comparing pumped samples, where vertical wellbore flows induced by sampling pumps produce a mixed sample representative of concentrations throughout the entire screened interval, with more depth discrete measurements provided by the downhole probe when the sampling pump is not in operation and the flow field around and through the wellbore is dominated by the injection flow regime. However, a more likely explanation for the tracer response observed in this test configuration, where the tracer injection test interval is less than the full saturated thickness of the aquifer, is that induced vertical gradients associated with aqueous sampling drew water along the casing and/or filter pack from above and/or below the test interval, thus diluting concentration measured within the test interval. Note that the magnitude and timing of the sampling-related change in tracer concentration is different at DG2 and INJ, the two locations where it was observed. This difference is most likely related to varying degrees of near-well vertical connectivity to zones outside the test interval. Whatever the cause, indications are that the results of the downhole specific conductance probes are more representative of in situ tracer concentrations within the test interval than aqueous sample results. For quantitative analysis of tracer test 1 response data, the decrease in the measured specific conductance in the downhole probes caused by operation of the sample pumps was filtered out and only unimpacted downhole probe data were used in the analysis.

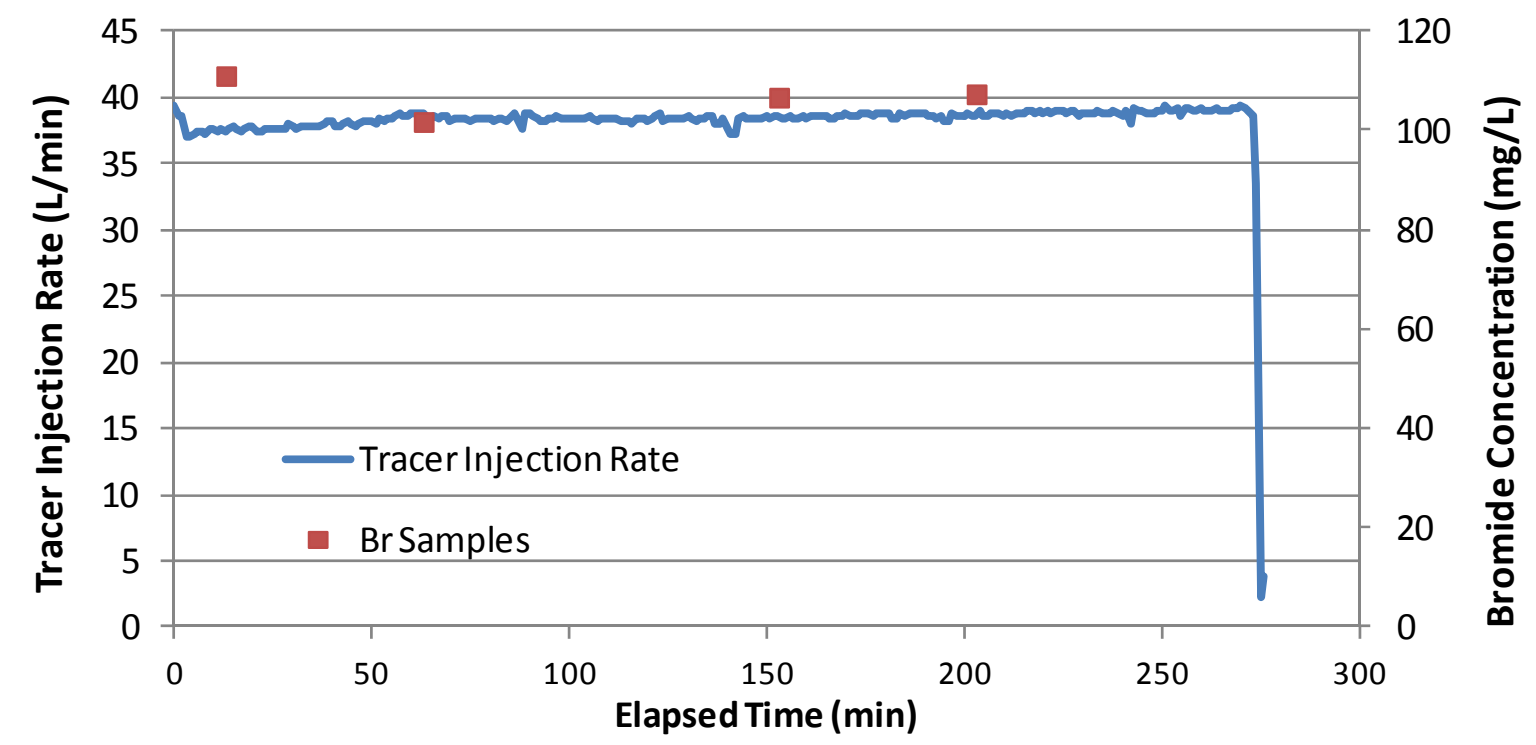

Figure 34. Tracer injection rate and measured bromide ([Br]; i.e., the injected tracer) concentration during tracer test 1 


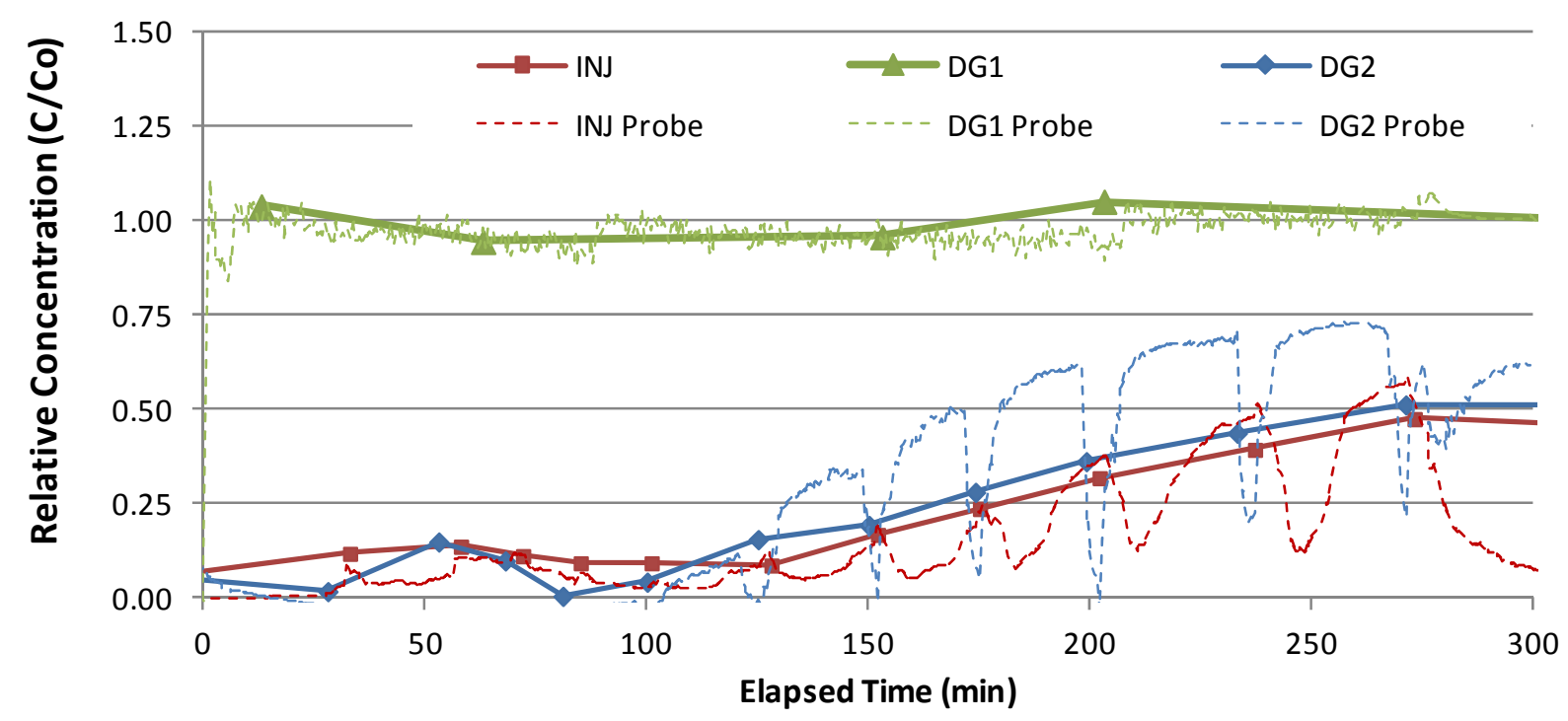

Figure 35. Tracer test 1 monitoring results during the injection phase for both discrete groundwater samples (points/solid lines) and the downhole probes (dashed lines)

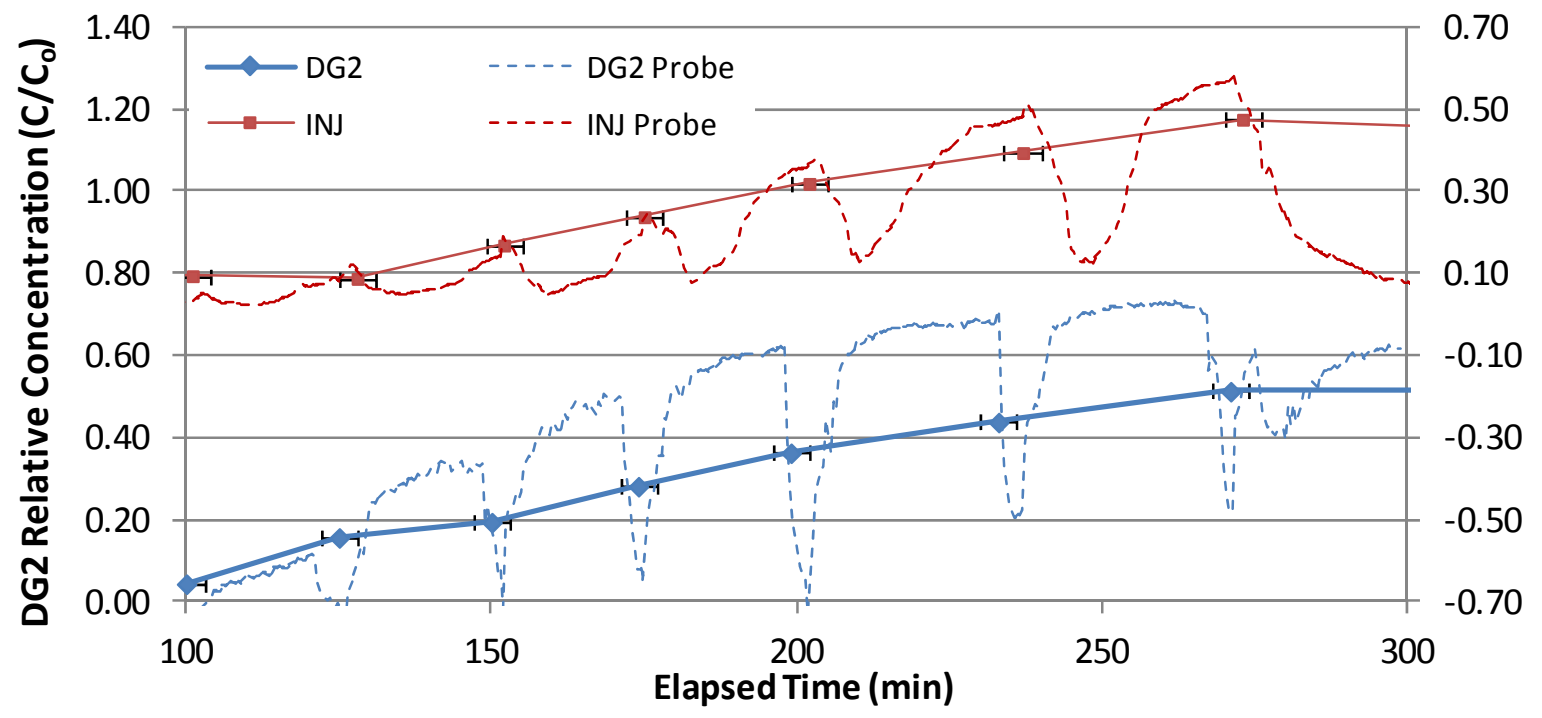

Figure 36. Comparison of data for groundwater samples (points/solid lines) and the downhole probes (dashed lines) for wells DG2 and INJ. Horizontal error-bar-like marks represent the estimated time when the sample pump was on during groundwater sample collection.

During the injection phase of the test, the arrival at downgradient location DG2 was faster than at the upgradient location INJ. This type of response indicates that either a horizontally anisotropic test response or that the injection rate was not sufficiently high to fully overcome the natural groundwater flow system during the injection phase (Figure 37). The tracer concentration in downgradient well DG2 reached $50 \%$ of the injection concentration $171 \mathrm{~min}$ after the start of the test. On the upgradient side, tracer concentration in INJ reached $50 \%$ of the injection concentration 245 min after the start of the test; INJ was lagged 74 min relative to DG2. All arrival times were determined from the downhole specific 
conductance probe data by fitting the arrival response to a linear function and solving for the time at which the relative concentration hit 50\% (Figure 38).

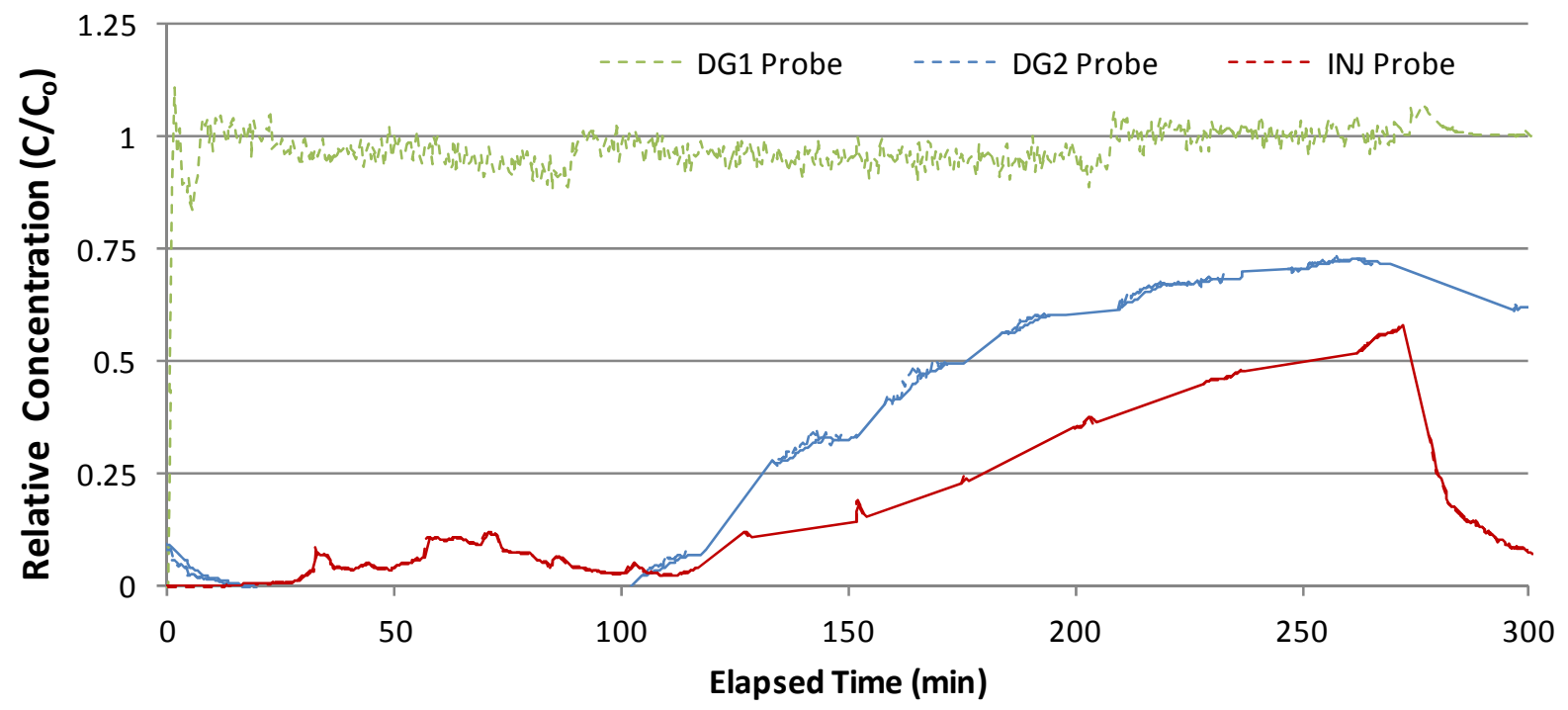

Figure 37. Arrival curves (dashed lines) for INJ and DG2 based on downhole probe data that has been filtered to remove artifacts resulting from groundwater sampling. The solid lines represent a moving average.

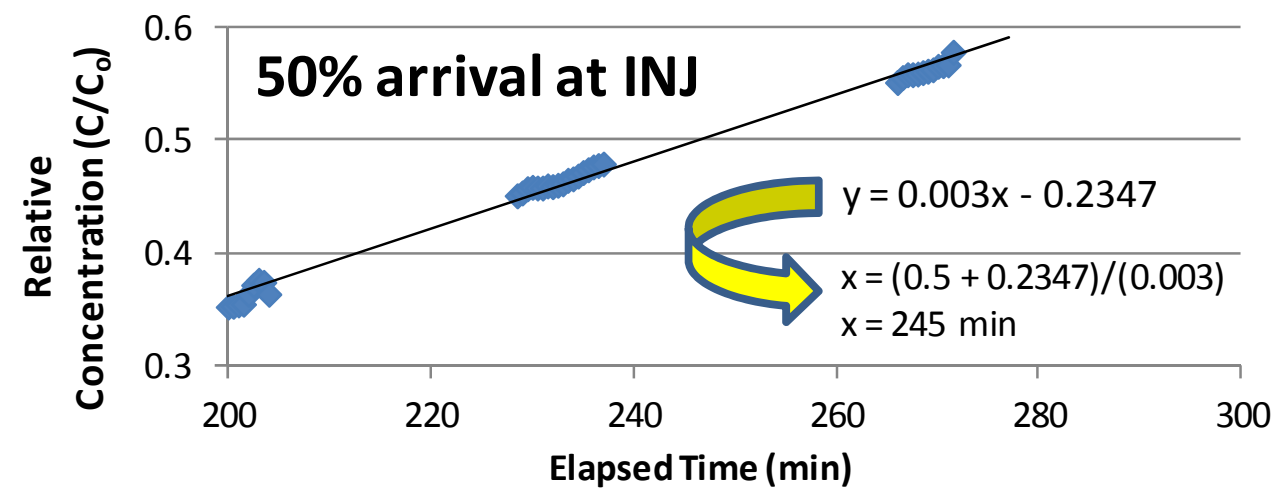

Figure 38. Plot depicting an example of how the 50\% arrival times were calculated; data in the vicinity of the $50 \%$ relative concentration were fit to a linear equation, which was then used to back-calculate the time for a relative concentration of $50 \%$ (i.e., 0.5 )

During the drift phase of the test, the tracer concentration in monitoring well INJ decreased very quickly after injection stopped; the tracer decreased from greater than $50 \%$ of the injection concentration to less than $10 \%$ of the injection concentration within 20 min of the termination of injection (Figure 39). Unfortunately, an equipment error in DG2 resulted in no downhole data being collected from that location during the drift phase. At the injection well (DG1), the tracer concentration decreased to 50\% 1143 min after the injection began, or 868 min after the relative concentration at INJ decreased to $50 \%$ of the injection concentration. 


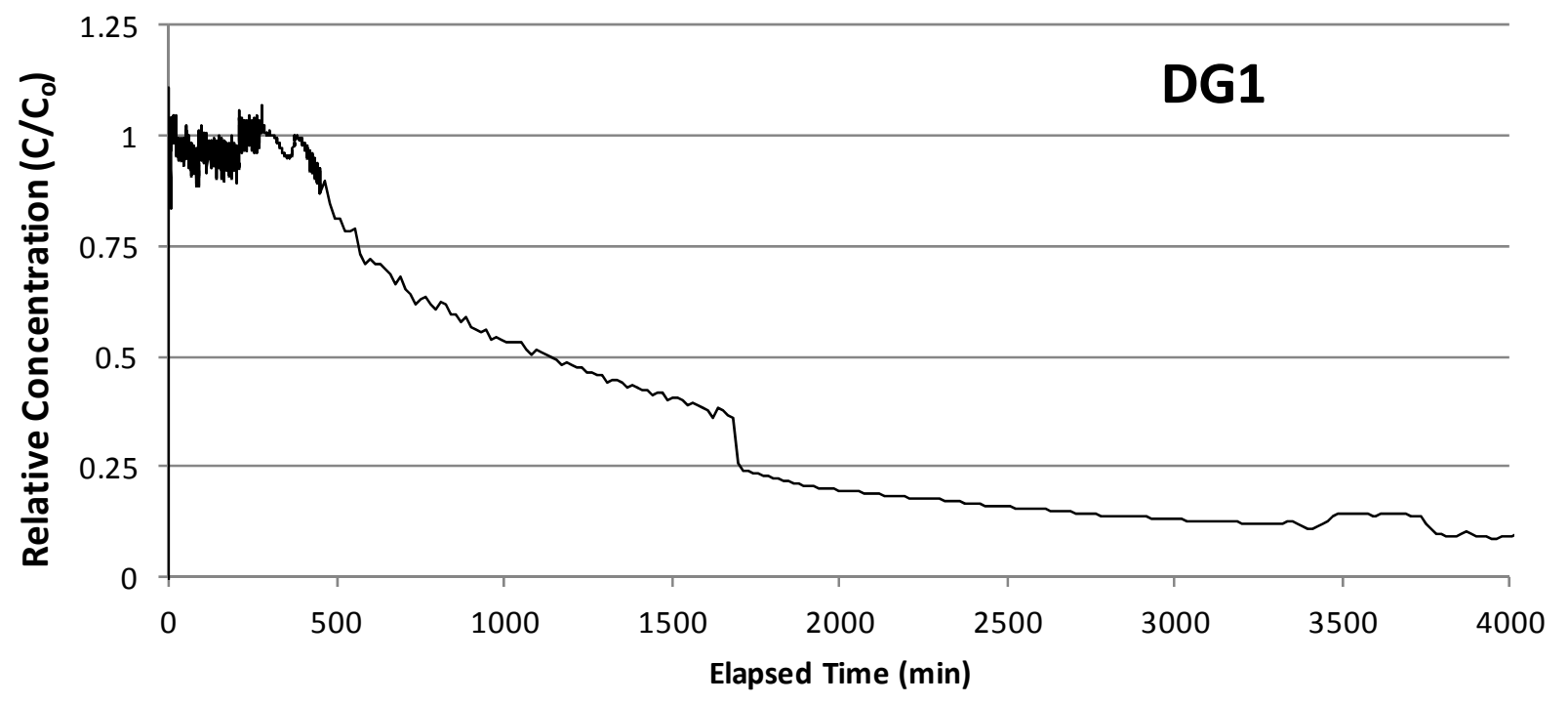

Figure 39. Downhole probe data for well DG1 during tracer test 1

Although not shown in the plots, samples were collected from the near-field aquifer tubes AT-9 through AT-12 during tracer test 1 . While there were some samples with detectable concentrations of bromide, the pattern was irregular and generally not consistent with what would be expected for a tracer arrival response. It is assumed that the bromide measured at these locations was residual bromide remaining from the initial scoping-level test. Based on the direction of the gradient during the tracer tests (nominally an azimuth of 45 degrees), it is unlikely that injected tracer would have reached these aquifer tubes centered downgradient around an azimuth of 35 degrees.

Tracer arrival/elution response times for DG1 during the injection and drift phase of the test were used to estimate effective porosity and drift velocity, respectively. When combined with the hydraulic gradient data (see Section 5.3), an independent estimate of hydraulic conductivity (Table 13) based on the observed tracer drift was obtained for comparison with estimates based on hydraulic test response (see Section 5.4.2). These simplified volumetric estimates assume a radial flow geometry (i.e., cylindrical injection volume) and a constant (time averaged) gradient during the tracer drift (see Equations [2-4]). Because it appears that natural groundwater flow was influencing the arrival times at both the upgradient and downgradient locations, the resulting effective porosity and hydraulic conductivity estimates should represent approximate upper and lower bounds, with the best estimate falling somewhere between, and likely near the average value, for the two monitoring locations. This simplified approach does not fully account for the impacts of the natural flow field on observed tracer arrival response at monitoring well locations. 
Table 13. Simplified calculation of the drift velocity based on the elution time at well DG1 and the effective porosity and hydraulic conductivity based on arrival times during tracer test 1

\begin{tabular}{lcccc}
\hline \multicolumn{1}{c}{ Parameter } & Units & \multicolumn{3}{c}{ Value } \\
\hline Radius of cylindrical plug of tracer (from DG1 to INJ), $\mathrm{r}_{\mathrm{e}}$ & $\mathrm{m}$ & & 3.08 \\
Elapsed time at 50\% elution at well DG1, $\mathrm{t}_{\mathrm{e} 50}$ & $\mathrm{Min}$ & & 868 & \\
Drift velocity, $\mathrm{v}$ & $\mathrm{m} / \mathrm{d}$ & & 5.11 & \\
Injection rate, $\mathrm{Q}$ & $\mathrm{L} / \mathrm{min}$ & & 38.2 & \\
Gradient, dh/dx & $\mathrm{m} / \mathrm{m}$ & & 0.00014 & \\
Well/summary statistic & - & $\mathrm{DG} 2$ & $\mathrm{INJ}$ & Average \\
Radius (distance from DG1 to observation well), $\mathrm{r}_{\mathrm{a}}$ & $\mathrm{m}$ & 3.08 & 3.07 & 3.08 \\
Elapsed time for 50\% arrival, $\mathrm{t}_{\mathrm{e} 50}$ & $\mathrm{~min}$ & 171 & 245 & 208 \\
Effective porosity, $\mathrm{n}_{\mathrm{eff}}$ & - & 0.14 & 0.21 & 0.175 \\
Hydraulic conductivity, $\mathrm{K}$ & $\mathrm{m} / \mathrm{d}$ & $5.26 \times 10^{3}$ & $7.53 \times 10^{3}$ & $6.39 \times 10^{3}$ \\
\hline
\end{tabular}

$$
\begin{gathered}
v=\frac{1440 \cdot r_{e}}{t_{e 50}} \\
n_{e f f}=\frac{t_{a 50} \cdot Q}{1000 \cdot V o l}=\frac{t_{a 50} \cdot Q}{1000 \cdot \pi \cdot r_{a}^{2} \cdot b} \\
K=\frac{v \cdot n_{e f f}}{d h / d x}
\end{gathered}
$$

where $\quad v=$ groundwater velocity $(\mathrm{m} / \mathrm{d})$

$r_{e}=$ injection radius $(\mathrm{m})$

$t_{e 50}=$ time for $50 \%$ elution $(\mathrm{min})$

$r_{a}=$ distance (radius) from injection well to observation well (m)

$t_{a 50}=$ time for $50 \%$ arrival $(\mathrm{min})$

$Q=$ injection rate $(\mathrm{L} / \mathrm{min})$

$\mathrm{Vol}=$ volume of cylinder of radius $r$ and test interval thickness $b\left(\mathrm{~m}^{3}\right)$

$b=$ test interval thickness $(\mathrm{m})$

$\mathrm{n}_{\text {eff }}=$ effective porosity $(-)$

$d h / d x=$ hydraulic gradient $(-)$

$K=$ hydraulic conductivity $(\mathrm{m} / \mathrm{d})$

$1000=$ conversion factor $\left(\mathrm{L} / \mathrm{m}^{3}\right)$

$1440=$ conversion factor $(\mathrm{min} / \mathrm{d})$.

\subsubsection{Tracer Test 2}

Tracer test 2 was a repeat of tracer test 1 , but with no aqueous sample collection. This test was conducted to supplement the tracer response dataset generated during the first tracer test. Additional and/or improved data quality requirements included removal of interferences associated with aqueous sample collection, extended injection duration to more fully develop arrival response at near-field monitoring locations, collection of drift phase data in DG2 that was missed during the first test because of an instrumentation malfunction, and installation of three new near-field drive-point aquifer tubes to allow 
for additional continuous monitoring at downgradient locations. For tracer test 2, a total of $12,586 \mathrm{~L}$ of tracer solution was injected into well DG1 for $307 \mathrm{~min}$, at an average rate of $41 \mathrm{~L} / \mathrm{min}$. The nominal bromide concentration was $120 \mathrm{mg} / \mathrm{L}$; however, because no samples were collected for analysis, the actual injection concentration was not measured. For ease of reporting and evaluation, all results were normalized to the injection concentration based on specific conductance measurements.

During the injection phase, the arrival at INJ was lagged in time relative to DG2, again indicating that the injection rate was not high enough to completely overcome the natural groundwater flow system (Figure 40). The tracer concentration in DG2 reached 93\% of the injection concentration after about $275 \mathrm{~min}$, and the concentration measured in INJ reached $70 \%$ of the injection concentration by the end of the injection phase. The concentration measured in CG1 reached $50 \%$ of the injection concentration by the end of the injection phase. The higher relative concentrations observed in tracer test 2 compared to tracer test 1 are likely a combined result of a lower hydraulic gradient (and natural groundwater velocity), the slightly higher injection rate, and the lack of sampling related dilution.

For the drift phase of tracer test 2 , the tracer eluted out of the upgradient monitoring wells INJ and CG1 quickly. Monitoring well INJ decreased from $68 \%$ to $50 \%$ of the injection concentration within 73 min of the end of tracer injection, and decreased to less than $10 \%$ within 300 min. This quick elution response indicates that the front edge of the plume did not move much further upgradient than INJ. However, this elution time was substantially longer than observed during tracer test 1 , which would be expected based on the increased injection volume and lower hydraulic gradient. During the drift phase, the concentration in the injection well (DG1) decreased at a rate similar to the rate observed at DG2. This comparable drift response provides an indication that DG2 was not directly downgradient of the injection well, consistent with the hydraulic gradient data (see Section 5.3). In addition, no tracer arrival response was observed in any of the near-field drive-point aquifer tube installations (AT-13 through AT-15) because the gradient azimuth was greater than the azimuth direction from the injection point to the aquifer tubes.

Based on the simplified volumetric calculations discussed above, the effective porosity, drift velocity, and hydraulic conductivity were calculated (Table 14). Results were very similar to the results obtained from tracer test 1 . The range of estimated values was larger for both effective porosity and hydraulic conductivity, but the average was nearly identical. Based on the simplified volumetric evaluation of results from the two upper zone tracer tests, hydraulic conductivity for the Hanford formation beneath the study area ranges between $4.6 \times 10^{3}$ and $7.6 \times 10^{3} \mathrm{~m} / \mathrm{d}$, with an average value of about $6.1 \times 10^{3} \mathrm{~m} / \mathrm{d}$. As discussed previously, this simplified approach does not fully account for the impacts of the natural flow field on observed tracer arrival response at monitoring well locations. A more rigorous, modeling based approach for interpretation of tracer test response data from this test is discussed in Section 5.4.4. 

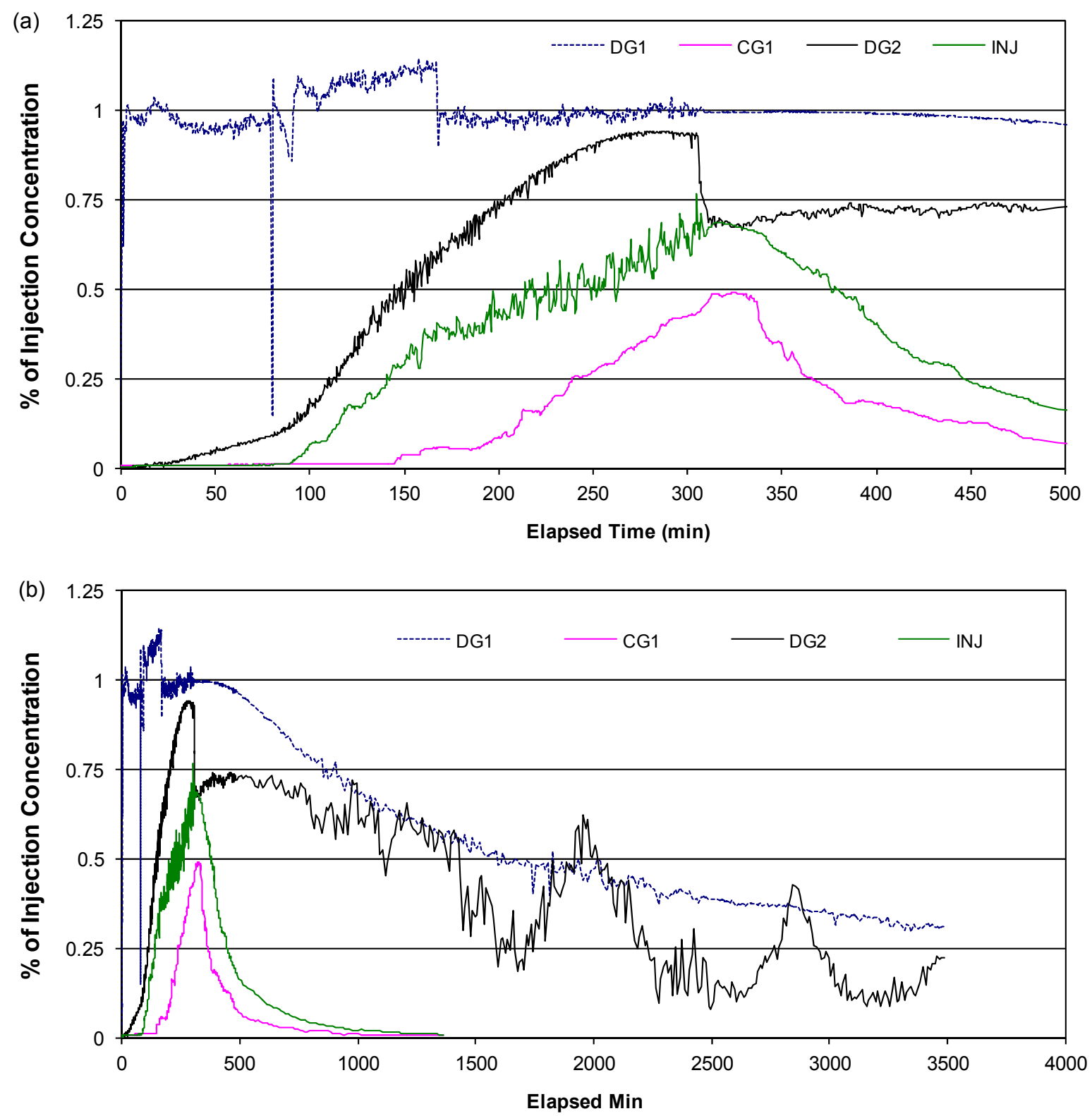

Figure 40. Arrival (a) and elution (b) curves measured during tracer test 2 
Table 14. Simplified calculation of the drift velocity based on the elution time at well DG1 and the effective porosity and hydraulic conductivity based on arrival times during tracer test 2

\begin{tabular}{|c|c|c|c|c|c|}
\hline Parameter & Units & \multicolumn{4}{|c|}{ Value } \\
\hline Radius of injected cylindrical plug of tracer, $r_{e}$ & $\mathrm{~m}$ & \multicolumn{2}{|c|}{$\begin{array}{c}3.08 \\
\text { (from DG1 to INJ) }\end{array}$} & \multicolumn{2}{|c|}{$\begin{array}{c}3.36 \\
\text { (from DG1 to CG1) }\end{array}$} \\
\hline Elapsed time at $50 \%$ elution at well DG1, $\mathrm{t}_{\mathrm{e} 50}$ & $\min$ & \multicolumn{2}{|c|}{1217} & \multicolumn{2}{|c|}{1320} \\
\hline Drift velocity, v & $\mathrm{m} / \mathrm{d}$ & \multicolumn{2}{|c|}{3.65} & \multicolumn{2}{|c|}{3.67} \\
\hline Injection rate, $\mathrm{Q}$ & $\mathrm{L} / \mathrm{min}$ & \multicolumn{4}{|c|}{41} \\
\hline Gradient, $\mathrm{dh} / \mathrm{dx}$ & $\mathrm{m} / \mathrm{m}$ & \multicolumn{4}{|c|}{0.000109} \\
\hline Test interval thickness, $\mathrm{b}$ & $\mathrm{m}$ & \multicolumn{4}{|c|}{1.5} \\
\hline Well/summary statistic & - & DG2 & INJ & CG1 & Average \\
\hline Radius (distance from DG1 to observation well), $r_{a}$ & $\mathrm{~m}$ & 3.08 & 3.07 & 3.35 & - \\
\hline Elapsed time for $50 \%$ arrival, $\mathrm{t}_{\mathrm{e} 50}$ & $\min$ & 150 & 243 & 310 & - \\
\hline Effective porosity, $\mathrm{n}_{\mathrm{eff}}$ & - & 0.14 & 0.22 & 0.24 & 0.18 \\
\hline Hydraulic conductivity, $\mathrm{K}$ & $\mathrm{m} / \mathrm{d}$ & $4.57 \times 10^{3}$ & $7.45 \times 10^{3}$ & $7.97 \times 10^{3}$ & $6.14 \times 10^{3}$ \\
\hline
\end{tabular}

\subsubsection{Tracer Test 3}

Tracer test 3 was conducted in CG2, the only well completed at a deeper interval, approximately $3 \mathrm{~m}$ below the base of the upper test interval. This test was originally planned as a tracer injection/pump-back test, but the high drift velocity made it impossible to recover the injected tracer. As a result, this tracer test was analyzed as a single-well tracer elution test based on the elution response at the injection well. During this test, $378 \mathrm{~L}$ of tracer solution was injected at a nominal rate of $17 \mathrm{~L} / \mathrm{min}$ across a $0.61-\mathrm{m}$ screen interval. The relative tracer concentration decreased to $50 \%$ of the injection concentration $410 \mathrm{~min}$ after the injection stopped (Figure 41).

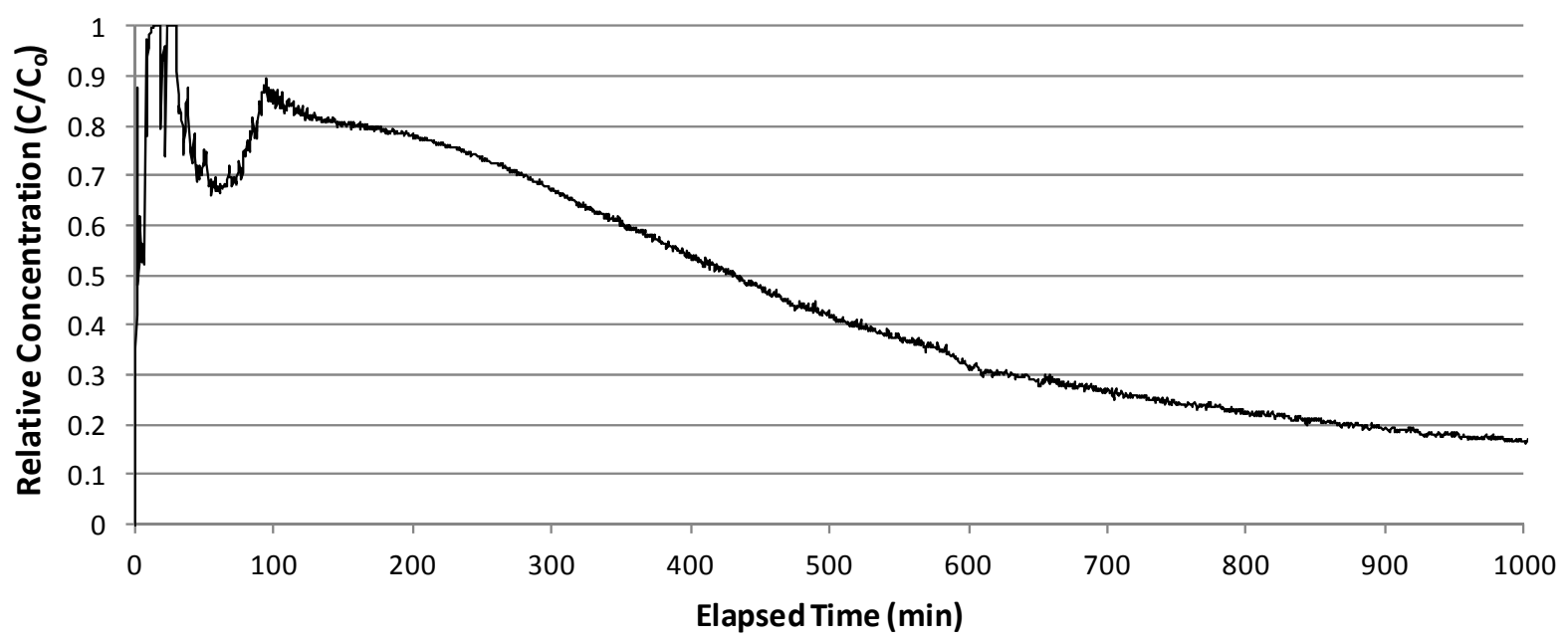

Figure 41. Tracer concentration in well CG2 during tracer test 3 (injection and subsequent drift)

During this test, no monitoring well data were available to define the tracer plume geometry; thus, a simple cylindrical geometry was assumed based on the test interval thickness, effective porosity estimates 
from the first two tracer tests, and volume of tracer solution injected. The elution response data for this single well test was combined with the measured gradient during the drift phase and the range of porosity values calculated during the first two tracer tests to calculate a range of drift velocities and hydraulic conductivities (Table 15). These results are very similar to the hydraulic conductivity estimates obtained from the first two tracer tests. These results provide some evidence that the hydraulic properties determined for the relatively thin test interval interrogated during tracer tests 1 and 2 are consistent with other depth intervals within the Hanford formation beneath the 100-C-7:1 site.

Table 15. Simplified calculation of the drift velocity and hydraulic conductivity based on tracer elution measured during tracer test 3 . Effective porosities represent the range of values calculated during tracer test 1 and 2 .

\begin{tabular}{ccccc}
\hline Estimate & $\begin{array}{c}\text { Effective porosity, } \mathrm{n}_{\text {eff }} \\
(-)\end{array}$ & $\begin{array}{c}\text { Drift Velocity, } \mathrm{v} \\
(\mathrm{m} / \mathrm{d})\end{array}$ & $\begin{array}{c}\text { Gradient, dh/dx } \\
(\mathrm{m} / \mathrm{m})\end{array}$ & $\begin{array}{c}\text { Hydraulic Conductivity, K } \\
(\mathrm{m} / \text { day })\end{array}$ \\
\hline Low & 0.14 & 4.17 & 0.000109 & $5.37 \times 10^{3}$ \\
High & 0.24 & 3.19 & 0.000109 & $7.03 \times 10^{3}$ \\
Average & 0.18 & 3.68 & 0.000109 & $6.09 \times 10^{3}$ \\
\hline
\end{tabular}

\subsubsection{Modeling Interpretation of the Tracer Test}

Groundwater flow and solute transport simulations were conducted to assess what values of hydraulic conductivity, porosity, and dispersivity are appropriate to match field data from two tracer tests. This section describes the observed data used for comparison to simulation results, the range of simulations conducted, and the outcome of the evaluation.

\subsubsection{Data}

As with many types of data, the sensor data for the tracer tests includes a high density of values and, at times, a significant level of "noise." To reduce the observed data (discussed in Section 5.4.3) to a uniform interval of reduced frequency and to represent the basic shape of the trend, these data were smoothed using the Loess algorithm (Cleveland and Devlin 1988). The data of interest for tracer test 2 are the arrival data for wells DG2, INJ, and CG1 during the 307-min long injection and the data for elution of tracer from well DG1 starting from the end of the injection. Figure 42 shows both the observed data (points) and the smoothed data (lines). The smoothed data were calculated over the time span of interest at 5-min intervals using 40 points for each evaluation ( 20 points for the elution curve). The smoothed data were used for comparison to simulation results. 


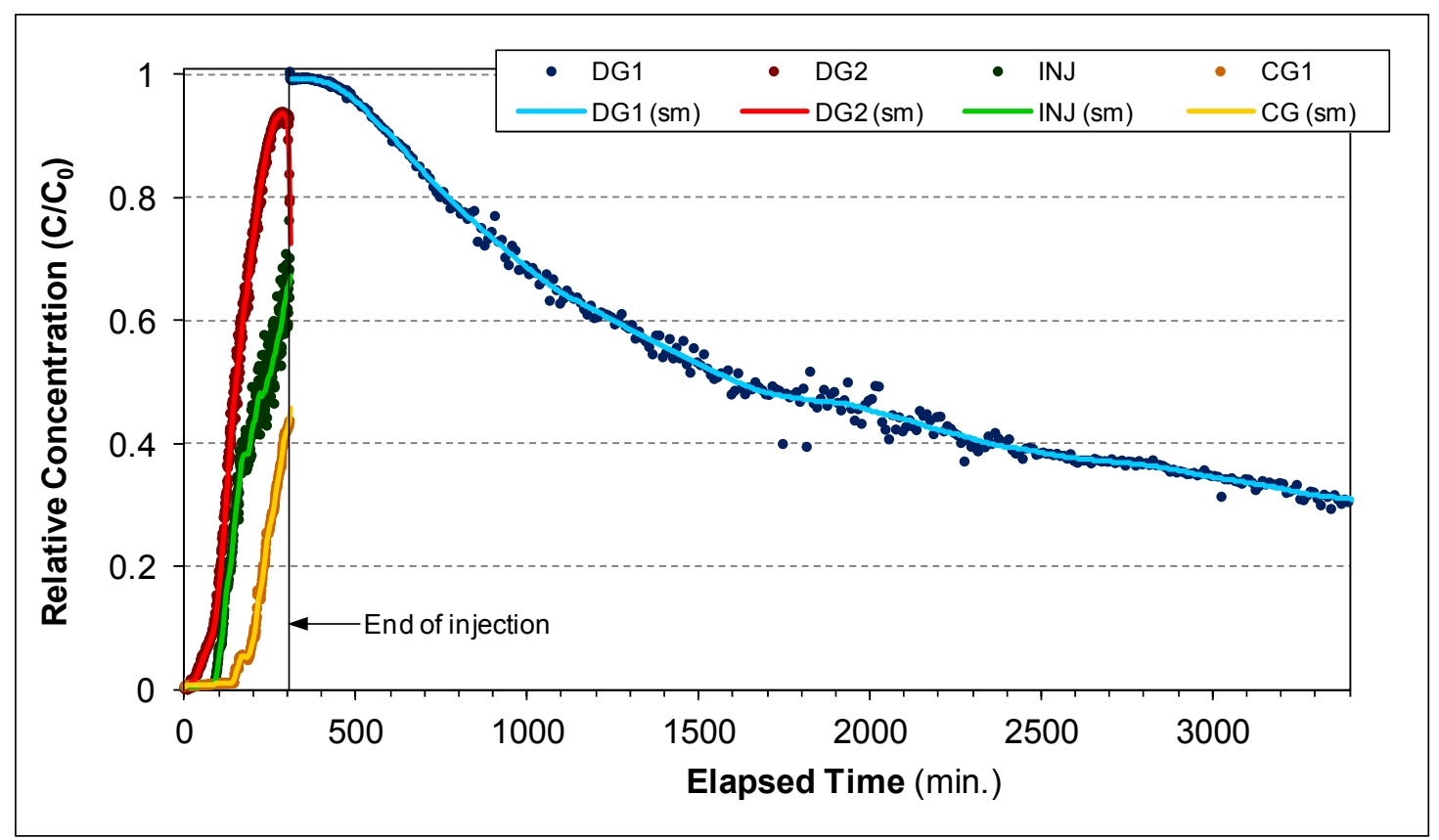

Figure 42. Data for tracer test 2 showing the arrival data at wells DG2, INJ, and CG1 and elution data for the injection well DG1 along with the corresponding smoothed data fits

\subsubsection{Simulations}

A matrix of simulations was prepared to evaluate the hydraulic conductivity, porosity, and dispersivity parameters within reasonable bounds. Table 16 lists the specific values assessed for each parameter, with the high and low values representing the presumed reasonable bounds for the site. To make the process manageable, the initial set of simulations applied a single dispersivity value of $0.25 \mathrm{~m}$, which is a good first estimate based on the size of the site and the configuration of the model. Subsequent simulations looked at variation of the dispersivity for specific values of hydraulic conductivity and porosity.

Table 16. Values of parameters tested in the simulation matrix

\begin{tabular}{ccc}
\hline Hydraulic Conductivity $(\mathrm{m} / \mathrm{d})$ & Porosity $(-)$ & Longitudinal Dispersivity $(\mathrm{m})$ \\
\hline 4572 & 0.150 & 0.15 \\
6096 & 0.175 & 0.25 \\
7620 & 0.200 & 0.35 \\
9144 & 0.225 & 0.45 \\
& 0.250 & 0.50 \\
\hline
\end{tabular}

\subsubsection{Simulation Results}

A hydraulic conductivity value of $6096 \mathrm{~m} / \mathrm{d}(20,000 \mathrm{ft} / \mathrm{d})$ and a porosity of 0.175 , at the resolution of the parameter variations, provided the best fit to the experimental data. Figure 43 shows that the arrival 
of the tracer is delayed as the porosity increases, with best fit to all three wells being for a porosity of 0.175 . The fit of simulation results to data for the range of hydraulic conductivities are shown in Figure 44. An increase in hydraulic conductivity serves to spread out the arrival of the tracer at the three wells, going from closer arrival times at lower hydraulic conductivities, to arrival times further apart at higher conductivities. While a hydraulic conductivity of $7620 \mathrm{~m} / \mathrm{d}$ matches the data well for DG1 and CG2, a hydraulic conductivity of $6096 \mathrm{~m} / \mathrm{d}$ matches better for all three wells. Given that the simulations were pointing to a hydraulic conductivity of $6096 \mathrm{~m} / \mathrm{d}$ and a porosity of 0.175 , a further set of simulations was run with these values and a range of dispersivity values (Figure 45). As dispersion increases, the simulated arrival curves go from sharper to flatter (more spread out). For this model, the dispersivity of $0.25 \mathrm{~m}$ appears to be the most appropriate. However, a model examining the aquifer at a larger scale may need to use a noticeably different value for dispersivity to account for the differing range of heterogeneity encountered at that larger scale.

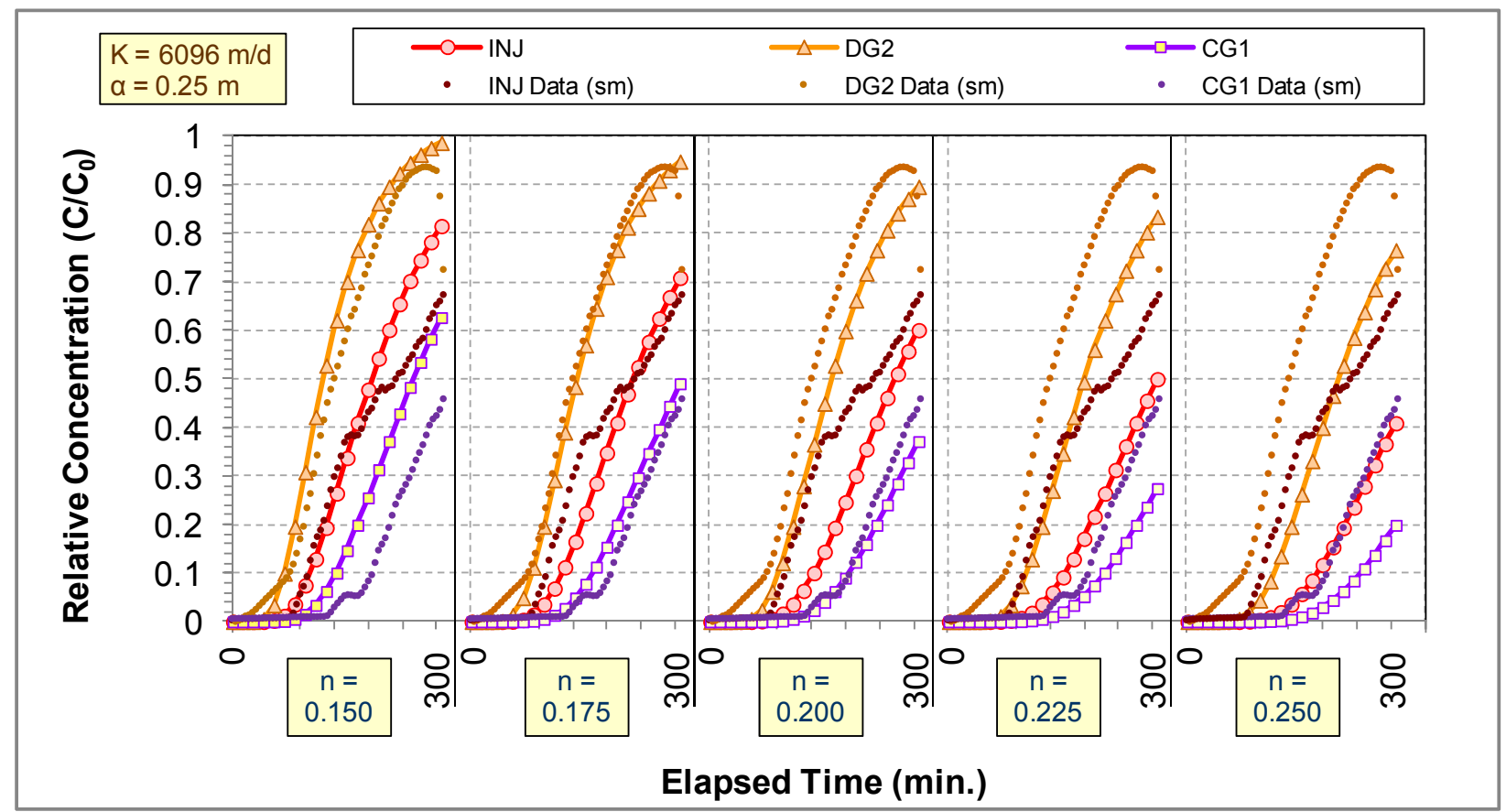

Figure 43. Arrival curves for wells DG2, INJ, and CG1 in tracer test 2 for simulations with varying porosity (n) values 


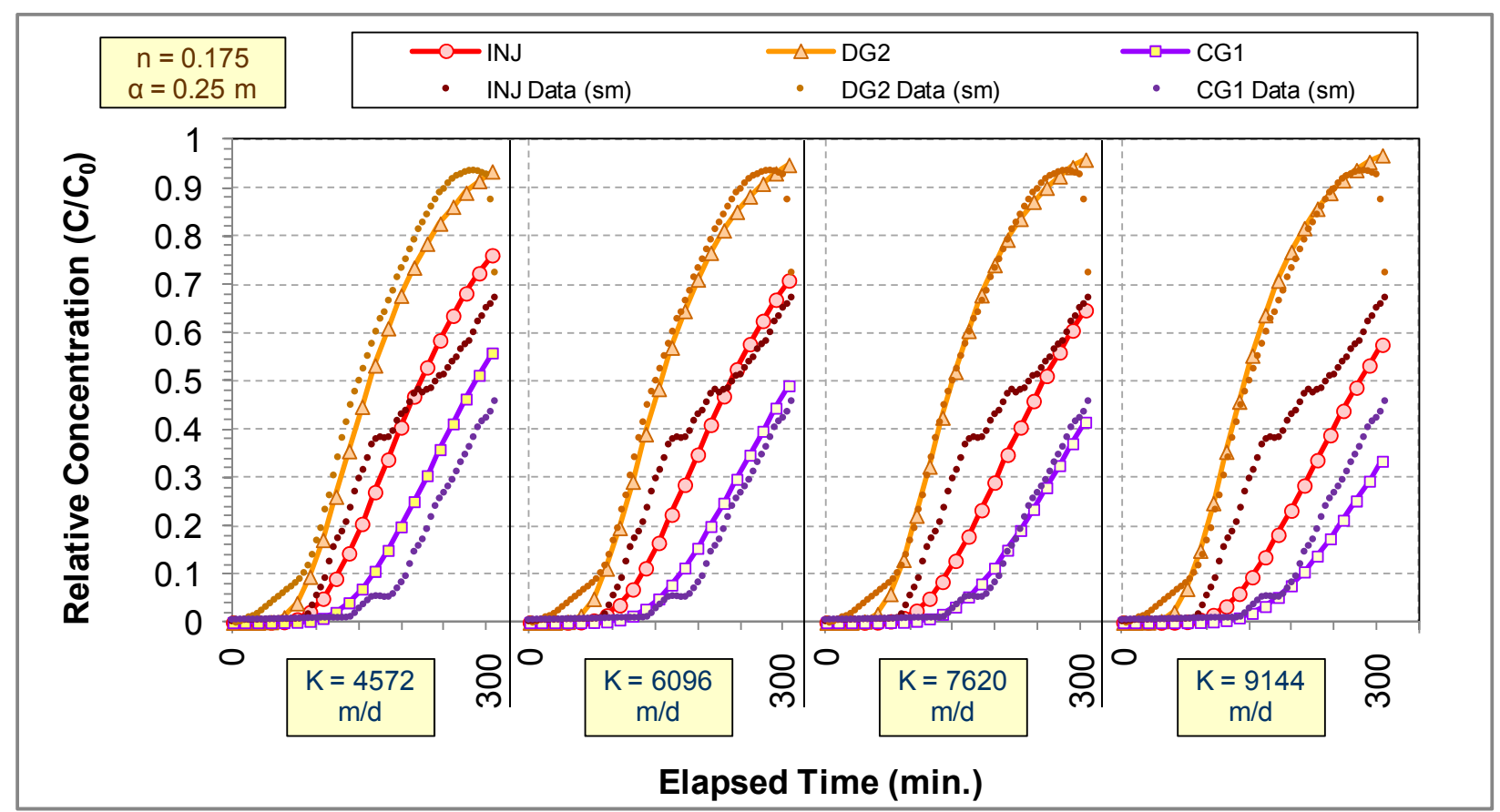

Figure 44. Arrival curves for wells DG2, INJ, and CG1 in tracer test 2 for simulations with varying longitudinal hydraulic conductivity $(\mathrm{K})$ values

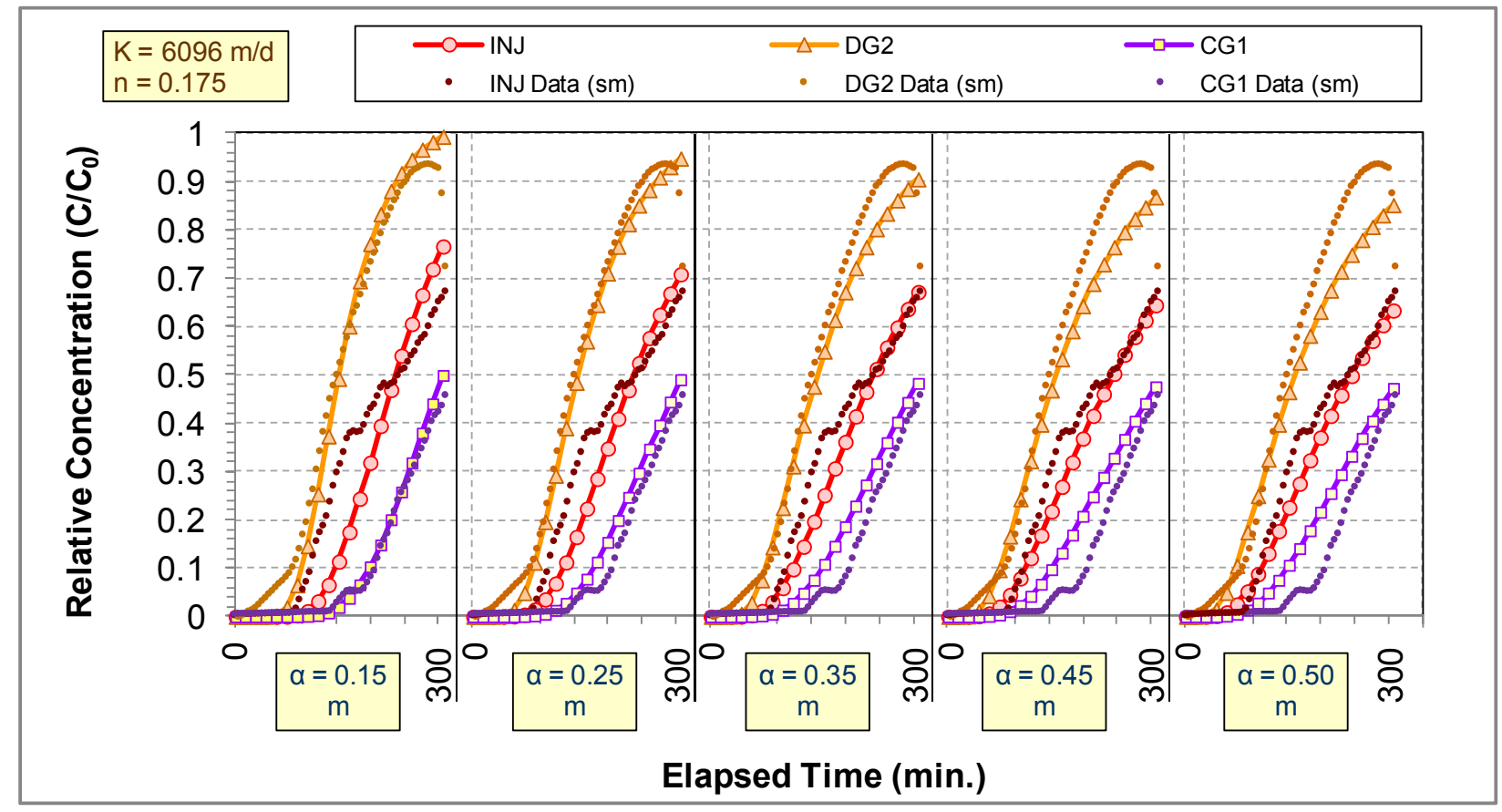

Figure 45. Arrival curves for wells DG2, INJ, and CG1 in tracer test 2 for simulations with varying dispersivity $(\alpha)$ values 
The other important data measured in tracer test 2 is the "elution" of tracer from the injection well location after the injection was halted. Figure 46 to Figure 48 show the simulation results for the elution curves that correspond to the arrival curve plots in Figure 43 to Figure 45. The observed elution data from well DG1 exhibits a basically exponential (slightly sigmoidal just after tracer injection ends) reduction in concentration over time, with concentrations after $2 \mathrm{~d}$ around $30 \%$ of the injected concentration. However, the numerical model results exhibit a sigmoidal-shaped elution curve that tend toward concentrations below $10 \%$ of the initial concentration after $2 \mathrm{~d}$. It is likely that the simplified model does not fully represent the heterogeneity of the aquifer in the vicinity of the site. Based on borehole flow meter data, it appears that there may be zones of differing hydraulic conductivity within the screened zone (see Section 5.4.1 for more discussion). Such real-world non-uniformities in the aquifer apparently lead to a more dispersed elution response and slower overall elution/drift of tracer at the DG1 well location. While it is therefore difficult to match this slow elution, it is apparent that the parameter values indicated by the arrival curves $(K=6096 \mathrm{~m} / \mathrm{d}, \mathrm{n}=0.175$, and $\alpha=0.25 \mathrm{~m})$ show reasonable results compared to the curves for other parameter combinations. In addition, it would be inappropriate to select, for example, the case with a high dispersivity of $0.5 \mathrm{~m}$ because the arrival curves (shown above) indicate that a lower dispersivity is more appropriate.

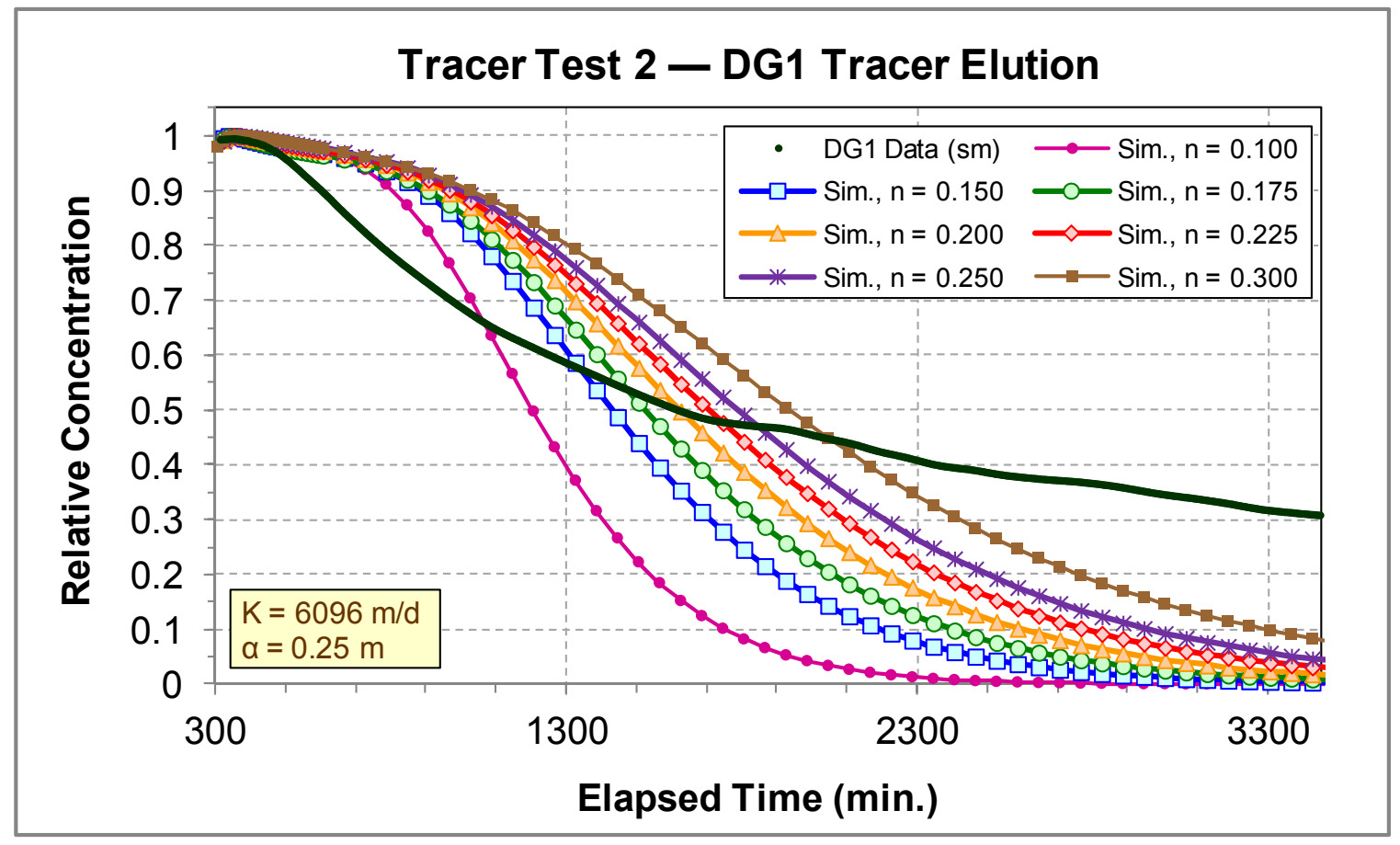

Figure 46. Elution curves for well DG1 in tracer test 2 for simulations with varying porosity (n) values 


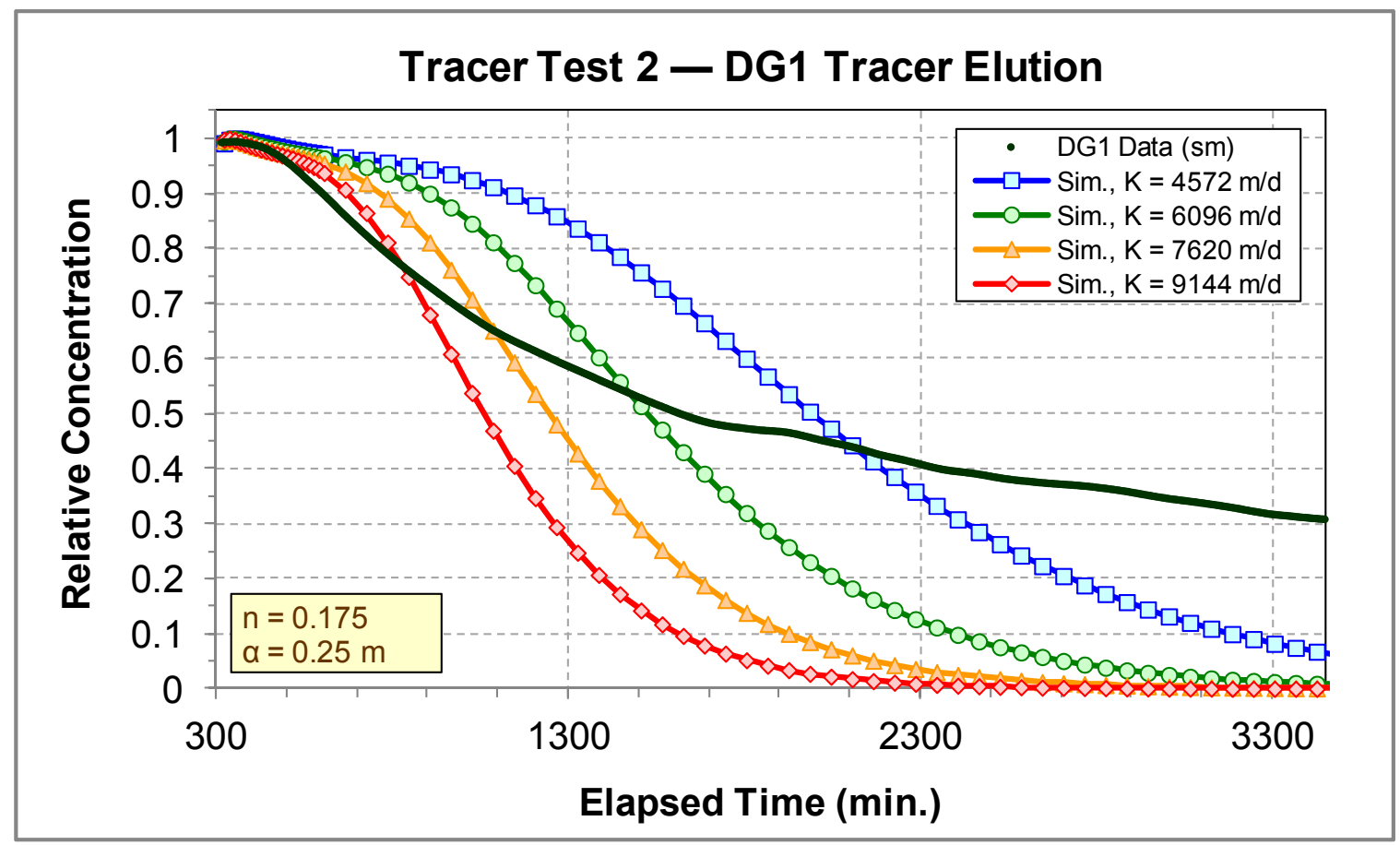

Figure 47. Elution curves for well DG1 in tracer test 2 for simulations with varying hydraulic conductivity $(\mathrm{K})$ values

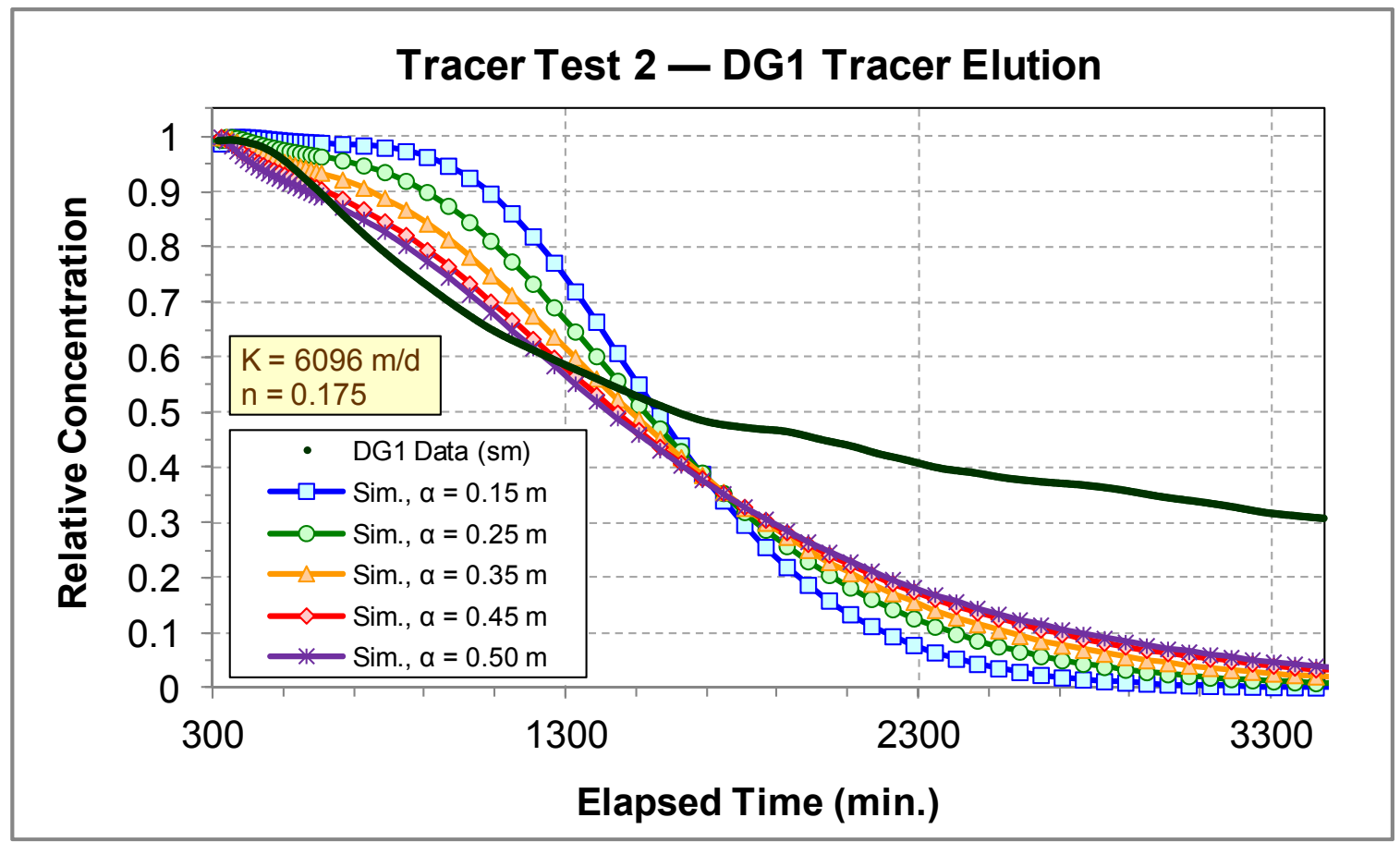

Figure 48. Elution curves for well DG1 in tracer test 2 for simulations with varying dispersivity $(\alpha)$ values 
The best fit parameter values (for $\mathrm{K}, \mathrm{n}$, and $\alpha$ ) with the suite of simulations performed for tracer test 2 were used in a simulation configured for tracer test 3 (primarily a change in layer thickness, boundary conditions, injection/drift durations, and the gradient appropriate for the test time frame). A single simulation was performed for the purpose of evaluating the suitability of the determined parameter values for representing the lower portion of the aquifer that is interrogated by well CG2. Figure 49 shows that the selected parameter values result in a simulation that does a good job of representing the elution of tracer from well CG2, although the simulation elutes slightly faster.

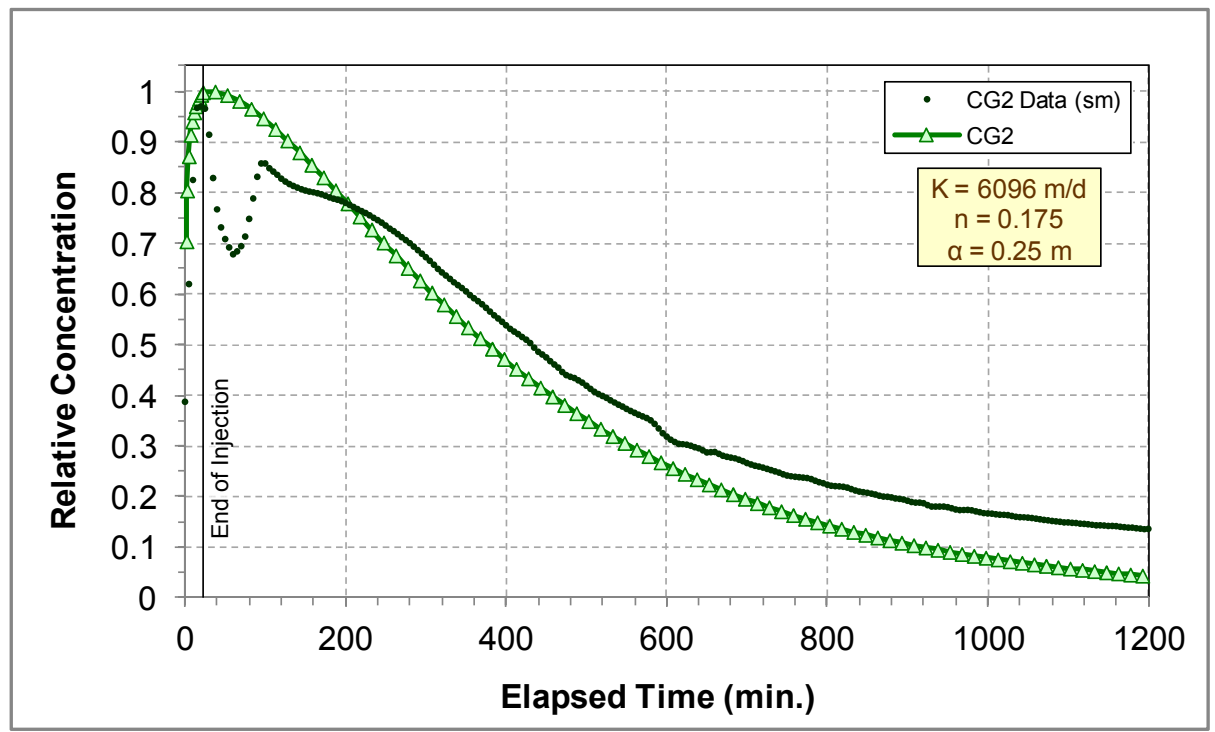

Figure 49. Comparison of (smoothed) tracer test 3 data to the corresponding simulation results (using parameter values selected based on tracer test 2 simulations)

\subsection{Conclusions and Recommendations}

Data collected from a network of aquifer tubes installed across the floor of the 100-C-7:1 excavation and from temporary small-diameter wells installed at the bottom of the entrance ramp to the excavation were used to evaluate $\mathrm{Cr}(\mathrm{VI})$ releases into the aquifer and to estimate local-scale hydraulic properties and groundwater flow velocity. Study information is summarized in the following sections, along with a discussion of how the data can be interpreted with respect to the larger-scale $\mathrm{Cr}$ (VI) plume. In addition, recommendations based on study results and methodology are provided.

\subsection{Summary of Study Information}

A key objective of the study was quantifying the flux of $\mathrm{Cr}(\mathrm{VI})$ from the vadose zone waste site into the groundwater. The $\mathrm{Cr}(\mathrm{VI})$ data show a short-lived and relatively small pulse of $\mathrm{Cr}(\mathrm{VI})$ was released to the groundwater at the excavation site during the study period, corresponding to the seasonal rise in the water table associated with increased Columbia River stage. By the end of the study period, even though the water table was still high, $\mathrm{Cr}(\mathrm{VI})$ concentrations had dissipated with no significant continuing source observed. Sorption of Cr(VI) to vadose zone or aquifer sediments is minimal. Therefore, $\mathrm{Cr}(\mathrm{VI})$ present in the lower vadose zone was readily mobilized when the groundwater table rose and contacted contaminated sediments. 
Previously available hydraulic property information in the upper Hanford formation in the 100-BC Area was sparse. Taking advantage of the excavation depth, temporary small-diameter wells were installed using economical direct-push methods. Hydraulic property information was determined by analysis of constant rate injection data, tracer injection arrival curves, tracer elution under natural gradient conditions, and electromagnetic borehole flow meter data. Direct-push penetration rate data also provided information about the local geological contact between the Hanford and Ringold Formations. The following hydraulic properties and characteristics can be derived from the results of these tests and the hydraulic gradient and groundwater flow direction estimated from hydraulic head measurements in area wells.

- The hydraulic conductivity estimate from both constant rate injection tests and tracer testing is $6100 \mathrm{~m} / \mathrm{d}(20,000 \mathrm{ft} / \mathrm{d})$. Even over the 3-m test interval thickness, there are small-scale, relatively large magnitude variations in hydraulic conductivity. At a large scale, these variations would tend to increase dispersion of solutes. During periods of hydraulic head variation, as induced by seasonal changes in the Columbia River stage, there can be vertical gradients in the Hanford formation, likely caused by discrete high-permeability zones that transmit hydraulic head variations laterally more rapidly than is translated at other depth intervals. These variations could also lead to additional solute dispersion on a large scale. On a small scale, these variations could cause vertical flow in well screens, as was observed at the 100-C-7:1 test site.

- The specific yield estimate obtained from the hydraulic test analysis ranged between 0.01 and 0.16 . These specific yield estimates are lower than estimates of effective porosity, and generally lower than what would be expected for the Hanford formation, although the upper end of this range is reasonable. The lower specific yield estimates are likely the result of the nearby constant-head boundary effects or other non-ideal test conditions, and should not be considered valid large-scale estimates.

- The effective porosity estimate, based on both simplified volumetric calculations and a more rigorous, modeling-based evaluation of tracer arrival response, indicate a best estimate for this parameter is 0.18. Although estimates of effective porosity based on simplified volumetric calculations ranged between 0.14 and 0.24 for all tests performed, most of this variability is associated with this methodology not accounting for the natural groundwater flow system. It is unclear how this parameter would scale to larger domains, but the comparable hydraulic and tracer drift responses observed in the two zones tested at the study site provide some evidence of uniformity over larger scales.

- Based on measured hydraulic gradients and local-scale hydraulic property estimates, groundwater velocities in the vicinity of the 100-C-7:1 site range from approximately 2 to $7 \mathrm{~m} / \mathrm{d}$, and vary seasonally in response to the Columbia River stage.

- Dispersivity at the test site scale was evaluated using tracer arrival and elution data. Suitable values for dispersivity from these analyses range from 0.15 to $0.5 \mathrm{~m}$, but are not necessarily representative of dispersivity that may occur at larger scales.

- The estimated elevation for the contact between the Hanford and Ringold Formations is $108 \mathrm{~m} \mathrm{msl}$. This information can be used to augment data from surrounding wells in assessing the elevation isopleths for this contact. 


\section{2 $\mathrm{Cr}(\mathrm{VI})$ Plume Interpretations}

Larger-scale interpretations of the local data collected at the 100-C-7:1 test site included an assessment of $\mathrm{Cr}(\mathrm{VI})$ flux from the excavation site to the downgradient aquifer, and the relationship between measured local-scale groundwater velocities and the observed spike in $\mathrm{Cr}(\mathrm{VI})$ concentration at the downgradient well.

\subsubsection{Downgradient Fluxes}

Hydrologic data (Table 17) were used to estimate the average monthly Darcy flux during the study time frame. A mass flux analysis using data from aquifer tubes AT-4 through AT-7 was then applied to estimate the amount of $\mathrm{Cr}(\mathrm{VI})$ being transported from the 100-C-7:1 site to the downgradient aquifer. In this analysis, the aquifer tube data were used to represent a two-dimensional plane at the downgradient edge of the site assumed to be perpendicular to the groundwater flow direction. This flux plane is nominally $80-\mathrm{m}$ wide. While the aquifer tube data only represent the top $3 \mathrm{~m}$ of the aquifer, the flux plane was extended to a thickness of $14 \mathrm{~m}$ (considering a nominal water table elevation of $122 \mathrm{~m}$ and a Hanford/Ringold Formation contact of $108 \mathrm{~m} \mathrm{msl}$ ) with the assumption that the $\mathrm{Cr}(\mathrm{VI})$ concentration declined linearly to zero between the bottom of the aquifer tube data $(3 \mathrm{~m})$ and $14 \mathrm{~m}$. These data from aquifer tubes AT-4 through AT-7 were equally weighted across the flux plane to obtain the average flux plane $\mathrm{Cr}(\mathrm{VI})$ concentrations at the specified depth intervals for $\mathrm{Cr}(\mathrm{VI})$ concentration data in May, June, and a combination of July and August data as shown in Table 18. Each time interval includes data from three sampling events. The data in Table 17 and Table 18 were combined to compute the $\mathrm{Cr}(\mathrm{VI})$ average flux plane concentrations, $\mathrm{Cr}(\mathrm{VI})$ mass discharge (mass discharge $=$ Darcy flux times the cross-sectional area times the average flux plane $\mathrm{Cr}(\mathrm{VI})$ concentration), and mass of $\mathrm{Cr}(\mathrm{VI})$ estimated to move downgradient of the 100-C-7:1 site over the time interval (Table 19). Over the study period, an estimated $1.3 \mathrm{~kg}$ of $\mathrm{Cr}(\mathrm{VI})$ was released from the $100-\mathrm{C}-7: 1$ site into the downgradient aquifer, subject to the assumptions and configuration used for the $\mathrm{Cr}(\mathrm{VI})$ flux analysis. The mass released prior to the study period that resulted in the observed Cr(VI) peak in well 199-B4-14 (see discussion below) has not been quantified.

Table 17. Hydrologic data used in the $\mathrm{Cr}(\mathrm{VI})$ flux calculation

\begin{tabular}{lccccc}
\hline \multicolumn{1}{c}{ Parameter } & Units & May & June & July & August \\
\hline Darcy flux, q & $(\mathrm{m} / \mathrm{d})$ & 0.763 & 1.141 & 1.092 & 0.769 \\
Groundwater velocity, $\mathrm{v}$ & $(\mathrm{m} / \mathrm{d})$ & 4.36 & 6.52 & 6.24 & 4.36 \\
Effective porosity, $\mathrm{n}$ & $(-)$ & 0.175 & 0.175 & 0.175 & 0.175 \\
Gradient, dh/dx & $(-)$ & $1.25 \times 10^{-4}$ & $1.87 \times 10^{-4}$ & $1.79 \times 10^{-4}$ & $1.26 \times 10^{-4}$ \\
Hydraulic conductivity, $\mathrm{K}$ & $(\mathrm{m} / \mathrm{d})$ & 6100 & 6100 & 6100 & 6100 \\
\hline
\end{tabular}


Table 18. Cr(VI) concentrations $(\mu \mathrm{g} / \mathrm{L})$ at specific depth intervals for aquifer tubes AT-4, AT-5, AT-6, and AT-7 based on samples collected in May, June, and July/August 2012

\begin{tabular}{ccccccc}
\hline $\begin{array}{c}\text { Depth Interval } \\
(\mathrm{m})\end{array}$ & $\begin{array}{c}\text { Thickness } \\
(\mathrm{m})\end{array}$ & AT-4 & AT-5 & AT-6 & AT-7 & $\begin{array}{c}\text { Average } \\
(\mu \mathrm{g} / \mathrm{L})\end{array}$ \\
\hline & & \multicolumn{5}{c}{ May } \\
$0-1$ & 1 & 36.67 & 16.67 & 13.33 & 26.67 & 23.33 \\
$1-3$ & 2 & 33.33 & 23.33 & 36.67 & 53.33 & 36.67 \\
$3-14$ & 11 & 16.67 & 11.67 & 18.33 & 26.67 & 18.33 \\
& & \multicolumn{5}{c}{ June } \\
$0-1$ & 1 & 30.00 & 10.00 & 13.33 & 16.67 & 17.50 \\
$1-3$ & 2 & 33.33 & 16.67 & 25.00 & 20.00 & 23.75 \\
$3-14$ & 11 & 16.67 & 8.33 & 12.50 & 10.00 & 11.88 \\
& & & July/August & & & \\
$0-1$ & 1 & 3.33 & 0.00 & 3.33 & 10.00 & 4.17 \\
$1-3$ & 2 & 3.33 & 3.33 & 5.00 & 11.67 & 5.83 \\
$3-14$ & 11 & 1.67 & 1.67 & 2.50 & 5.83 & 2.92 \\
\hline
\end{tabular}

Table 19. Cr(VI) mass information determined from flux plane calculations for aquifer tubes AT-4, AT-5, AT-6, and AT-7 based on data in Table 17 and Table 18

\begin{tabular}{|c|c|c|}
\hline Parameter & Units & Value \\
\hline \multicolumn{3}{|c|}{ May } \\
\hline Monthly weighted average & $\mu \mathrm{g} / \mathrm{L}$ & 21.3 \\
\hline Monthly mass discharge & $\mathrm{g} / \mathrm{d}$ & 18.2 \\
\hline Monthly mass & $\mathrm{g}$ & 564 \\
\hline \multicolumn{3}{|c|}{ June } \\
\hline Monthly weighted average & $\mu \mathrm{g} / \mathrm{L}$ & 14.0 \\
\hline Monthly mass discharge & $\mathrm{g} / \mathrm{d}$ & 17.9 \\
\hline Monthly mass & $\mathrm{g}$ & 536 \\
\hline \multicolumn{3}{|c|}{ July/August } \\
\hline Monthly weighted average & $\mu \mathrm{g} / \mathrm{L}$ & 3.4 \\
\hline Monthly mass discharge & $\mathrm{g} / \mathrm{d}$ & 3.6 \\
\hline Monthly mass & $\mathrm{g}$ & 221 \\
\hline
\end{tabular}

\subsubsection{Correlation to Well 199-B4-14 Data}

Hanford Site groundwater monitoring data for Cr(VI) is routinely collected from well 199-B4-14 (see Figure 8), which is located approximately $300 \mathrm{~m}$ nominally downgradient from the center of the 100-C-7:1 excavation. Cr(VI) concentration data extracted from the Hanford Environmental Information System (HEIS) show that concentrations in this well started to increase in October 2011 and reached their peak observed concentration of $179 \mu \mathrm{g} / \mathrm{L}$ in April 2012, after which the concentrations dropped back to near baseline values by June 2012. Local-scale groundwater velocity estimates in the vicinity of the 100-C-7:1 site ranged from 2 to $6 \mathrm{~m} / \mathrm{d}$ over the duration of excavation operations. Using this velocity range (neglecting the effect of dispersion), the travel time from the center of the 100-C-7:1 excavation to 
well 199-B4-14 ranges from 50 to $150 \mathrm{~d}$. Thus, it is possible that $\mathrm{Cr}(\mathrm{VI})$ from the $100-\mathrm{C}-7: 1$ excavation released into the groundwater between November 2011 and February 2012 could have resulted in the observed Cr(VI) concentration peak in well 199-B4-14 in April 2012. As discussed in Section 5.4, there were local-scale heterogeneous features identified in the Hanford formation beneath the 100-C-7:1 site that may lead to large-scale preferential flow paths and dispersion of solutes. This type of heterogeneous flow system could act to decrease the travel time and decrease the maximum concentration of a $\mathrm{Cr}(\mathrm{VI})$ pulse moving from the 100-C-7:1 site to well 199-B4-14.

\subsection{Recommendations}

Access to the excavation floor near the water table enabled collection of a large amount of hydrologic and contaminant transport/distribution information within a short time frame. These data would be costly and more difficult to obtain with wells installed from the ground surface. Other opportunities where excavations provide relatively shallow access to the groundwater and enable use of direct-push drilling could be used to augment the hydraulic and contaminant data for the Hanford Site. Importantly, the ability to install multiple temporary wells enables use of constant rate injection (or discharge) testing with a stressed well and observation well(s), and to jointly conduct tracer tests that provide more comprehensive and quantitative hydraulic property information than can be obtained from single-well slug testing that has been typically applied at the Hanford Site due to constraints on well installation cost.

\subsection{References}

Agarwal RG. 1980. "A New Method to Account for Producing Time Effects When Drawdown Type Curves are Used to Analyze Pressure Buildup and Other Test Data." SPE Paper 9289, presented at the 55th SPE Annual Technical Conference and Exhibition, September 21-24, 1980, Dallas, Texas.

Boman GK, FJ Molz, and KD Boone. 1997. "Borehole Flowmeter Application in Fluvial Sediments: Methodology, Results, and Assessment." Ground Water 35(3):443-450.

Clement TP. 1997. RT3D-A Modular Computer Code for Simulating Reactive Multi-Species Transport in 3-Dimensional Groundwater Aquifers. PNNL-11720, Pacific Northwest National Laboratory, Richland, Washington.

Clement TP, Y Sun, BS Hooker, and JN Petersen. 1998. "Modeling Multi-Species Reactive Transport in Groundwater Aquifers." Ground Water Monitoring and Remediation 18(2):79-92.

Clement TP and CD Johnson. 2002. RT3D v2.5 Update Document. Pacific Northwest National

Laboratory, Richland, Washington. Available online at http://bioprocess.pnl.gov/rt3d_down.htm\#doc.

Cleveland WS and SJ Devlin. 1988. "Locally-Weighted Regression: An Approach to Regression Analysis by Local Fitting." Journal of the American Statistical Association 83(403):596-610.

Devlin JF. 2003. “A Spreadsheet Method of Estimating Best Fit Hydraulic Gradients Using Head Data from Multiple Wells." Ground Water 41(3):316-320. 
DOE Order 414.1C. 2005. “Quality Assurance.” U.S. Department of Energy, Washington, D.C.

EPA. 1993. Method 300.0 - Determination of Inorganic Anions by Ion Chromatography. EPA Method 300.0, U.S. Environmental Protection Agency, Cincinnati, Ohio.

EPA. 2007. Method 6020A-Inductively Coupled Plasma-Mass Spectrometry. Revision 1, Method 6020A, U.S. Environmental Protection Agency, Washington, D.C.

Ferris JG, DB Knowles, RH Brown, and RW Stallman. 1962. Theory of Aquifer Tests. Water-Supply Paper 1536-E, U.S. Geological Survey, Reston, Virginia.

Fritz BG, RD Mackley, NP Kohn, GW Patton, TJ Gilmore, DP Mendoza, D McFarland, AL Bunn, and EV Arntzen. 2007. Investigation of the Hyporheic Zone at the 300 Area, Hanford Site. PNNL-16805, Pacific Northwest National Laboratory, Richland, Washington.

Harbaugh AW, ER Banta, MC Hill, and MG McDonald. 2000. MODFLOW-2000, the U.S. Geological Survey Modular Ground-Water Model - User Guide to Modularization Concepts and the Ground-Water Flow Process. Open-File Report 00-92, U.S. Geological Survey, Reston, Virginia.

Khaleel R and BA Williams. 2011. Geohydrologic Data Package in Support of 100-BC-5 Modeling. SGW-44022, Rev. 1, CH2M HILL Plateau Remediation Company, Richland, Washington.

McDonald MG and AW Harbaugh. 1988. "A Modular Three-Dimensional Finite-Difference Flow Model." In Techniques of Water Resources Investigations of the U.S. Geological Survey, Book 6. U.S. Geological Survey, Reston, Virginia.

Molz FJ, RH Morin, AE Hess, JG Melville, and O Gueven. 1989. "The Impeller Meter for Measuring Aquifer Permeability Variations: Evaluation and Comparison with Other Tests." Water Resources Research 25(7):1677-1683. [not found]

NAVD88. 1988. North American Vertical Datum of 1988.

Neuman SP. 1972. "Theory of Flow in Unconfined Aquifers Considering Delayed Response of the Water Table." Water Resources Research 8(4):1031-1045.

Neuman SP. 1974. "Effect of Partial Penetration of Flow in Unconfined Aquifer Considering Delayed Gravity Response.” Water Resources Research 10(2):303-312.

Neuman SP. 1975. "Analysis of Pumping Test Data from Anisotropic Unconfined Aquifers Considering Delayed Gravity Response.” Water Resources Research 11(2):329-342.

Young SC, HE Julian, HS Pearson, FJ Molz, and GK Boman. 1998. Application of the Electromagnetic Borehole Flowmeter. EPA/600/R-98/058, U.S. Environmental Protection Agency, Ada, Oklahoma. 
PNNL-21845

RPT-DVZ-AFRI-005

\section{Distribution}

No. of

Copies

ONSITE

4 DOE Richland Operations Office

BL Charboneau

JG Morse

GL Sinton

Admin Records (100-BC-5 OU)

2 CH2M HILL Plateau Remediation

Company

PA Burke

MJ Hartman
No. of

Copies

U.S. Environmental Protection Agency

L Buelow B1-46

(PDF)

(PDF)

A6-38

A6-38

(PDF)

(PDF)
3 Pacific Northwest National Laboratory

MJ Truex

K6-96

VR Vermeul

K6-96

DM Wellman 


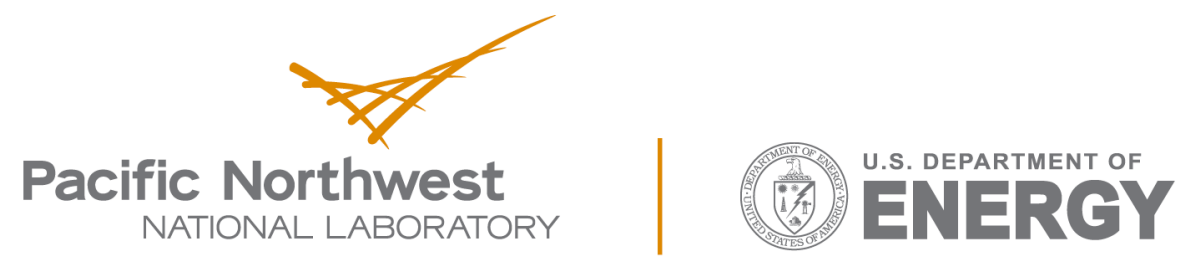

Proudly Operated by Battelle Since 1965

902 Battelle Boulevard

P.O. Box 999

Richland, WA 99352

1-888-375-PNNL (7665)

www.pnnl.gov 